*aMIS View/Print Document Cover Sheet

This document was retrieved from the Boeing ISEARCH System.

Accession \#: D196071705

Document \#: SD-WM-DGS-003

Title/Desc:

STRUCTURAL ACCEPTANCE CRITERIA FOR THE EVALUATION OF EXISTING DOUBLE SHELL WASTE STORAGE TANKS LOCATED AT HANFORD SITE RICHLAND WA 


\begin{tabular}{|l|l|}
\hline $\begin{array}{l}\text { 2. To: (Receiving Organization) } \\
\text { K. V. Scott }\end{array}$ & $\begin{array}{l}\text { 3. From: Coriginating Organization) } \\
\text { Integrity Assessment }\end{array}$ \\
\hline $\begin{array}{l}\text { 5. Proj./Prog./Dept./Div.: } \\
\text { Mpgrades Julyk }\end{array}$ \\
\hline
\end{tabular}

\section{Originator Renarks:}

Submitted for approval and release.
4. Related EDT No.:

$$
N / A
$$

7. Purchase Order No.:

$N / A$

9. Equip./Component Mo.:

$$
\mathrm{N} / \mathrm{A}
$$

10. System/Bldg./Facility: Double-She11 Tanks

\section{Receiver Renarks:}

\section{Major Assm. Dwg. No.:}

13. Permit/Permit Application No.: $N / A$

14. Required Response Date:

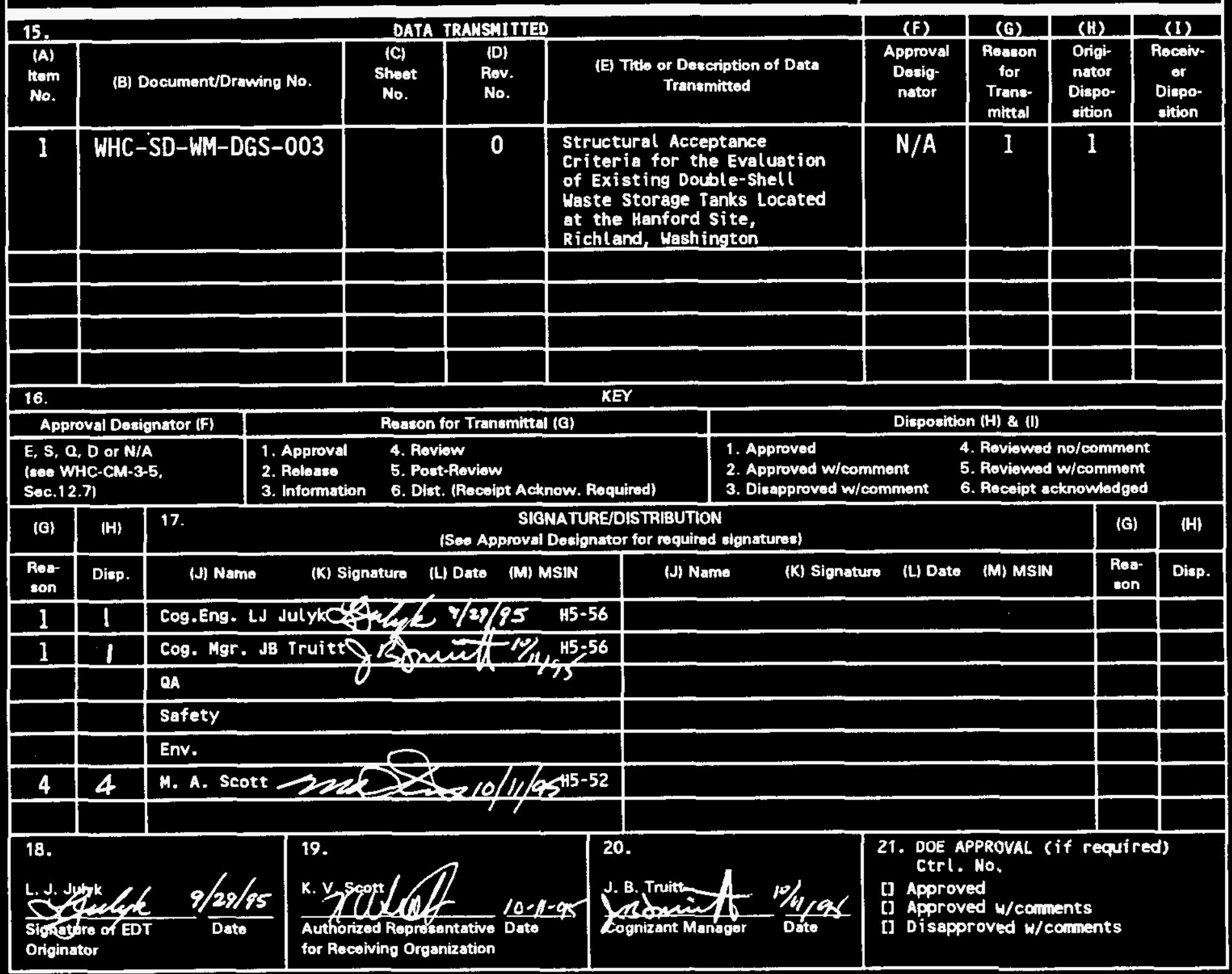


THS PAGE INTENTIONALLY LEFT BLANK 


\section{RELEASE AUTHORIZATION}

Document Number: WHC-SD-WM-DGS-003, Rev, 0

Structural Acceptance Criteria for the Evaluation of Existing Double-Shel1 Waste Storage Tanks

Document Title: Located at the Hanford Site. Richland. Washington

Release Date: $\quad 10 / 27 / 95$

This document was reviewed following the
procedures described in WHC-CM-3-4 and is:

APPROVED FOR PUBLIC RELEASE

WHC Information Release Administration Specialist:

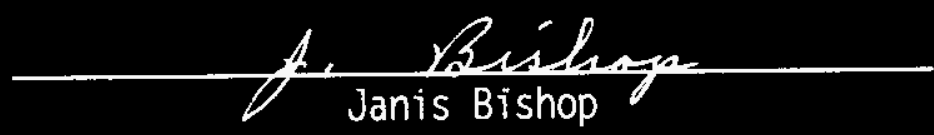

TRADEMARK DISCLAIMER. Reference herein to any specific commercial product. process, or service by trade name, trademark, manufacturer, or otherwise. does not necessarily constitute or imply its endorsement, recommendation, or favoring by the United States Government or any agency thereof or its contractors or subcontractors.

This report has been reproduced from the best available copy. Available in paper copy. Printed in the United States of America. To obtain copies of this report, contact:

Westinghouse Hanford Company - Document Control Services

P.0. Box 1970. Mailstop H6-08, Richland. WA 99352

Telephone: (509) 372-2420; Fax: (509) 376-4989 
THIS PAGE INTENTIONALLY LEFT BLANK 
2. Title

Structural Acceptance Criteria for the Evaluation of Existing Double-Shell Waste Storage Tanks Located at the Hanford Site, Richland, Washington

\section{Key Words}

Structural Acceptance Criteria Double-She11 Tank Waste Storage Tank Life Management

3. Nuber

WHC-SD-WM-DGS-003

4. Rev No.

\section{Abstract}

The structural acceptance criteria contained herein for the evaluation of existing underground double-shell waste storage tanks located at the Hanford Site is part of the Life Management/Aging Management Program of the Tank Waste Remediation System. The purpose of the overall life management program is to ensure that confinement of the waste is maintained over the required service life of the tanks.

Characterization of the present condition of the tanks, understanding and characterization of potential degradation mechanisms, and development of tank structural acceptance criteria based on previous service and projected use are prerequisites to assessing tank integrity, to projecting the length of tank service, and to developing and applying prudent fixes or repairs. The criteria provided here in summarize the requirements for the analysis and structural qualification of the existing double-shell tanks for continued operation. Code reconciliation issues and material degradation under aging conditions are addressed. Although the criteria were developed for double-shell tanks, many of the provisions are equally applicable to single-shell tanks. However, the criteria do not apply to the evaluation of tank appurtenances and buried piping.

8. RELEASE STAMP

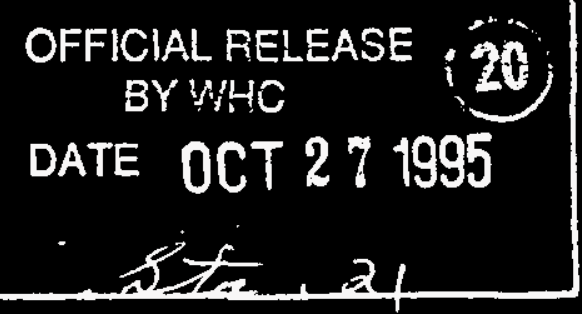


THIS PAGE INTENTIONALLY LEFT BLANK 


\title{
STRUCTURAL ACCEPTANCE CRITERIA FOR THE EVALUATION OF EXISTING DOUBLE-SHELL WASTE STORAGE TANKS LOCATED AT THE HANFORD SITE, RICHILAND, WASHINGTON
}

\author{
Prepared for \\ Westinghouse Hanford Company \\ September 1995 \\ Technical Contributors \\ J. P. Day ${ }^{1}$ \\ A. D. Dyrness ${ }^{1}$ \\ L. J. Julyk \\ C. J. Moore \\ W. S. Peterson ${ }^{2}$ \\ M. A. Scott ${ }^{3}$ \\ H. P. Shrivastava \\ J. S. Shulman ${ }^{1}$ \\ T. N. Watts ${ }^{1}$ \\ 1 ADVENT Engineering Services, Inc. \\ ${ }^{2}$ AMK Services Consultant \\ ${ }^{3}$ Westinghouse Hanford Company
}

Prepared by

ICF Kaiser Hanford Company

Richland, Washington 


\title{
STRUCTURAL ACCEPTANCE CRITERIA FOR THE EVALUATION OF \\ EXISTING DOUBLE-SHELL WASTE STORAGE TANKS LOCATED AT THE HANFORD SITE, RICHLAND, WASHINGTON
}

\author{
Prepared by \\ ICF Kaiser Hanford Company \\ Richland, Washington \\ for \\ Westinghouse Hanford Company \\ Richland, Washington \\ Under TPCN N3038
}

Compiled by:

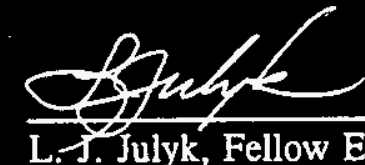

L. J. Julyk, Fellow Engineer

$9 / 29 / 95$

Reviewed by:

Mechanical Engineering

Date

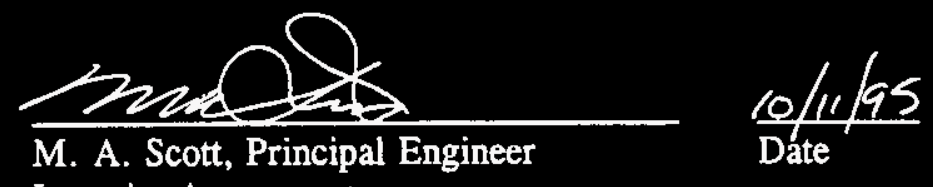

Approved by: $\frac{\substack{\text { B. Truitt, Deputy Manager } \\ \text { Mechanical Engineering }}}{\text { Date }}$

Integrity Assessment

Westinghouse Hanford Company

Westinghouse Hanford Company

Approved by:

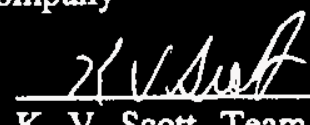

K. V. Scott, Team Leader

$\frac{10-11-95}{\text { Date }}$

Integrity Assessment 


\section{INDEPENDENT REVIEW}

Document Reviewed Structural Acceptance Criteria for the Evaluation of Existing Double-Shell Waste Storage Tanks Located at the Hanford Site, Richland, Washington

Author L. J. Julyk Report No. WHC-SD-WM-DGS-003 EDT No. 612141

The subject document has been reviewed by the undersigned. The reviewer reviewed and verified the following items as applicable [EP.4.1].

- Engineering Specification

- Design Input

- Basic Assumption

- Approach/Design Methodology

r Related Information

- Conclusion/Result Interpretation

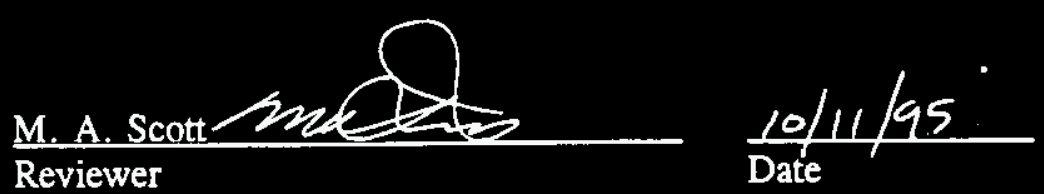




\section{CHECKLIST FOR INDEPENDENT REVIEW}

Document Reviewed Structural Acceptance Criteria for the Evaluation of

Existing Double-Shell Waste Storage Tanks Located at the

Hanford Site Richland Washington

Author L. J. Julvk

Yes No N/A

X [ ] [ ] Problem completely defined.

X [ ] [ ] Necessary assumptions explicitly stated and supported.

[ ] [ ] Computer codes and data files documented.

[ ] [ ] $\$ Data used in calculations explicitly stated in document.

W [ ] [ ] Data checked for consistency with original source information as applicable.

[ ] [ ] $\$$ Mathematical derivations checked including dimensional consistency of results.

[ ] [ ] Models appropriate and used within range of validity or use outside range of established validity justified.

[ ] [ ] X Hand calculations checked for errors.

[ ] [ ] Code run streams correct and consistent with analysis documentation.

[ ] [ ] Code output consistent with input and with results reported in analysis documentation.

Q [ ] [ ] Acceptability limits on analytical results applicable and supported. Limits checked against sources.

Q [ ] [ ] Safety margins consistent with good engineering practices.

[ ] [ ] \ Conclusions consistent with analytical results and applicable limits.

[ ] [ ] $\$ Results and conclusions address all points required in the problem statement.

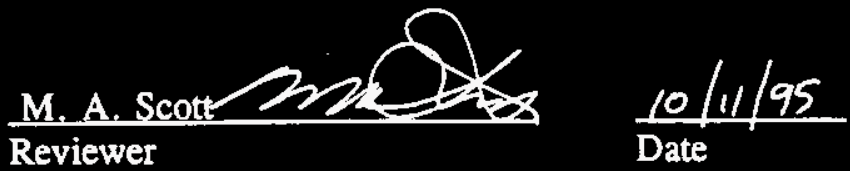




\section{CONTENTS}

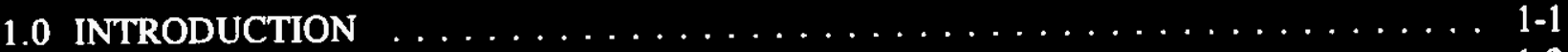

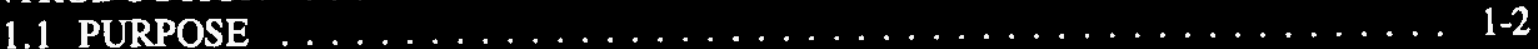

1.2 FACILITY DESIGN CHARACTERISTICS $\ldots \ldots \ldots \ldots \ldots \ldots \ldots \ldots$

1.2.1 Primary Tank . . . . . . . . . . . . . . . . . . . . 1 1-4

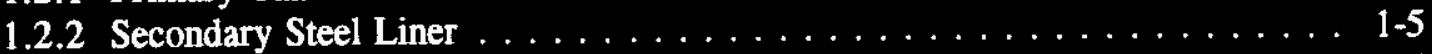

1.2.3 Secondary Concrete Tank $\ldots \ldots \ldots \ldots \ldots \ldots \ldots \ldots \ldots \ldots$

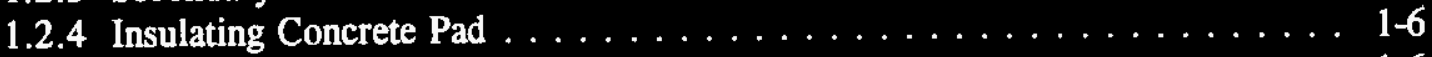

1.2.5 Facility Safety Classification . . . . . . . . . . . . . . 1-6

1.3 DOE ORDER APPLICABILITY $\ldots \ldots \ldots \ldots \ldots \ldots \ldots \ldots \ldots \ldots \ldots \ldots \ldots$

1.4 CODES AND STANDARDS $\ldots \ldots \ldots \ldots \ldots \ldots \ldots \ldots \ldots \ldots \ldots$

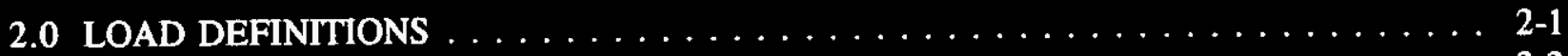

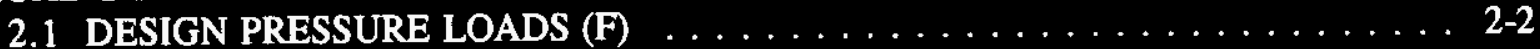

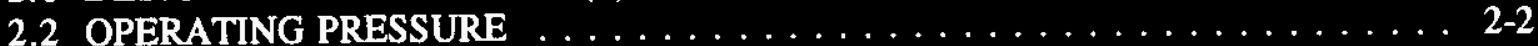

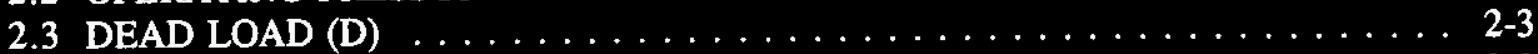

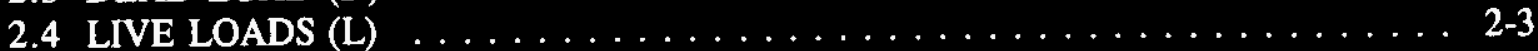

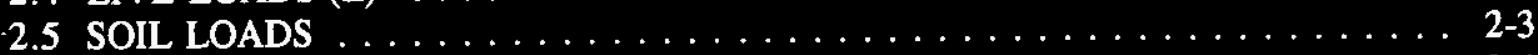

2.6 THERMAL LOADING $(\mathrm{T}) \ldots \ldots \ldots \ldots \ldots \ldots \ldots \ldots \ldots \ldots \ldots \ldots \ldots$

2.7 SEISMIC LOADING $\left(\mathrm{E}_{\mathrm{s}}\right) \ldots \ldots \ldots \ldots \ldots \ldots \ldots \ldots \ldots \ldots \ldots \ldots \ldots \ldots$

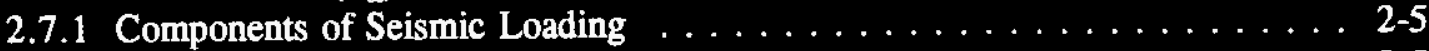

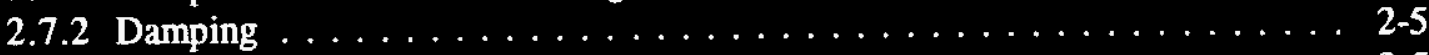

2.7.3 Combination of Component Seismic Loads . . . . . . . . . . . 2-5

2.7.4 Soil-Structure-Interaction Seismic Analysis . . . . . . . . . . . 2-5

2.7.4.1 Soil-Structure-Interaction Analysis Procedure. . . . . . . . . 2-6

2.7.4.2 Continuum Model Approach. . . . . . . . . . . . 2-6

2.7.4.3 Vault-to-Vault Interaction. . . . . . . . . . . . . . 2-6

2.7.5 Earthquake Induced Loading on Primary Tank Walls $\ldots \ldots \ldots \ldots \ldots$ 2-6 . . . . . . .

2.7.5.1 Seismic Input to Primary Tank Analysis. . . . . . . . . . . . 2-7

2.7.5.2 Hydrodynamic Wall Pressures . . . . . . . . . . . . 2-7

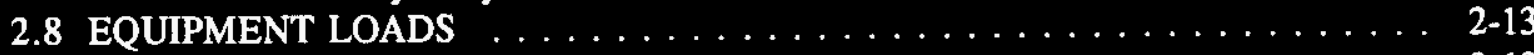

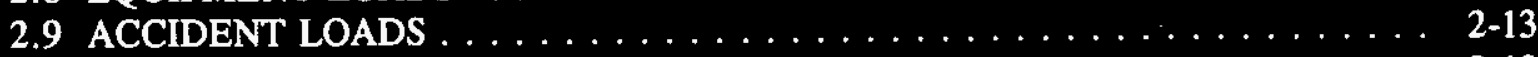

2.9 .1 Equipment Drops . . . . . . . . . . . . . . . . . 2-13

2.9 .2 Ignition of Flammable Gases . . . . . . . . . . . . . 2-14

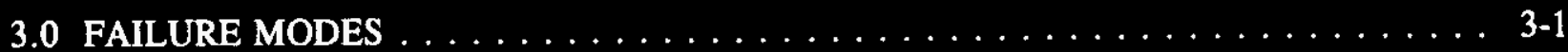

3.1 BUCKLING . . . . . . . . . . . . . . . . . . . 3-1

3.1.1 Primary Steel Tank and Secondary Steel Liner Buckling $\ldots \ldots \ldots \ldots \ldots$ 3-2

3.1.1.1 Elephant-Foot Buckling. . . . . . . . . . . . . . . . 3-2

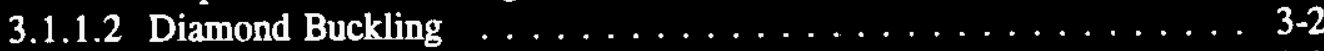

3.1.1.3 Harmonic Buckling. . . . . . . . . . . . . . 3-2

3.1.1.4 Between Studs Buckling. . . . . . . . . . . . 3-3

3.1.1.5 Flat Bottom Plate Buckling. . . . . . . . . . . . . . 3-3

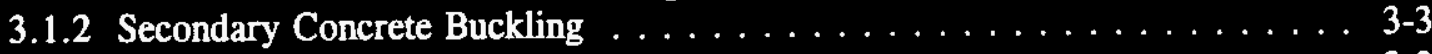

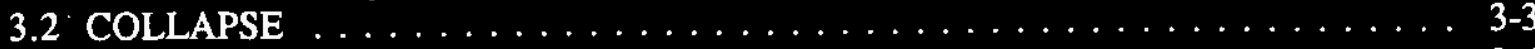

3.2.1 Primary Tank Collapse $\ldots \ldots \ldots \ldots \ldots \ldots \ldots \ldots \ldots \ldots \ldots$ 
3.2.2 Secondary Concrete Collapse $\ldots \ldots \ldots \ldots \ldots \ldots \ldots \ldots \ldots \ldots$

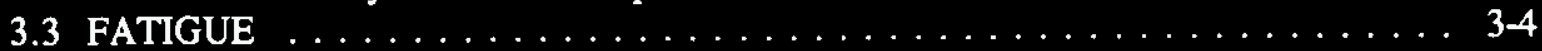

3.3.1 Primary Tank . . . . . . . . . . . . . . . . . 34

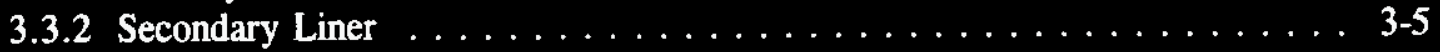

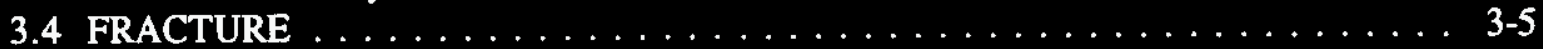

3.4.1 Fracture of Low-Carbon Steel . . . . . . . . . . . . . . . . 3-5

3.4.2 Stress-Corrosion Cracking of Carbon Steel . . . . . . . . . . . . 3-5

3.4.3 Concrete Cracking and Spallation . . . . . . . . . . . . . 3-6

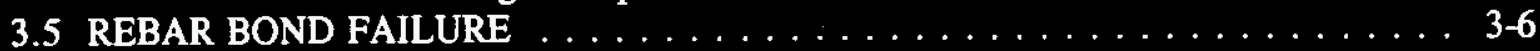

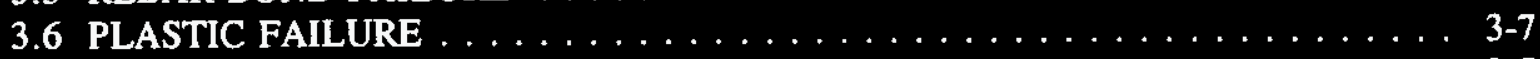

3.7 CONCRETE CRUSHING $\ldots \ldots \ldots \ldots \ldots \ldots \ldots \ldots \ldots \ldots \ldots \ldots \ldots \ldots$

3.7.1 Crushing of Secondary Concrete $\ldots \ldots \ldots \ldots \ldots \ldots \ldots \ldots \ldots$ 3-7

3.7.2 Crushing of Insulating Concrete $\ldots \ldots \ldots \ldots \ldots \ldots \ldots \ldots \ldots$

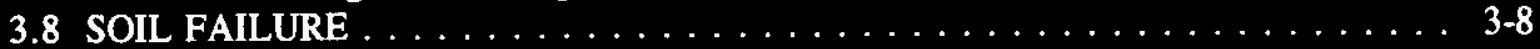

4.0 PROTECTION AGAINST FAILURE $\ldots \ldots \ldots \ldots \ldots \ldots \ldots \ldots \ldots \ldots \ldots \ldots$. . . . . . .

4.1 ASME CODE-BASED PROTECTION AGAINST FAILURE $\ldots \ldots \ldots \ldots \ldots \ldots$. . . . .

4.1.1 Stress Categories and Stress Limits for ASME Code Evaluations . . . . . . 4 4-3

4.1.1.1 Stress Categories. . . . . . . . . . . . . . . . 4-3

4.1.1.2 Derivation of Stress Intensities. . . . . . . . . . . . . . 44

4.1.1.3 Stress Allowables. . . . . . . . . . . . . . . . . . . . 4-5

4.1.1.4 Plastic Analysis, Limit Analysis, and Shakedown Analysis. . . . . 4-5

4.1 .2 Primary Tank Evaluation . . . . . . . . . . . . . . . 4-6

4.1.2.1 Design and Service Level A. . . . . . . . . . . . . . 4-6

4.1.2.2 Service Level B. . . . . . . . . . . . . . . . . . 4-7

4.1.2.3 Service Level C. . . . . . . . . . . . . . . . . . 4-7

4.1.2.4 Service Level D. . . . . . . . . . . . . . . . . 4-7

4.1.2.5 Fatigue Evaluation. . . . . . . . . . . . . . . 4-8

4.1.2.6 Buckling Criteria for Cylindrical Tank. . . . . . . . . . . . . . . 4-9

4.1.2.7 Buckling Criteria for Dome and Lower Knuckle. . . . . . . . . . . . . 4-14

4.1.2.8 Buckling of Bottom Plate Under Partial Vacuum. . . . . . . . . . 4-14

4.1.2.9 Slosh Height. . . . . . . . . . . . . . . . . . . . . 4-14

4.1.2.10 Tank Sliding Capacity. . . . . . . . . . . . . . . . 4-15

4.1.3 Evaluation of Secondary Liner and Primary Tank Dome . . . . . . . . . 4-17

4.1.3.1 Loads and Load Combinations . . . . . . . . . . . . . . . . . 4 4-17

4.1.3.2 Code Allowables. . . . . . . . . . . . . . . . . 4-18

4.1 .4 Stud Evaluation . . . . . . . . . . . . . . . . . . 4-18

4.1.5 Penetration Assemblies . . . . . . . . . . . . . . . . . 4-21

4.2 ACI CODE-BASED PROTECTION AGAINST FAILURE . . . . . . . . . . . 4-22

4.2.1 Load Classification and Combinations . . . . . . . . . . . . . . 4-22

4.2.2 Secondary Concrete Tank - ACI Code Evaluation . . . . . . . . . . . 4-28

4.2.2.1 Flexure and Axial Load Code Evaluation. . . . . . . . . . . . 4-28

4.2.2.2 Rebar Bond-Slip Failure . . . . . . . . . . . . . . . 4-30

4.2.2.3 Twisting Moment Code Evaluation. . . . . . . . . . . . . 4-32

4.2.2.4 Transverse Shear Code Evaluation. . . . . . . . . . . . . . . 4-32

4.2.2.5 In-Plane Shear Code Evaluation. . . . . . . . . . . . . . 4 4-33

4.2.2.6 Strength Reduction Factors. . . . . . . . . . . . . . . 4-34

4.2.2.7 Concrete Shell Buckling Code Evaluation. . . . . . . . . . . . . . . 4-34

4.2.2.8 Code Evaluation for Impact Loads . . . . . . . . . . . . . . . . 4 4-40 
4.2.3 Insulating Slab - Code . . . . . . . . . . . . . . 4-40

4.3 ALTERNATE TECHNIQUES FOR MEETING ACI CODE REQUIREMENTS FOR COMBINED FLEXURE AND AXIAL LOAD . . . . . . . . . . 4-40

4.3.1 Factored Limit-Analysis for Flexure and Axial Load Code Evaluation . . . . 4-41

4.3.2 Step-Wise Limit Analysis to Demonstrate Structural Redundancy . . . . . . 4-43

4.4 PRIMARY TANK - STRAIN LIMIT FAILURE CRITERION $\ldots \ldots \ldots \ldots . .4 .43$

5.0 CODE RECONCILIATION $\ldots \ldots \ldots \ldots \ldots \ldots \ldots \ldots \ldots \ldots \ldots$ 5-1

6.0 MATERIAL CHARACTERIZATION $\ldots \ldots \ldots \ldots \ldots \ldots \ldots \ldots \ldots \ldots$ 6-1

6.1 STEEL LINERS PROPERTIES $\ldots \ldots \ldots \ldots \ldots \ldots \ldots \ldots \ldots \ldots \ldots \ldots 6.1$

6.2 REINFORCEMENT STEEL PROPERTIES $\ldots \ldots \ldots \ldots \ldots \ldots \ldots \ldots \ldots \ldots 6-1$

6.3 REINFORCED CONCRETE PROPERTIES $\ldots \ldots \ldots \ldots \ldots \ldots \ldots \ldots \ldots$. . . . . . . .

6.3.1 Initial Properties . . . . . . . . . . . . . . . . . . 6-2

6.3.2 Thermal and Aging Effects $\ldots \ldots \ldots \ldots \ldots \ldots \ldots \ldots \ldots \ldots, 6 \ldots \ldots$

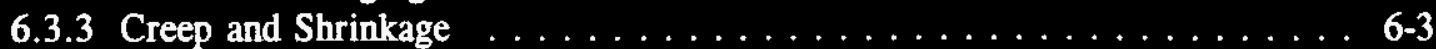

6.4 INSULATING CONCRETE PROPERTIES $\ldots \ldots \ldots \ldots \ldots \ldots \ldots \ldots$. $\ldots$.3

6.5 SOIL PROPERTIES AND STRUCTURAL ANALYSIS CONSIDERATIONS . . . . 6-4

6.5.1 Soil Properties . . . . . . . . . . . . . . . . . 6-4

6.5.2 Soil-Structural Interaction Analysis Considerations $\ldots \ldots \ldots \ldots \ldots$ 6-4

6.6 CORROSION CONSIDERATIONS $\ldots \ldots \ldots \ldots \ldots \ldots \ldots \ldots \ldots \ldots .6 .4 \ldots$

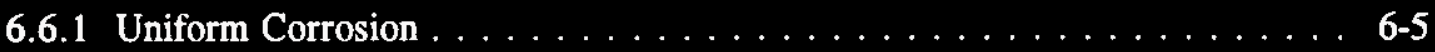

6.6.2 Pitting Corrosion and Crevice Corrosion $\ldots \ldots \ldots \ldots \ldots \ldots \ldots$ 6-5

6.6.3 Stress-Corrosion Cracking $\ldots \ldots \ldots \ldots \ldots \ldots \ldots \ldots \ldots \ldots$ 6.5

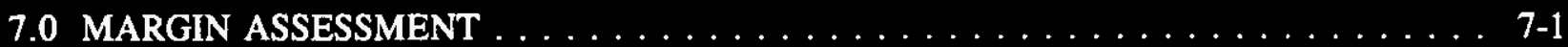

7.1 MARGIN TO CODE LIMITS $\ldots \ldots \ldots \ldots \ldots \ldots \ldots \ldots \ldots \ldots \ldots \ldots$ 7-1

7.2 BUCKLING LOAD INTERACTION OF SECONDARY CONCRETE $\ldots \ldots \ldots$. $7-2$

8.0 REFERENCES $\ldots \ldots \ldots \ldots \ldots \ldots \ldots \ldots \ldots \ldots \ldots \ldots \ldots$. $\ldots$.1 


\section{FIGURES}

1.2-1. Double-Shell Tank and Ancillary Equipment Configuration. . . . . . . . . . 1-9

1.2.3-1. Details of the Wall-Basemat Interface for Double-Shell

Tanks 241AY, AZ, AW, and SY. . . . . . . . . . . . . . 10

1.2.3-2. Details of the Wall-Basemat Interface for Double-Shell Tank 241AN. . . . . . . 1-11

1.2.3-3. Details of the Wall-Basemat Interface for Double-Shell Tank 241AP. . . . . . . 1-12

2.7.5-1. Liquid Sloshing in a Tank. . . . . . . . . . . . . . . 2-15

3.5-1. Force System for a Splitting Bond Failure of Rebar . . . . . . . . . . . . 3-9

4.2.2.1-1. Typical Concrete Interaction Diagram for Bending-Plus-Axial Load. . . . . . . . 4 4-48

4.2.2.1-2. Balanced Condition for Reinforced Concrete Section. . . . . . . . . . . . . . 4-49

4.2.2.1-3. Force Balance for Axial Compression without Bending

in Reinforced Concrete Section. . . . . . . . . . . . . . . . . . . . . . 4-50

4.2.2.2-1. Theory of Splitting Bond Failure of Rebar - Failure Surfaces . . . . . . . . . 4-51

4.2.2.7-1. Theoretical Buckling Loads for Clamped Spherical Cap $\ldots \ldots \ldots \ldots \ldots \ldots \ldots$. . . . . . 4-52

4.2.2.7-2. Values of $\psi$ for Effect of Concrete Cracking and

Amounts and Type of Reinforcement $\ldots \ldots \ldots \ldots \ldots \ldots \ldots$. . . . . . . . . . . . . .

4.2.2.7-3. Effect of Geometric Imperfections on Buckling Load . . . . . . . . . . . . . 4-54

4.2.2.7.4. Reduction Factor $\alpha_{3}$ for Concrete Cracking and

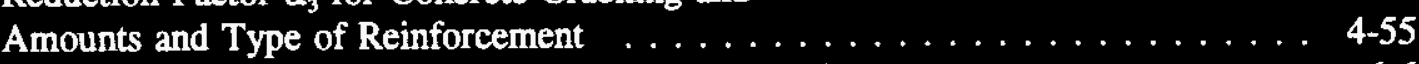

6.2-1. Steel Reinforcing Bar Adjusted Mean Stress-Strain Curves . . . . . . . . . . 6-6

7.1-1. Applied Load vs. Axial Response. . . . . . . . . . . . . . 74

7.2-1. Variation of Parameter, $b$, as a Function of Batdorf Parameter, Z, for

Post-Buckling Behavior of a Cylinder $\ldots \ldots \ldots \ldots \ldots \ldots \ldots \ldots$ 


\section{TABLES}

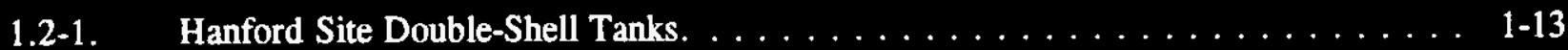

2.0-1. Design Load Summary for Existing Double-Shell Tanks. . . . . . . . . . . . . . . . 2-16

2.7.2-1. Response Level and Damping. . . . . . . . . . . . . . . . . 2-17

2.7.5-1. Values of Coefficient $\left(C_{i}\right)_{r}$ in Equation $2.7 .5-4 \ldots \ldots \ldots \ldots \ldots \ldots \ldots$

2.7.5-2. Values of Coefficient $\left(C_{v}\right)_{r}$ in Equation $2.7 .5-23 . \ldots \ldots \ldots \ldots \ldots \ldots \ldots$

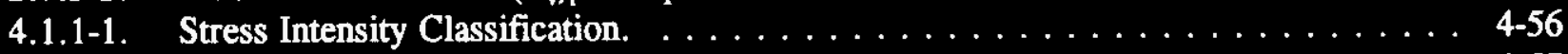

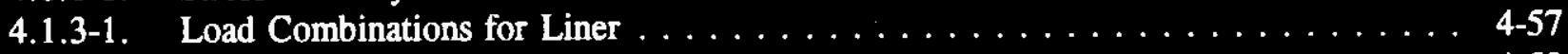

4.1.3-2. Liner Strain Allowables. . . . . . . . . . . . . . . . . . . 4-58

4.1.4-1. Liner Anchor Allowables. . . . . . . . . . . . . . . . . . . . . . 4-59

4.1.4-2. $\quad F_{y}$ and $F_{u}$ Relationships for Nelson Studs with Full Embedment (Ductile Behavior). . . . . . . . . . . . . . . . . 4-60

4.1.4-3. Ultimate Displacements for Nelson Studs with Full Embedment (Ductile Behavior). . . . . . . . . . . . . . . . . 4-61

5.0-1. Summary of Hanford Double-Shell Tank Codes of Record for Primary Tank and Secondary Steel Liner. . . . . . . . . . . . . . . . . 5-4

5.0-2. Summary of Hanford Double-Shell Tank Structural Concrete Design Basis. . . . . . . . . . . . . . . . . . 5-5

6.1-1. Design Stress Intensity Values, $\mathbf{s}_{\mathrm{m}}, \ldots \ldots \ldots \ldots \ldots \ldots \ldots \ldots \ldots$

6.1-2: Nominal Mean Coefficients of Thermal Expansion for Steel vs. Temperature. . . . . 6-8

6.1-3. Moduli of Elasticity for Steel vs. Temperature. . . . . . . . . . . . . . . 6-9

6.2-1. Reinforcement Steel Properties . . . . . . . . . . . . . . . 6-10 
TIIS PAGE TNTENTONALLY

IDIDT BLANK 


\subsection{INTRODUCTION}

At the Hanford Site there are 177 steel-lined reinforced-concrete underground tanks providing interim storage of high- and low-level radioactive waste until further processing and permanent disposal options become available. Many of these tanks are over $\mathbf{4 0}$ years old. Periodic releases of flammable gases, the development of potentially unstable organic and ferrocyanide compounds, and high waste temperatures within some tanks has raised public health and safety concerns. The primary function of these tanks is to provide confinement during storage and in-tank processing of the waste by maintaining leak tightness and structural stability. The tanks are arranged in groups called tank farms. The tank designs within a single farm are identical with a few minor exceptions. However, two fundamentally different designs comprise the entire inventory of tanks: single-shell and double-shell tanks.

A total of 149 single-shell tanks (SST), providing single containment, were constructed between 1943 and 1964 with a design service life of 20 years. All SSTs were put into service in the as-welded condition. As many as 68 of the SSTs are believed to have leaked significant amounts of liquid to the underlying soil. All SSTs were removed from service (not allowed to receive additional waste) on or before November 21, 1980. A total of 106 of the SSTs have been interim stabilized (contain less than $50,000 \mathrm{gal}$ of drainable interstitial liquids and less than $5,000 \mathrm{gal}$ of supernatant liquid). The SSTs are proceeding to closure via the Hanford Facility Agreement and Consent Order (Tri-Party Agreement) (TPA 1995). Interim stabilization of all SSTs (except high-heat tank 241-C-106) is scheduled for completion by September 2000 (TPA milestone M-41-00). Waste retrieval and closure of all SSTs is scheduled for completion by September 2018 (M-45-05) and September 2024 $(\mathrm{M}-45-06)$, respectively.

A total of twenty-eight double-shell tanks (DST), providing double containment, were constructed between 1968 and 1986. Two were designed for a 20-year life, two for a 40-year life, and the remaining 24 for a 50-year life; however the four DST designs have no major differences in design or service. The primary steel tanks in all DSTs were thermal stress relieved after welding. No leaks have been detected from any DST. These tanks are needed for storage and pretreatment of waste before final disposal of the Hanford tank waste is completed by December 2028 (TPA milestone $\mathbf{M - 5 0 - 0 0 )}$.

Characterization of the present condition of the tanks, understanding and characterization of potential degradation mechanisms, and development of tank structural acceptance criteria based on previous service and projected use are prerequisites to assessing tank integrity, to projecting the length of tank service, and to developing and applying prudent fixes or repairs. An ultrasonic inspection program is planned for the steel tank walls of the DSTs to establish their present condition. Corrosion is the most probable degradation mechanism of the steel tank components in contact with the waste or waste vapors. Thermal degradation of concrete resulting from elevated temperature exposure is the most probable degradation mechanism of the concrete tank structure. The criteria provided herein summarize the requirements for the analysis and structural qualification of the existing DSTs for continued operation. Although the criteria were developed for DSTs, many of the provisions are equally applicable to SSTs. However, the criteria do not apply to the evaluation of tank appurtenances and buried piping. 


\subsection{PURPOSE}

Continued use of existing waste storage tanks beyond their intended service life; changes in functional requirements; the identification of loads not previously addressed by the original design documentation; degradation in either the physical properties and/or the material conditions; or the imposition of new regulatory requirements are all conditions that warrant a re-evaluation of these existing structures. Depending on the age of the structure, the code of record will likely differ by varying degrees from the current accepted practice. Choosing the appropriate Codes and Standards for structural evaluation criteria can be problematic. Consensus structural acceptance criteria provide the underpinnings of a consistent basis for the evaluation of existing underground waste storage tanks. This document is developed to that end. However, the criteria provided herein do not preclude the use of alternate criteria. The development and application of the acceptance criteria contained herein is part of the Life Management/Aging Management Program (WHC 1994) of the Tank Waste Remediation System (TWRS). The purpose of the overall life management program is to ensure that confinement of the waste is maintained over the required service life of the tanks.

The primary objective in any re-evaluation of the existing waste storage tanks for continued operation or remediation is to show that the tank structures remain within code-based limits for the original design-based loads, for the actual service conditions or changes in requirements if they exceed the design conditions, and for future remediation activity loads.

This document is organized in a logical sequence starting with a description of the facilities, loads that must be sustained, identification of potential failure modes, followed by discussion of approaches to protect against such failures. The approach includes the application of code-based criteria. Alternate methodologies to the code based approach are recommended to account for localized overstressing, load redistribution, and reduction in section capacities due to material degradation. Code reconciliation issues and material degradation under aging conditions are addressed.

\subsection{FACILITY DESIGN CHARACTERISTICS}

The twenty-eight DSTs are located in six separate tank farms as indicated in Table 1.2-1. Four of these tanks, located two each in the 241-AY and AZ tank farms designated as Aging Waste Facility (AWF) tanks, have a nominal design waste capacity of $1,000,000$ gal each (operational limit is $980,000 \mathrm{gal} / \mathrm{tank}$ ). Aging waste (neutralized current acid waste [NCAW]) is defined as high level, first cycle solvent extraction waste from the PUREX ${ }^{1}$ plant. The remaining twenty-four tanks (nonaging waste tanks) have a nominal design capacity of $1,160,000$ gal each $^{2}$ (operational limit is $1,140,000 \mathrm{gal} /$ tank).

1Plutonium Uranium Extraction Facility.

${ }^{2}$ A $1.16 \mathrm{Mgal}$ waste capacity corresponds to a waste depth of $422 \mathrm{in}$. which reaches the tangent line to the upper knuckle of the primary tank. Only the AP tanks were designed originally for $1.16 \mathrm{Mgal}$ of liquid waste and the plate thickness of the primary tank was increased from $\%$ to $1 / 2$ in. in the region of the upper knuckle. The SY, AW, and AN tanks were designed originally for a $1.0 \mathrm{Mgal}$ waste capacity (per reference design drawings) corresponding to a waste depth of $363 \mathrm{in}$. (18 in. below the secondary liner tangent line elevation). These tanks were then later qualified by analysis for a maximum $1.16 \mathrm{Mgal}$ waste capacity. 
Between the DST farms, the tank designs are structurally similar with some variations in concrete and rebar strength, rebar arrangement in the haunch region, and some variation in the basemat foundation designs. The tanks are $83 \mathrm{ft}$ in outer diameter, $50 \mathrm{ft}$ high, consisting of a reinforced concrete secondary tank with an attached secondary steel liner encasing an integral primary steel tank (see Figure 1.2-1). The secondary concrete tank is cylindrical in shape with a shallow dome type roof (15-ft rise) buried below ground with a minimum soil cover of $6.5 \mathrm{ft}$ relative to the dome apex. The secondary concrete dome and cylindrical shell is supported vertically through steel bearing plate rings at the bottom of the cylindrical wall which are supported by a circular reinforced concrete basemat (foundation slab). The bearing plates are separated by a thin layer of dry graphite to allow radial thermal expansion relative to the basemat within an initial outward radial gap of approximately $1 \mathrm{in}$. at the wall-basemat interface. The primary tank is an integral welded-plate carbon-steel cylindrical tank with an ellipsoidal head attached to the inner surface of the concrete dome and a knuckled flat bottom that rests on an 8-in. thick layer of insulating concrete. The secondary steel liner is a welded-plate carbon-steel cylindrical liner attached to the inner cylindrical wall and haunch region of the secondary concrete tank up to a point of tangency with the primary tank dome and has a knuckled flat bottom that rests on the concrete basemat. The primary tank and secondary liner are structurally independent and are separated at the bottom by the 8 -in. layer of insulating concrete.

The primary steel tank provides containment for the stored liquid waste and secondary steel liner/reinforced concrete tank provides a redundant leakage barrier. There is a nominal 30-in. annulus between the primary tank cylindrical wall and the steel-lined secondary concrete tank cylindrical wall. The annulus contains systems for leak detection and ventilation/cooling. The secondary concrete tank and basemat carry the surface live loads, static and dynamic soil loads, and dead weight loads. The primary steel tank resists the hydrostatic and hydrodynamic liquid waste loads and the internal pressure.

The dome has a number of penetration risers to allow access for the following ancillary equipment or systems:

- Tank forced air (active) ventilation pipes and filters

- Annulus forced air ventilation pipes and filters

- Mechanical and/or hydraulic tank waste retrieval devices

- Tank sampling and inspection equipment

- Annulus leak detection systems

- Mixer, transfer, and decant pumps

- Steam heat exchanger/airlift circulators (AWF tanks).

The AY and AZ AWF tanks have approximately 140 penetration risers in the dome and annulus region of each tank. Non-aging waste DSTs have approximately 60 penetration risers in the dome and annulus region of each tank. The penetration risers range in diameter from $3 / 4$ to $42 \mathrm{in}$. The penetration risers were fabricated from seamless carbon-steel pipe except for those greater than 20 in. in diameter which were rolled from steel plate and seam welded. The penetration risers are welded to the dome liner and encased in the concrete dome with radial protruding anchor studs welded to the surface of the tubular risers. Some of the risers extend up through the soil to the surface while others extend up into reinforced concrete pits. The pits either rest on the surface of the concrete dome or are separated by soil from the dome. The pits are not structurally connected to the dome except through the riser interface. The pits are capped at grade with reinforced concrete cover blocks. 


\subsubsection{Primary Tank}

The primary carbon-steel tank provides containment for the stored liquid waste. The functionality of the primary tank is to maintain leak-tightness. The bottom and wall of the primary tank retain the liquid waste, and these areas are of most concern for leakage. Leaks in the lower wall or bottom of the primary tank are more serious than leaks at the liquid level near the top of the tank. The primary tank varies in thickness from a minimum of $\%$ in. in the dome to a maximum of 1 in. at the bottom center of the tank. The primary tank is constructed from a series of formed segmented plates welded in a staggered arrangement. All butt welds on the primary tank received $100 \%$ radiographic examination. The primary tank was heated internally after erection to fully stress relieve the tank welds. After the primary tank was stressed relieved a full hydrostatic pressure test was conducted by filling the primary tank with water to a depth of $39 \mathrm{ft}$ from the bottom of the tank. The dome of the primary tank is directly attached to the concrete dome through uniformily spaced J-bolts. The J-bolts are threaded into Nelson ${ }^{3}$ tapped studs welded to the primary tank dome in a uniformly spaced 2- by 2-ft square pattern. During construction the secondary steel liner and the primary tank dome acted as the inside form for the concrete walls and dome. Tank supports were provided to maintain the tanks geometric shape during concrete placement.

The primary tank dome acts as a composite section with the reinforced concrete dome via the uniformly spaced J-bolts. The secondary concrete tank is much stiffer than the primary steel tank. Hence, displacements of the concrete dome resulting from concrete shrinkage and creep under load dictate the displacement response of the primary tank dome.

The primary tank is essentially displacement controlled relative to external soil loads supported by the secondary concrete tank, governed by continuity with the dome concrete. The primary tank rests on an 8-in. slab of unreinforced insulating concrete. Seismic induced sloshing loads experienced at the dome roof would be resisted by the primary tank and the secondary concrete tank. The freestanding cylindrical portion of the primary tank resists the hydrostatic and hydrodynamic liquid waste induced loads, and the internal pressure. During a seismic event relative motion could develop between the basemat and the primary tank because the primary tank is not structurally connected to the basemat. Such relative motion would be resisted by friction between the primary tank steel bottom and the insulating concrete.

There are multiple penetrations in the dome ranging in diameter from $3 / 4$ to $42 \mathrm{in}$. These penetrations are located in the dome region of both the primary tank plenum and the annulus between the primary tank and the secondary liner. Thickness changes, stud connections, and penetrations are locations susceptible to stress concentrations. The point of separation from the concrete backing in the dome haunch region (springline) as well as the relatively sharp radius ( $1 \mathrm{ft}$ ) at the bottom knuckle of the primary tank are also locations of stress concentration. These regions of local stress concentrations can lead to premature ductile failure under energetic accident load conditions, particularly in transition regions of local constraint imposed by the concrete.

The primary steel tank resists the hydrostatic and hydrodynamic liquid waste loads and the internal pressure. Failure of the primary tank below the waste liquid level will lead to leakage of the drainable liquids which should be contained by the secondary steel liner.

\footnotetext{
${ }^{3}$ Nelson is a registered trademark of TRW Incorporated.
} 


\subsubsection{Secondary Steel Liner}

The secondary steel liner is a welded-plate carbon-steel cylindrical liner attached to the cylindrical wall and haunch of the secondary concrete tank up to a point of tangency with the primary tank dome. The secondary liner has a knuckled flat bottom that rests on the concrete basemat. All butt welds on the secondary liner joining floor plates, knuckles, and side plates of cylindrical sections up to $27 \mathrm{ft}$ above the floor plates received $100 \%$ radiographic examination. The welds of the secondary steel liner were not stress relieved. The primary tank and secondary liner are separated at the bottom by an 8 -in. layer of insulating concrete and radially by a 30 -in. air annulus that reduces to zero at the point of tangency in the dome. The primary tank and secondary liner are structurally independent. The secondary liner starts in the haunch region and creates a composite section with the reinforced-concrete wall via uniformly spaced tie-rods threaded into tapped studs welded to the secondary liner in a 2 - by 2 -ft square pattern. During construction the secondary steel liner and the primary tank dome were used as the inside form for the concrete walls and dome.

The structural response of the secondary liner is essentially displacement controlled, governed by continuity with the concrete wall. The secondary liner provides a redundant leakage barrier for the confinement of stored wastes. The stud connections and the unbacked lower knuckle of the secondary liner are locations of stress concentration. The bottom and wall of the secondary steel liner are the important areas for maintaining containment in the event that leaks occur in the primary tank. The secondary steel liner provides secondary containment against leakage but is not relied on for its structural contribution.

\subsubsection{Secondary Concrete Tank}

During construction the secondary steel liner and the primary tank dome acted as the inside form for the concrete walls and dome. Tank supports were provided to maintain the tank geometric shape while the wall and dome concrete was being placed. High-early-strength cement was used in concrete for the haunch and dome region. The reinforced-concrete dome is thinnest $(15 \mathrm{in}$.) at the dome apex with a radius to thickness ratio of approximately 80 . The haunch is more than twice as thick and fortified with a significant quantity of reinforcement to act as a tension ring to support the membrane loads transmitted through the dome. The secondary concrete cylindrical tank and dome carry the static-and dynamic soil loads, surface loads transmitted through the soil, and pressure loads.

The cylindrical wall is constructed monolithically (18-in. thick) with a keyed construction joint below the haunch. The side walls of the secondary concrete tank resist the lateral earth pressures and act as an edge support to the dome which carries the overburden loads. The wall rests on a reinforced concrete basemat foundation with no structural connection between the wall and basemat. Steel bearing plates separated by a thin layer of dry graphite serve as the interface between the wall and the footing. The basemat foundation design includes a shear key to restrict relative motion between the wall and basemat, thus allowing limited radial expansion between the wall and footing. This detail is designed to minimize the effects of foundation settlement on the wall, but can be a source of large shear forces in the restraint key and high secondary liner stresses when loading conditions result in relative translation at the wall-basemat interface. The details of the wall-basemat interface differ between tank farm designs (see Figures 1.2.3-1 through 1.2.3-3). In all designs an outward radial gap of approximately $1 \frac{1 / 4}{\mathrm{in}}$. filled with urethane sealant is provided. The outer radial

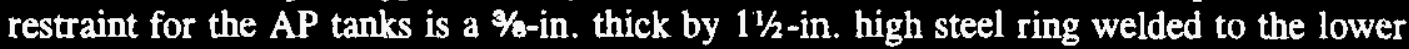
circumferential bearing plate on the basemat. For all other DSTs the outer restraint is formed by an 
outer ring of concrete with an embedded steel angle adjacent to the wall. The major difference in radial restraint of the wall is that an inner radial restraint is also provided in the AN (Figure 1.2.3-2) and AP (Figure 1.2.3-3) tank basemat foundations but not in the other DSTs (Figure 1.2.3-1).

The bottom slab (basemat) of the secondary concrete structure acts as a foundation. The internal portion of the slab supports the vertical loads imposed by the liquid waste. The outer portion of the slab acts as a footing supporting the wall, dome and overburden soil. Failure of the basemat or soil to support the basemat could lead to settling of the tank. The detail design of the basemat varies between tank farms. The basemat thickness is greatest under the wall and the center of the tank in all DSTs except in the AP tank which has a constant slab thickness.

The effects of steady-state thermal loads and thermal transients from fill and drain cycles are mitigated for the secondary concrete tank wall and basemat by the air annulus between the primary tank and the concrete wall and by the insulating concrete and air cooling channels within the insulating concrete. Failure of the secondary concrete dome or wall would be catastrophic because they support the external loads from the surrounding soil, self weight, dead weight of dome supported equipment, and live loads at surface. Local failure of the foundation below the wall could result in local settlement of the soil which could result in leakage of the primary steel tank and jeopardize the secondary steel liner containment function.

\subsubsection{Insulating Concrete Pad}

The 8-in. thick insulating concrete pad is loaded in bearing by the primary tank and its contents. It is also subject to thermal loads. This concrete pad is intended to provide thermal insulating protection to the concrete basemat of the secondary concrete tank during stress relieving of primary steel tank. The cast-in-place refractory concrete was designed to limit the surface temperature of the basemat to a maximum temperature of $500^{\circ} \mathrm{F}$ during the stress relieving operation of the primary tank where temperatures were required to reach $1,100^{\circ} \mathrm{F}$. The pad also provides channels for cooling airflow, access for inspection of the bottom of the primary tank, and drainage channels for leak detection. The insulating pad is not directly connected to the other major structures of the tank but is restrained radially by a $3 / 4$-in. thick circumferential ring. A crushing failure of the insulating concrete is not desirable because the cooling airflow channels could become blocked and the weight of the primary tank and waste content would be transferred to the dome in a displacementcontrolled fashion.

\subsubsection{Facility Safety Classification}

In accordance with the safety equipment list for DSTs (WHC 1992 and 1993a) the safety function of the primary tank is to provide containment and confinement of the hazardous/radioactive liquid waste over the lifetime of the tank facility. The primary tank and its dome penetration risers are designated as safety class 1 , corresponding to a safety class designation in the nomenclature of DOE Order 6430.1A (DOE 1989).

The secondary reinforced concrete structure supports the primary tank and provides an annulus space to contain and allow for detection of leaks from the primary tank. The concrete shell isolates the primary tank and secondary tank liner from soil loadings, dead loads, live loads, seismic loads and loads caused by temperature gradients between the tank waste and the soil. The secondary 
concrete structure is designated as safety class 1 because it directly supports the primary tank and is therefore necessary to ensure the structural integrity of the primary tank.

The secondary tank liner lines the secondary concrete structure, extending along the bottom, side, and upper haunch of the secondary concrete structure to the upper knuckle of the primary tank. The function of the secondary tank liner is to contain liquid waste in the event of a leak from the primary tank. The secondary liner is only required to contain the liquids until the leak has been stopped and the liquid in the liner has been removed. The liner is required, in conjunction with the ventilation system, to confine the liquids, maintain a negative air pressure in the annulus, provide a filtered pathway to the environment and to protect the facility worker during remediation activities. Because the failure of the secondary liner could impact the primary liner, the secondary liner is designated as safety class $3 / 1$. Such a designation signifies that for structural considerations, safety class 1 requirements are applicable.

The insulating concrete pad is located between the bottom of the primary tank and the secondary liner. The pad is designated as safety class 1 because its failure could lead to structural degradation of the safety class 1 primary tank.

\subsection{DOE ORDER APPLICABILITY}

The following U.S. Department of Energy (DOE) Orders are applicable to the analysis and structural qualification of the existing DSTs for continued operation:

- $\quad$ DOE Order 6430.1A, General Design Criteria (DOE 1989)

- $\quad$ DOE Order 5430.28, Natural Phenomena Hazard Mitigation (DOE 1993).

\subsection{CODES AND STANDARDS}

Except as modified or amended herein, the analysis and structural qualification of the existing DSTs for continued operation shall be performed using the following codes and standards as guidance:

- U.S. DOE Report BNL 52361, Seismic Design and Evaluation Guidelines for the Department of Energy High Level Waste Tanks and Appurtenances (BNL 1993).

- U.S. DOE Report U.CRL 15910, Design and Evaluation Guidelines for Department of Energy Facilities Subjected to Natural Phenomena Hazards (UCRL 1990).

- $\quad$ ASCE Standard 4-86, Seismic Analysis of Safety Related Nuclear Structures and Commentary on Standard for Seismic Analysis of Safety Related Nuclear Structures (ASCE 1986).

- Hanford Plant Standards, HPS-SDC-4.1, Rev. 12, Standard Arch-Civil Design Criteria, Design Loads for Facilities, (SDC-4.1 1993). 
- Primary Tank: The primary tank shall be evaluated against the requirements of the $A S M E$ Boiler \& Pressure Vessel Code, Section III, Division I, Subsection NC, Article NC-3200 (ASME 1992a).

- Secondary Concrete Structure: The secondary concrete structure shall be evaluated against the requirements of ACI 349-90, Code Requirements for Nuclear Safety Related Concrete Structures (1992).

- Secondary Tank Liner: The secondary tank liner shall be evaluated in accordance with the requirements of the ASME Boiler \& Pressure Vessel Code, Section III, Division 2, Subsection CC (ASME 1992d). Those portions of the liner which are not backed by concrete shall be evaluated to the requirements of the ASME Boiler \& Pressure Vessel Code, Section III, Division 1, Subsection NC (ASME 1992a).

- Insulating Conerete Pad: The insulating concrete pad shall be evaluated against the bearing stress requirements of ACI 349-90, Code Requirements for Nuclear Safety Related Concrete Structures (1992).

- Primary Tank Dome \& Secondary Liner Anchorage Systems: The anchorage systems for that portion of the tank steel which is backed by concrete shall meet the requirements of the ASME Boiler \& Pressure Vessel Code, Section III, Division 2, Subsection CC (ASME 1992d).

A code reconciliation, as described in Section 5.0, shall be performed for new or revised analyses that are based on codes more current than the codes of record. See Tables 5.0-1 and 5.0-2 for code of record for the primary tank and secondary steel liner and the secondary concrete structure, respectively. The above documents provide the basis for the minimum requirements for the analysis and structural qualification of the existing DSTs for continued operation. More stringent requirements may be desirable or imposed based on sound engineering knowledge, experience, and judgement as may be appropriate for the special conditions associated with these underground waste storage tanks. 
Figure 1.2-1. Double-Shell Tank and Ancillary Equipment Configuration.

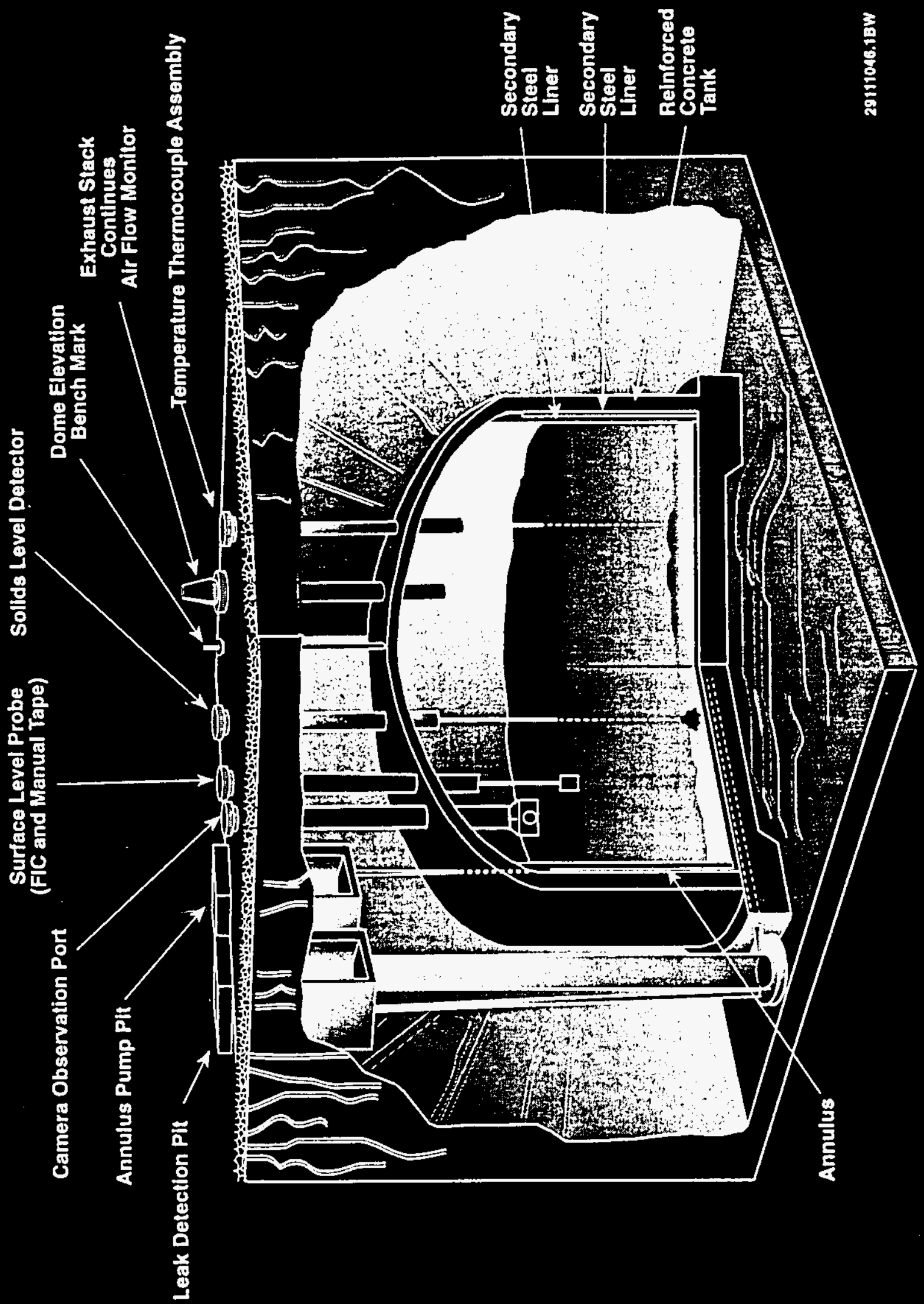


Figure 1.2.3-1. Details of the Wall-Basemat Interface for Double-Shell Tanks 241AY, AZ, AW, and SY.

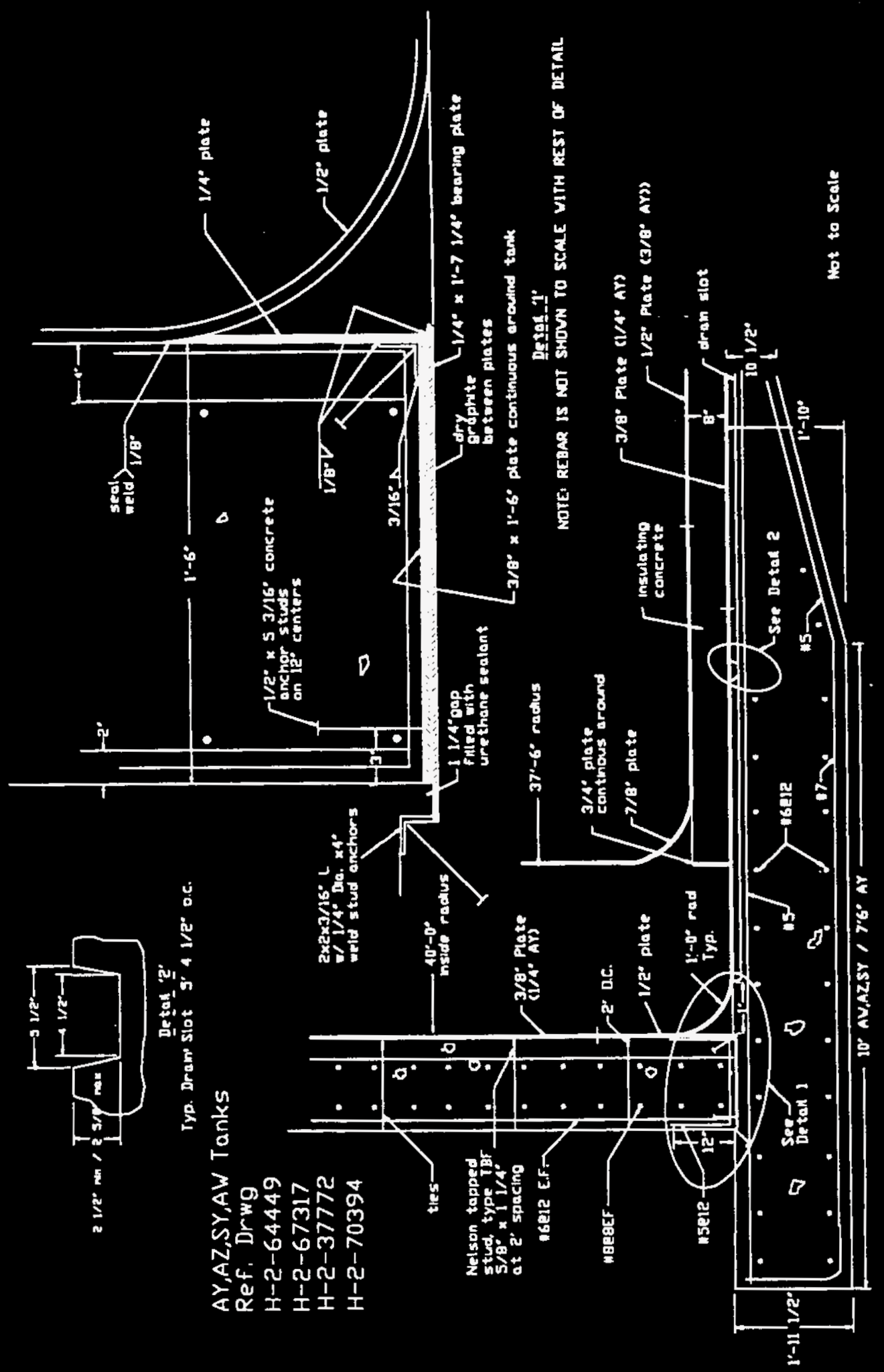


Figure 1.2.3-2. Details of the Wall-Basemat Interface for Double-Shell Tank 241AN.

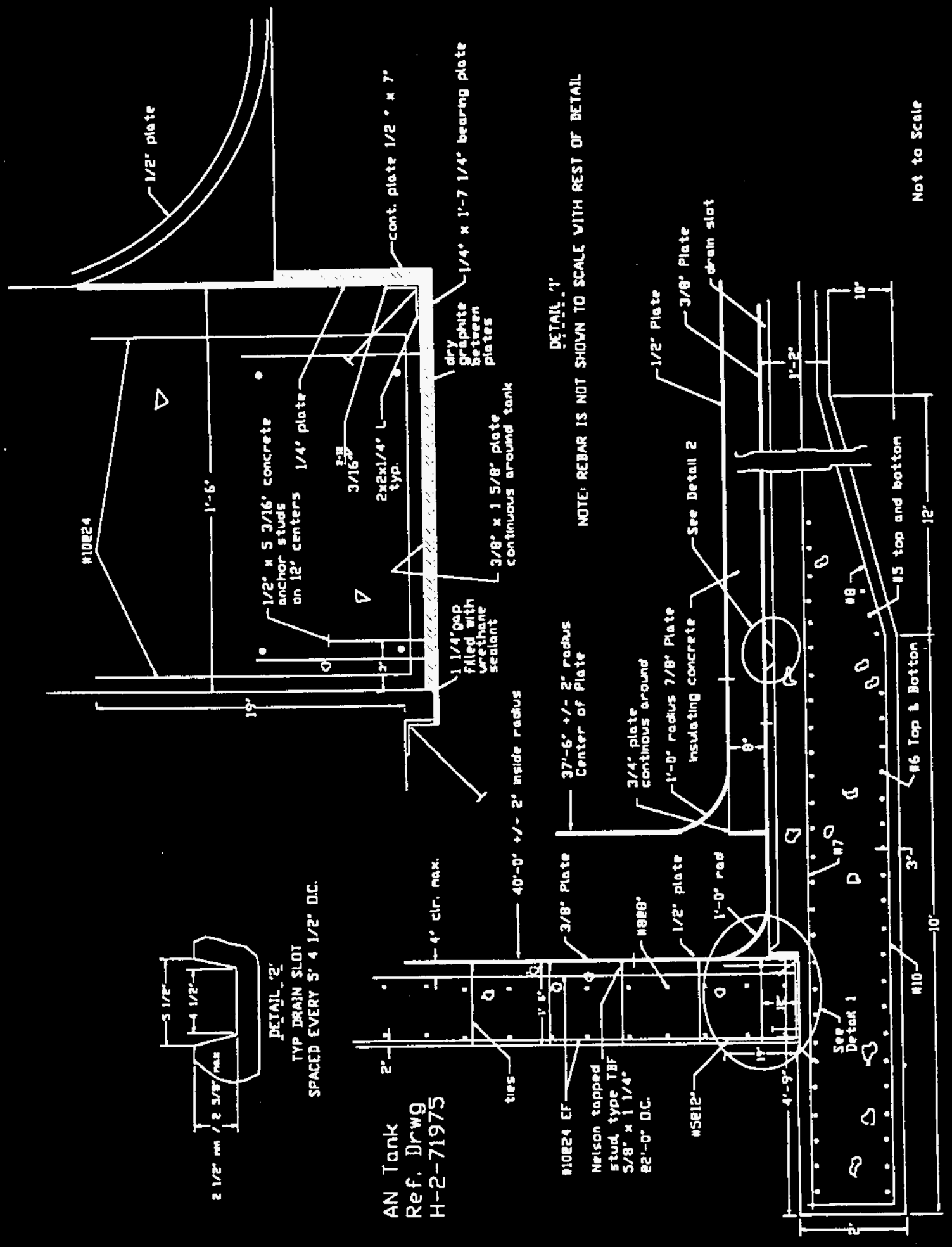


Figure 1.2.3-3. Details of the Wall-Basemat Interface for Double-Shell Tank 241AP.

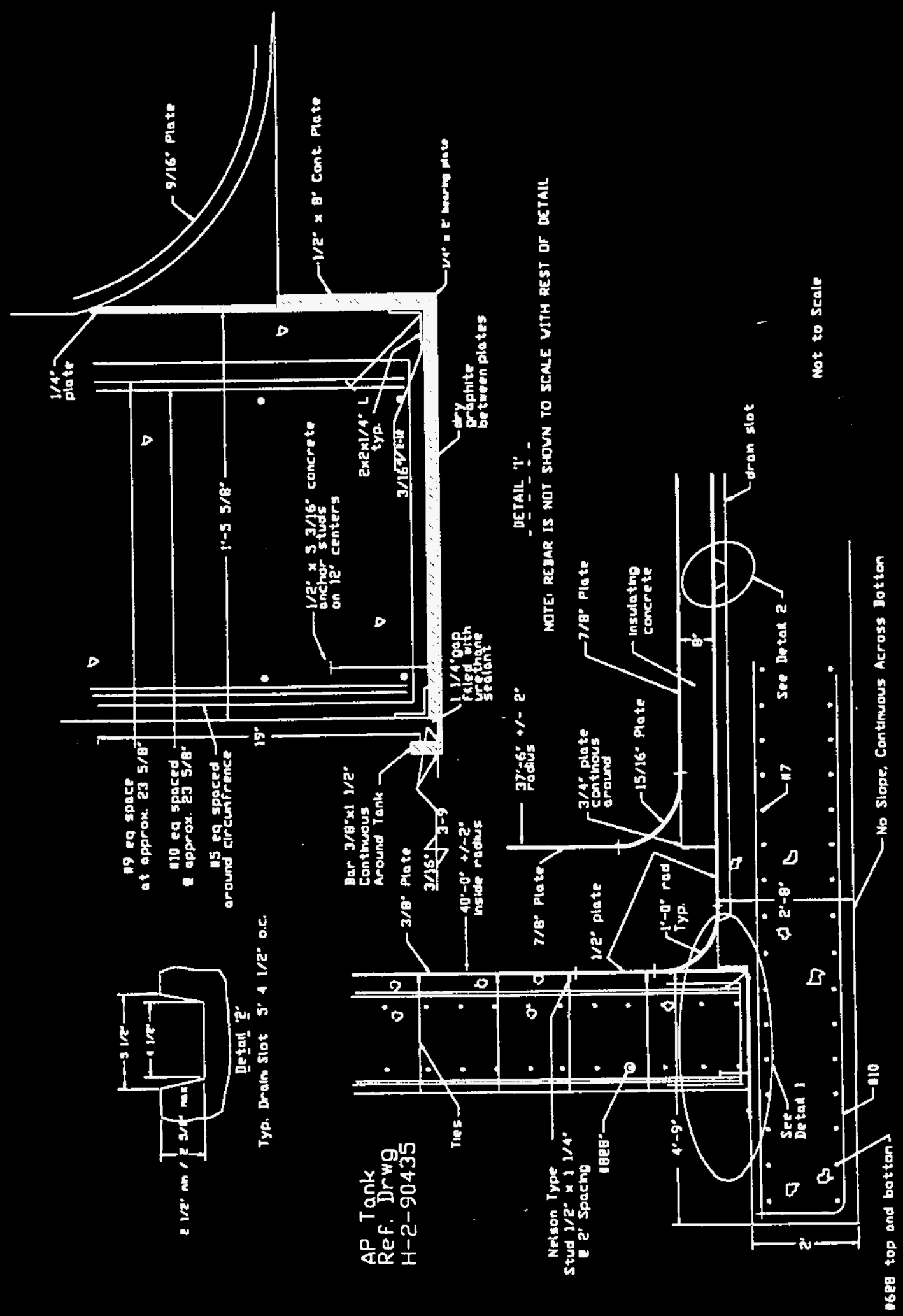


Table 1.2-1. Hanford Site Double-Shell Tanks.

\begin{tabular}{|c|c|c|c|c|c|c|}
\hline \multirow{2}{*}{$\begin{array}{l}\text { Tank } \\
\text { Farm } \\
241-\end{array}$} & \multirow{2}{*}{$\begin{array}{c}\text { Number } \\
\text { of } \\
\text { Tanks }\end{array}$} & \multirow{2}{*}{$\begin{array}{c}\text { Date of } \\
\text { Construction }\end{array}$} & \multirow{2}{*}{$\begin{array}{c}\text { Capacity } \\
\text { per Tank } \\
\text { (Mgal) }\end{array}$} & \multicolumn{2}{|c|}{ Service Life (yr) } & \multirow{2}{*}{$\begin{array}{c}\text { Reference } \\
\text { Drawing }\end{array}$} \\
\hline & & & & $\begin{array}{l}\text { Original } \\
\text { Basis }\end{array}$ & $\begin{array}{l}\text { Desired }^{1} \\
\text { Minimum }\end{array}$ & \\
\hline \multicolumn{7}{|c|}{ Aging Waste Facility Double-Shell Tanks (equipped with airlift circulators) } \\
\hline AY & 2 & 1968-70 & 1.00 & $40^{2}$ & $60-58$ & H-2-64300 \\
\hline $\mathbf{A Z}$ & 2 & $1971 \& 77$ & 1.00 & $20^{2}$ & $57 \& 51$ & H-2-68300 \\
\hline \multicolumn{7}{|c|}{ Non-Aging Waste Double-shell Tanks } \\
\hline SY & 3 & $1974-76$ & $1.16^{3}$ & $50^{2}$ & $54-52$ & H-2-37700 \\
\hline $\mathbf{A W}$ & 6 & $1978-80$ & $1.16^{3}$ & 50 & $50-48$ & H-2-70300 \\
\hline $\mathbf{A N}$ & 7 & $1980-81$ & $1.16^{3}$ & 50 & $48-47$ & H-2-71900 \\
\hline $\mathbf{A P}$ & 8 & $1983-86$ & 1.16 & 50 & $45-42$ & H-2-90435 \\
\hline
\end{tabular}

Date of construction and waste storage capacity taken from Tank Farm Surveillance and Waste Status Summary Report (WHC 1994b).

1 The desired minimum service life for each tank farm is based on original construction date and TriParty Agreement (TPA 1995) milestone to complete pretreatment of Hanford tank waste (TPA milestone M-50-00). However, this milestone is subject to change. The double-shell tank closure sequence has not been established at this time but it will depend on structural integrity considerations, the need for specific tank capabilities (i.e., airlift circulators) and the tank location relative to processing facilities.

${ }^{2}$ Assumed design lives for tanks AY, AZ, and SY since design lives is not stated explicitly in respective construction or design specifications for these tanks. The nominal design lives indicated for the $A Y$ and $A Z$ tanks are reported to come from property management amortization tables. The nominal design life indicated for the SY tanks was selected because the SY tanks are believed to be more consistent with the more recent tanks (AN, AW, and AP).

${ }^{3}$ The $1.16 \mathrm{Mgal}$ waste capacity corresponds to a waste depth of $422 \mathrm{in}$. Only the AP tanks were designed originally for $1.16 \mathrm{Mgal}$ of liquid waste. The SY, AW, and AN tanks were designed originally for a $1.0 \mathrm{Mgal}$ waste capacity (per reference design drawings) corresponding to a waste depth of 363 in. (18 in. below the secondary liner tangent line elevation). These tanks were then later qualified by analysis for a maximum $1.16 \mathrm{Mgal}$ waste capacity. 
THIS PAGE NTENTIONALLY

LEFT BLANK 


\subsection{LOAD DEFINITIONS}

The design loads for the double-shell tanks are established by the their construction specifications, safety analysis report, or other basis documents which shall be collectively designated as the Functional Design Criteria (FDC) for the tank farm of interest. DSTs design loadings include those associated with normal operation: dead, live, hydrostatic, thermal, and soil overburden; with abnormal conditions: wind generated missiles, abnormal pump induced loads, and earthquake loads; and extreme conditions: flammable gas burn or equipment drop loads. Evaluation of these loads under time dependent material degraded properties is required to estimate usable life for DSTs. A design load summary is given in Table 2.0-1 for selected design conditions for the DSTs.

Based on their load classification in the source documents and best engineering judgement, loads have been grouped into three categories: normal, abnormal, and extreme.

1. Normal Loads--Loads encountered during normal operation. For the primary steel tank, the major contributors to DST stresses during normal operation are the hydrostatic load and the soil overburden. The other loads contribute a relatively small amount to the overall stress state. For the secondary steel liner and the concrete structure, the major demand comes from the thermal loads, the soil loads, and the concentrated live load. The normal loads are listed below.

a. Dead Loads--Structure weight and permanent equipment loads.

b. Live Loads-Movable equipment loads and other loads that vary with intensity and occurrence, except soil pressures, which are included separately.

c. Hydrostatic Load--Hydrostatic pressure, including fill/drain cyclic variations.

d. Thermal Loads--Thermal effects and loads from differential thermal expansion and thermal gradients.

e. Soil Loads--Soil overburden and lateral soil pressure.

f. Operating Pressure Loads--Pressures in the primary DST vapor space and the annulus determined from the operational safety document and operational safety requirement defined values.

g. Pump Loads--Weight, vibration, and thrust loads from pump operation (normally evaluated on a tank-by-tank basis).

2. Abnormal Loads-Abnormal loads have a lower probability of occurrence and include:

a. Pressure Loads--A sudden release of gases causing a brief increase in the primary DST vapor pressure.

b. Wind Loads-Although the tanks are below grade, they are subject to wind generated objects acting as missiles. 
c. Pump Loads--Maximum pump vibration (impeller plugged), maximum pump thrust (one nozzle plugged), wasteberg striking the pump column, installing and removing loads, discharge pipe assembly failure (pump loads are addressed on a tank-by-tank basis).

d. Earthquake Loads--Loads generated by the Design Basis Earthquake (DBE). This includes seismically induced hydrodynamic sloshing loads and soil-structure interaction loads.

3. Extreme Loads--These loads are accident loads imposed on the DSTs as a result of various extreme conditions identified in either the functional design criteria or in the safety analysis report. These loading conditions are typically dynamic in nature and demand is typically compared to failure criteria rather than design criteria.

a. Equipment Drop Loads--Drop of heavy equipment on dome or within tank.

b. Ignition of Flammable Gases-Very rapid pressure pulse caused by deflagration of flammable gases.

\subsection{DESIGN PRESSURE LOADS (F)}

For the primary tank, the maximum positive and negative design pressure (freeboard vapor pressure above the waste) shall be obtained from the FDC (see Table 2.0-1). The design pressure must account for the negative pressure in the annulus between the primary tank and secondary liner to obtain the net pressure on the primary tank. The total pressure on the tank walls shall be the sum of this net vapor pressure and the static liquid head which shall be calculated using a waste slurry specific gravity given in the FDC. Combinations of waste height and vapor pressure shall be considered to obtain the most severe load condition.

For the secondary concrete structure and the secondary liner the following pressure loads shall be considered for evaluation for degraded material conditions:

1. Normal Pressure: Normal pressure in the annulus shall be per the applicable FDC. This will be treated as fluid $(F)$ load for the concrete structure and pressure load $\left(P_{v}\right)$ for the liner.

2. Abnormal Pressure: In the most unlikely event of primary tank leakage, the slurry will be contained by the secondary liner. The secondary concrete structure wall pressure above the liquid surface will then be equal to the internal design pressure for the primary tank. The wall pressures distribution below the liquid surface will be the sum of the vapor pressure and the hydrostatic liquid pressure. The resulting pressures shall be considered as fluid (F) load in load combination Equations 8 and 9 of Section 9.2 of ACI 349-90 (1992) for the concrete structure and as $P_{v}$ in the "extreme environmental" load combination for the liner.

\subsection{OPBRATING PRESSURE}

The operating pressure for the tank shall be obtained from the applicable FDC. This pressure shall be used in combination with the seismic loads. 


\subsection{DEAD LOAD (D)}

The tanks shall be evaluated for dead loads associated with the self weight of the structure and permanent equipment. The structure self-weight load includes the weight of the concrete dome, walls, insulating pad, and basemat foundation along with the weight of the steel primary tank and secondary steel liner. Dead load calculations shall be based on the following unit weights in lieu of measured in situ values:

\begin{tabular}{lc} 
& $\begin{array}{c}\text { Unit Weight } \\
\left(\mathrm{lbf} / \mathrm{ft}^{3}\right)\end{array}$ \\
\cline { 2 - 2 } Reinforced concrete & 150 \\
Structural steel & 490 \\
Backfill and earth cover & 125
\end{tabular}

A net concentrated load of $\mathbf{5 0}$ tons (discounting for displaced soil) shall be considered to account for placement of permanent equipment. Eccentric application of this concentrated load shall be considered to ensure that the maximum stresses are determined in the tank structure.

\subsection{LIVE LOADS (L)}

The tanks shall be evaluated for live loads consisting of a uniformly distributed surface load of $40 \mathrm{lbf} / \mathrm{ft}^{2}$ and a 100,000-lbf (50-ton) concentrated surface load. Eccentric application of the concentrated live load shall be considered to ensure that the maximum stresses are determined in the tank structure. The design basis ashfall loading of $24 \mathrm{lbf} / \mathrm{ft}^{2}$ and snow loading of $20 \mathrm{lbf} / \mathrm{ft}^{2}$ as specified in SDC-4.1 (SDC-4.1 1993) are considered to be included (need not be combined) in the design uniformly distributed surface load of $40 \mathrm{Ibf} / \mathrm{ft}^{2}$.

Encroachment of heavy crawler type cranes near the tank dome shall also be considered. One objective of the reanalysis is to determine the allowable live load for each of the DSTs so that the acceptability of operation and removal activities on and around the tanks can be better evaluated.

\subsection{SOIL LOADS (H)}

The tanks shall be evaluated for static and dynamic soil loads as defined below:

1. A soil unit weight of $125 \mathrm{lbf} / \mathrm{ft}^{3}$ shall be used for the soil backfill overburden unless determined by a site-specific ${ }^{4}$ subsurface evaluation. A higher density may conservatively be used to account for higher water content and compaction variability.

2. Soil bearing information from the site-specific subsurface investigation shall be used for foundation soil. If site-specific data is not available then values used shall be justified.

\footnotetext{
Some site-specific data for the Hanford tanks has been compiled for the soil overburden unit weight and soil cover depth in Pianka 1994 and 1995, respectively.
} 
3. The effect of dynamic earth pressures shall be considered in the analysis.

4. The tank walls shall be evaluated for at-rest lateral earth pressures. Load distribution with depth shall be based on classical earth-pressure theory and with guidance provided by Moore $1995 b$. Superimposed lateral pressures resulting from uniform and concentrated surcharge loadings shall be calculated by using at-rest pressure coefficients.

5. Consideration shall be given to passive soil loading produced by thermal expansion of tank as a result of waste temperatures.

6. The soil weight inside an extended cylinder above the tank wall shall be applied as an axisymmetric nonuniformly distributed load on the dome with due account taken for variation in soil height above the dome due to the dome curvature.

\subsection{THERMAL LOADING (T)}

The tanks shall be evaluated for structural loading as a result of thermal gradients, differential thermal expansion, and the effects of transient fill/drain cycles. The evaluation shall consider the effect of differences between the thermal expansion of concrete and steel. Degraded material properties based either on the design temperature or on actual temperature history data shall be considered.

Heat transfer analyses shall be performed to obtain the temperature distributions in the structural components. The thermal history for a tank or bounding history for a group of tanks shall be determined from tank monitored temperature data and waste content data.

The secondary concrete structure shall be evaluated for the effects of creep. The evaluation shall consider the factors that influence creep, such as loading sequence, water-cement ratio, exposing the concrete to drying conditions and to high temperatures. The creep analysis shall account for large deflections, temperature variations, and cracking.

The secondary concrete structure shall be evaluated also for the temperature distribution occurring as a result of primary tank leakage. As this is an accident condition, the loading shall be classified as $T_{2}$ per loading definition in Section 9.0 of ACI 349-90.

Deformations of the secondary concrete structure shall be considered in the structural evaluations of the primary tank and secondary liner.

\subsection{SEISMIC LOADING $\left(\mathrm{E}_{\boldsymbol{\omega}}\right)$}

Components of horizontal and vertical seismic loading, combination methodology, damping, and methodology for determination of total seismic demand on tank are presented below in accordance with SDC-4.1 (1993) except that the "equal hazard" response spectra data derived for the 200 East and West Areas by Geomatrix (1994) are imposed. Only the mass of equipment or subsystems that meet the decoupling requirements of ASCE 4-86 (ASCE 1986) need to be included in the soil-structure interaction (SSI) structural model. In-structure response spectra shall be developed at equipment support locations in accordance with ASCE 4-86. 


\subsubsection{Components of Seismic Loading}

The tanks shall be evaluated for a design basis earthquake (DBE) with a horizontal peak ground acceleration (PGA) of $0.20 \mathrm{~g}$ as given in SDC-4.1 for non-reactor safety class 1 structures. The normalized "equal hazard" design response spectra shall be applied as given in Geomatrix 1994 for the 200 East and West Area. The design response spectrum for vertical motion is taken as $2 / 3$ the horizontal spectrum for frequencies less than $2 \mathrm{~Hz}$ and equal to the horizontal spectrum for frequencies equal to or greater than $3.3 \mathrm{~Hz}$.

Corresponding synthetic earthquake time histories that envelop the design response spectra are provided in Weiner 1995. These time histories shall be used for time-history analyses by scaling their amplitudes linearly such that the scaled peak ground acceleration is equal to the required PGA.

\subsubsection{Damping}

The damping values given in Table 2.1 (see Table 2.7.2-1, herein) of the Tank Seismic Expert Panel (TSEP) Guidelines (BNL 1993) shall be used for evaluating the underground tanks. The underground tanks shall be evaluated using elastic response analyses with response level 3 damping.

- Response levels are based on the ratio of total elastic computed demand to code strength capacity. Response level 1 is for ratios less than 0.5 . Response level 2 is for ratios between 0.5 and 1. Response level 3 is for ratios greater than 1. Response levels 1 and 2 are intended for analyses to develop in-structure spectra for determining seismic excitation of supported components. The appropriate damping level used in developing in-structure spectra depends on the stress level in the supported structure. Response level 3 is intended for analyses of the tank structure. Care must be exercised if nonlinear analyses are used in order to avoid double counting of damping effects represented by response level 3 values and hysteretic damping inherent in the nonlinear analyses.

\subsubsection{Combination of Component Seismic Loads}

Because the DSTs are axisymmetric structures the design response spectra need only be applied in one horizontal and the vertical direction. The 100/80/60 load reduction method for orthogonal ground motions discussed in UCRL-15910 (UCRL 1990) shall not be used. The structural response from each earthquake component shall be combined by the square-root-of-sum-of-squares (SRSS) method for each response parameter (moment, membrane load, and shear).

\subsubsection{Soil-Structure-Interaction Seismic Analysis}

The purpose of this section is to provide direction for performing the required soil-structureinteraction (SSI) analysis of the tanks. The specific directions given are intended to be an implementation of Chapter 6 of the TSEP Guidelines (BNL 1993). Periodic references are made to specific TSEP Guidelines. Directions are also given for developing seismic member loads for the individual tank components. 
2.7.4.1 Soil-Structure-Interaction Analysis Procedure. Section 6.5.2 of the TSEP Guidelines, refers to two different methods for performing SSI calculations, involving lumped-parameter and continuum models. The lumped-parameter approach may be utilized to perform various preliminary parametric studies including characterization of soil and structural stiffness uncertainties. However, the final analysis shall use the continuum approach.

Prior to the SSI model development, free-field analyses shall be performed using the SHAKE (Lysmer et al. 1991) computer code to obtain strain-iterated soil properties. Lower-bound, bestestimate, and upper-bound low-strain soil properties shall be considered in accordance with Section 6.2 of the TSEP Guidelines.

2.7.4.2 Continuum Model Approach. A finite-element continuum model of the tank assembly shall be generated, using the System for Analysis of Soil-Structures Interaction (SASSI) computer code (Lysmer et al. 1991). The model shall be a three-dimensional, ninety degree sector model of the composite tank. The structural model shall be of sufficient detail to directly obtain reasonable estimates of the seismic induced member loads.

The guidance given in Section 4.3.8 of the TSEP Guideline is directed at lumped parameter modeling of the hydrodynamic mass effects. For the three-dimensional SASSI model, it is desirable to appropriately distribute the hydrodynamic masses to obtain reasonable stresses in the primary tank. See, for example, Section 3.1.6.3 of ASCE 1986. Precise distributions of the hydrodynamic masses in the three-dimensional SASSI model can become complex, especially for the convective masses. Some insight into the proper modeling of the hydrodynamic masses may be obtained from parametric studies using the lumped parameter model. Further guidance is provided also in Moore $1995 \mathrm{~b}$.

2.7.4.3 Vault-to-Vault Interaction. Section 6.6 of the TSEP Guidelines states that there is "some evidence" that vault-to-vault interaction is not significant if the spacing between vaults (concrete structures) is greater than one half of the vault radius. This has been verified for Hanford DSTs through a 3-D SSI analysis and is discussed in Moore 1995b. Because the distance between DSTs (24 ft) is greater than one half of the vault radius $(41.5 \mathrm{ft} / 2=20.75 \mathrm{ft})$, vault-to-vault interaction is not a concern for the DSTs.

\subsubsection{Earthquake Induced Loading on Primary Tank Walls}

Ideally, a nonlinear coupled analysis that includes the concrete tank, primary tank, waste, and soil interaction would provide a means to capture any potential sliding at the concrete-wall to basemat interface and at the primary-tank-bottom to insulating-concrete interface. However, such an analysis would be very complex and costly; hence, an uncoupled analysis of the primary tank is desirable.

For an uncoupled analysis of the primary tank the following effects shall be considered:

1. Primary Tank Accelerations. Primary tank accelerations shall be determined from the analysis of the tank-vault-soil system which accounts for the effects of soil-structure interaction.

2. Dynamic Displacements of Primary Tank Dome Nodes Anchored in the Concrete Dome. These displacements are obtained from seismic analysis of the secondary concrete structure. The seismic displacements shall be combined with thermal displacements and analyzed with the normal operating thermal condition. 
3. Sliding. Consideration shall be given to potential relative sliding motion between the primary tank bottom and the insulating concrete pad; as well as, potential sliding of the concrete wall relative to the basemat foundation (see Section 4.1,2.10).

4. Hydrodynamic Pressures Associated with Liquid Motions Induced by Earthquake Ground Motions. The TSEP Guidelines methodology for hydrodynamic pressure calculations shall be applied as discussed in Section 2.7.5.2, herein.

2.7.5.1 Seismic Input to Primary Tank Analysis. The fluid accelerations from the SSI analysis shall be used to obtain the hydrodynamic pressures on the tank walls. The seismic displacements of the secondary concrete structure shall be applied to a more detailed primary tank model.

2.7.5.2 Hydrodynamic Wall Pressures. The procedures, delineated below, for calculating earthquake induced hydrodynamic pressures on the primary tank wall are those that are provided by the TSEP Guidelines. Other analysis methods including a time-history analysis may also be used, if required.

\section{Axsumptions}

- The effects of variable wall thickness on the natural frequencies can be accounted for by an equivalent uniform wall thickness as suggested in Section 4.3.2.2 of the TSEP Guidelines.

- As the primary tank is restrained at both top and bottom, the effect of roof mass is negligible on the natural frequency.

- The hydrodynamic effects are critical when the tank is full. No evaluation is required for a partially filled condition.

- As the top of the tank is anchored to concrete by closely spaced studs and the bottom is supported by a thick concrete pad, the "hinged" boundary condition at the top is applicable to these tanks.

- The ASME Code applicable to primary tank construction does not have a provision for inelastic energy absorption factor, $F_{\mu}$, which can be applied to reduce the elastically computed seismic demand. Instead, the ASME Code has factors on the allowable stresses for different service levels. Per TSEP Guidelines, a seismic load factor, $L_{2}$, should be used to adjust elastically computed demand to inelastic-factored seismic demand and then that should be reduced by $F_{\mu}$ factor to calculate the actual seismic demand. For a risk reduction factor of 20 , the ratio $L_{2} / F_{\mu}$ for the primary tank ranges between 0.767 and 0.92 . Although the ASME criterion is conservative, this ratio may be assumed equal to 1.0 to comply with the code. Therefore, no adjustment in the calculated hydrodynamic wall pressures need be made.

2.7.5.2.1 Effects of Horizontal Motion. The TSEP Guidelines provide methodologies, in Sections 4.3 and 4.5 , to calculate tank wall pressures due to earthquake induced horizontal and vertical motions. The solutions given in Section 4.3 are based on the assumption that the tank base experiences purely horizontal motion and, therefore, do not include the effects of rocking component of foundation motion. 
Section 4.4 of the TSEP Guidelines discusses a technique to evaluate the rocking effects. It is stated that the rocking effects on the convective component of response are negligibly small and the effects of rocking on the impulsive component of response need to be considered.

The rocking effects on the horizontal component of the impulsive response is considered by utilizing a horizontal response spectra which envelops the tank top and bottom horizontal spectra generated from the SSI analysis for the horizontal ground motion. The spectral acceleration from this enveloped spectra shall be used for calculating the tank wall pressures.

\section{Primary Tank Wall Pressure}

The hydrodynamic fluid pressure on the tank wall, due to lateral motions, is given by superposition of a component contributed by the convective fluid motion and an impulsive pressure component. The instantaneous value of the hydrodynamic pressure at a point is given by:

$$
\mathrm{p}(\eta, \theta, \mathrm{t})=\mathrm{c}_{\mathrm{i}}(\eta) \rho_{\mathrm{l}} \mathbf{R} \mathbf{A}_{\mathrm{i}}(\mathrm{t}) \cos \theta+\sum\left[\mathrm{c}_{\mathrm{cn}}(\eta) \rho_{1} \mathbf{R} \mathbf{A}_{\mathrm{cn}}(\mathrm{t})\right] \cos \theta
$$

where

$$
\begin{aligned}
& c_{\mathrm{i}}=\text { Dimensionless function of } \eta \text { associated with impulsive pressure } \\
& \eta=\mathbf{z} / \mathrm{H}_{1} \\
& \mathrm{z}=\text { Height from the tank base } \\
& \mathrm{H}_{1}=\text { Maximum height of liquid measured from the tank base } \\
& \rho_{1}=\text { Mass density of liquid } \\
& \mathbf{R}=\text { Tank radius } \\
& A_{\mathrm{i}}(\mathrm{t}), \text { Aseudo-acceleration response functions for single-degree-of-freedom } \\
& \mathrm{c}_{\mathrm{ca}}=\text { Dimensionless function of } \eta \text { associated with convective pressure } \\
& \theta=\text { Circumferential angular position of the point. }
\end{aligned}
$$

Replacing $A_{i}(t)$ by their maximum or spectral value and using $\cos \theta=1$, the maximum value of impulsive pressures at a given height is given by:

$$
p_{\text {imp }}=c_{i}(\eta) \rho_{1} R\left(S_{A}\right)_{i}
$$

Neglecting the second and higher convective modes as the pressures for these modes are small compared to first mode pressure, and replacing $A_{c 1}(t)$ by its spectral value $\left(S_{A}\right)_{c a}$, the maximum convective pressure (for $\cos \theta=1$ ) can be expressed as:

$$
P_{c o n}=c_{e 1}(\eta) \rho_{1} R\left(S_{\mathrm{A}}\right)_{c 1}
$$




\section{Procedure for Calculating $\mathbf{D}_{\text {mp }}$}

1. Calculate the fundamental natural frequency of the impulsive mode using the following equation:

$f_{i}=(1 / 2 \pi)\left(1 / H_{1}\right)\left(E_{i} / \rho_{t}\right)^{0.5}\left(C_{i}\right)_{r}\left[127\left(t_{w w} / R\right) /\left(\rho_{1} / \rho_{t}\right)\right]^{0.5}$

where $E_{t}$, and $\rho_{t}$ are elastic modulus of tank material and mass density, respectively. $\left(C_{i}\right)_{r}$ is a reference dimensionless coefficient given in Table 4.3 of the TSEP Guidelines and $t_{w}$ is the tank wall thickness. If the wall thickness varies with the height, the average wall thickness, $t$, over the lower two-thirds of the liquid height should be used in the above equation.

$\mathrm{H}_{1}$ and $\mathrm{t}_{\mathrm{a}}$ can be calculated from the tank geometry and liquid storage requirements. Values of coefficient $\left(\mathrm{C}_{\mathrm{i}}\right)_{\mathrm{r}}$ for top-hinged boundary condition from Table 4.3 of the TSEP Guidelines are listed in Table 2.7.5-1, herein.

In order to account for $\pm 15 \%$ peak broadening of the amplified response spectra, consider a frequency range $0.85 f_{i} \leq f_{i} \leq 1.15 f_{i}$.

2. Obtain the peak spectral acceleration, $\left(S_{A}\right)_{i}$, in the above frequency range from the SSI analyses. The damping value to be used is $4 \%$ which corresponds to response level 3 in Table 3.2 of the TSEP Guidelines for impulsive mode of liquid containing metal tanks.

3. Calculate element $c_{\mathrm{i}}(\eta)$ for each element along the primary tank wall using the following equation:

$$
\begin{aligned}
c_{\mathrm{i}}(\eta)= & \mathrm{D}_{\mathrm{i}}[\cos (\pi / 2) \eta-0.11 \cos (3 \pi / 2) \eta+ \\
& 0.04 \cos (5 \pi / 2) \eta-0.02 \cos (7 \pi / 2) \eta+\ldots]
\end{aligned}
$$

In the above equation $\eta=z / H_{1}$ where $\mathrm{z}$ is the height of the element centroid above the tank base. $D_{i}$ is a dimensionless function of $H_{4} / R$ as given in column 2 of Table 4.2 of the TSEP Guidelines.

4. Calculate $p_{\text {imp }}$ using Equation 2.7.5-2 and parameters calculated in steps 2 and 3.

\section{Procedure for Calculating Dom}

For peak convective pressure, Equation 2.7.5-3 shall be used. $c_{c 1}(\eta)$ and $\left(S_{A}\right)_{c 1}$ shall be calculated using the following procedure:

1. Calculate the fundamental frequency of the sloshing mode using the following equation:

$f_{c 1}=(1 / 2 \pi)\left[\lambda_{1}(g / R) \tanh \left(\lambda_{1}\left(H_{1} / R\right)\right)\right]^{0.5}$

where $\lambda_{1}$ is the first root of the first derivative of the Bessel function of the first kind and first order and equals $1.841 ; g$ is the gravitational acceleration in consistent units with $\mathbf{R}$. 
2. In accordance with Table 3.2 of the TSEP Guidelines, $0.5 \%$ damping shall be used for the convective mode of liquid containing metal tanks. The spectral acceleration, $\left(S_{\mathrm{A}}\right)_{\mathrm{el}}$, at the above calculated frequency shall be obtained from the SSI analyses.

3. Value of $c_{\mathrm{ct}}(\eta)$ shall be calculated from the following equation:

$c_{c 1}(\eta)=\frac{2}{\lambda_{1}^{2}-1} \frac{\cosh \left[\lambda_{1}\left(H_{l} / R\right) \eta\right]}{\cosh \left[\lambda_{1}\left(H_{l} / R\right)\right]}$.

Using $\lambda_{1}=1.841$, the above equation reduces to:

$c_{c l}(\eta)=0.837 \frac{\cosh \left[\lambda_{1}\left(H_{l} / R\right) \eta\right]}{\cosh \left[\lambda_{1}\left(H_{l} / R\right)\right]}$.

4. The maximum convective pressure shall then be calculated using Equation 2.7.5-3 and the parameters calculated in steps 2 and 3 above.

\section{Procedure for Calculating Pressure due to Sloshing}

The maximum vertical displacement (slosh height) of the liquid surface shall be calculated using the TSEP Guidelines. Considering only the fundamental sloshing mode, the slosh height is given by the following equation:

$$
h_{1}=R\left\{0.837\left(S_{A}\right)_{c 1} / g\right\}
$$

where $\mathbf{R}$ is the tank radius, $g$ is the gravitational acceleration, and $\left(S_{A}\right)_{c 1}$ is the fundamental sloshing. mode spectral acceleration.

The slosh height demand shall be determined from the above equation by increasing the above response by a seismic load factor. Using a load factor equal to 1.15 in Equation 5.1 of the TSEP Guidelines, the slosh height demand (including 1.6 safety factor) is given by:

$$
\mathrm{h}_{\mathrm{ed}}=1.84 \mathrm{~h}_{\mathrm{s}} \text {. }
$$

The available slosh height capacity, $h_{v c}$, can be calculated from the following equation:

$$
h_{x c}=h_{c}+\left(h_{d} / 4\right)
$$

where $h_{c}$ is the cylindrical wall height above the liquid surface and $h_{d}$ is the dome height above the cylindrical wall.

If $h_{x c}$ is less than $h_{x d}$, sufficient freeboard does not exist. The tank wall pressures will increase because of constraint provided by the roof and the roof itself will experience additional pressures because of slosh impact. Because the TSEP Guidelines do not provide adequate guidelines for calculating the slosh impact pressure for the ellipsoidal geometry of the primary tank dome, the following methodology was developed in Shrivastava 1995 and is outlined below.

An empirical correlation developed by Kurihara 1992 for the sloshing impact pressure in flat roofed liquid tanks is modified to account for the ellipsoidal geometry of the primary tank dome. 
First, a flat roof at height $h_{\mathrm{zc}}$ (see Figure 2.7.5-1) above the at-rest liquid free surface is assumed. Then, the maximum impact pressure, $P_{\max }$, on the flat roof (at circumferential angle $\theta=0$ ) is calculated and then modified for the ellipsoidal geometry.

The impact pressure is a function of freeboard and fluid velocity and acceleration at the time of impact. To calculate the impact pressure, one must know the velocity of the impacting fluid. The movement of the sloshing crest is assumed sinusoidal. The wave height, $\mathrm{u}$, when no roof exists can be written as

$$
u=h_{d d} \sin \omega t
$$

where $\omega$ is the circular sloshing frequency, $2 \pi$ times the cyclic frequency determined from Equation 2.7.5-6. The vertical velocity of the fluid, $v$, can be obtained by differentiating Equation 2.7.5-12 with respect to time:

$$
v=h_{\alpha d} \omega \cos \omega t \text {. }
$$

The time, $t_{1}$, when the liquid surface reaches the flat roof can be calculated from Equation 2.7.5-12:

$$
\omega t_{1}=\sin ^{-1}\left(\frac{h_{s}}{h_{s d}}\right) \text {. }
$$

The velocity, $\mathrm{v}_{1}$, before impact is obtained from Equations 2.7.5-13 and 2.7.5-14:

$$
v_{1}=h_{s d} \omega \cos \left(\sin ^{-1} \frac{h_{s c}}{h_{s d}}\right) \text {. }
$$

Because the difference between the velocity immediately before the impact and the velocity when the largest pressure occurs is small, the velocity given by Equation 2.7.5-15 is used to evaluate the largest impact pressure given by (Kurihara 1992):

$$
P_{\max }=6.63 \rho_{t} \frac{H_{t} R}{h_{s c}} \frac{\left(0.2 R+H_{t}\right)}{\left(0.4 R+H_{t}\right)^{2}} v_{1}^{2}+0.35 \rho_{l} \frac{R H_{t}}{\left(0.4 R+H_{t}\right)} \omega v_{1}
$$

where $R$ is the tank radius, $H_{t}=H_{1}+h_{a c}, H_{1}$ is the at-rest liquid height, and $\rho_{1}$ is the mass density of the liquid.

Assuming the maximum pressure calculated by the above equation acts at the highest point on the liquid surface and that the vertical and circumferential distributions of the impact pressure are the same as those of the fundamental convective pressure in the unconstrained tank, the tank wall pressure due to sloshing is given by the following equation:

$$
\begin{aligned}
P_{s l o s h}(z, \theta) & =P_{\max }\left[\frac{\cosh \left(\frac{\lambda_{1} z}{R}\right)}{\cosh \frac{\lambda_{1}\left(H_{l}+h_{e d}\right)}{R}}\right] \cos \left(\frac{\pi \theta}{2 \theta_{0}}\right) \text { for }-\theta_{0}<\theta<\theta_{0} \\
& =0 \text { when } \theta \geq \theta_{0} \text { and } \theta \leq-\theta_{0}
\end{aligned}
$$

where $\theta_{0}$ is half contact angle shown in Figure 2.7.5-1. 
$\theta_{0}$ can be obtained by calculating the radius of the parallel circle, $\mathbf{x}_{1}$, from the dome geometry and the known value of $h_{z d}$. For a semi-ellipsoidal dome with the center located at $h_{c}$ above the at-rest liquid surface and at $x=0$ and $x_{1}$ can be calculated using the following equation of an ellipse which is with respect to a coordinate system $(x, y, z)$ whose origin is located at the center of the ellipse:

$$
\frac{x^{2}}{a^{2}}+\frac{z^{2}}{b^{2}}=1
$$

The $\mathrm{x}$-coordinate, $\mathrm{x}_{1}$, at the maximum height of the liquid surface is obtained by solving Equation 2.7.5-18 for $x$ at $z=h_{2 d}-h_{c}$ :

$$
x_{1}=a \sqrt{1-\left(\frac{h_{c d}-h_{c}}{b}\right)^{2}} .
$$

Assuming the cylinder is extended to the maximum liquid height and the liquid impacts a flat roof at that height, the half contact angle, $\theta_{0}$, can be easily calculated by:

$$
\theta_{0}=\cos ^{-1}\left(\frac{x_{1}}{R}\right) \text {. }
$$

The pressures calculated by Equation 2.7.5-17 shall be added to the impulsive and convective pressures calculated per TSEP Guidelines by square-root-of-sum-of-squares (SRSS) method.

\section{Total Hydrodynamic Pressure due to Lateral Motion}

The maximum total hydrodynamic pressure induced against the tank wall, $\mathrm{p}_{\mathrm{h}}$, due to lateral motion is given by:

$$
p_{h}=\left[\left(p_{\text {imp }}\right)^{2}+\left(p_{\text {con }}\right)^{2}+\left(p_{\text {siont }}\right)^{2}\right]^{0.5} \text {. }
$$

The above equation provides the maximum pressure due to lateral seismic motion at $\theta=0$. For the axisymmetric tank, the wall pressure may be assumed to vary in the circumferential direction as $\cos \theta$. This assumption is conservative as the wall pressure due to sloshing reduces to zero at $\theta= \pm \theta_{0}$.

2.7.5.2.2 Effects of Vertical Motion. The hydrodynamic wall pressure induced by the vertical component of ground shaking is uniformly distributed in the circumferential direction and may be considered to increase from top to bottom as a half-sine wave. The maximum value of this pressure is given by:

$$
\mathrm{P}_{\mathrm{v}}(\eta)=0.8[\cos (\pi / 2) \eta] \rho_{1} \mathrm{H}_{1}\left(\mathrm{~S}_{\mathrm{A}}\right)_{\mathrm{v}}
$$

where $\left(\mathrm{S}_{\mathrm{A}}\right)_{\mathrm{v}}$ is the vertical spectral acceleration at the fundamental vertical frequency which can be calculated by the equation given below:

$$
f_{v}=(1 / 2 \pi)\left(1 / H_{i}\right)\left(E_{v} / \rho_{v}\right)^{0.5}\left(C_{v}\right)_{r}\left[127\left(\mathrm{t}_{2} / R\right) /\left(\rho_{l} / \rho_{f}\right)\right]^{0.5}
$$


In the above equation, $\left(C_{v}\right)_{r}$ can be obtained from Table 4.3 of the TSEP Guidelines and the other parameters have been already defined earlier.

The hydrodynamic pressure due to vertical motion can be calculated in the following manner:

1. Calculate the vertical frequency using Equation 2.7.5-23 and $\left(\mathrm{C}_{\mathrm{v}}\right)_{\mathrm{r}}$ from Table 4.3 of the TSEP Guidelines listed in Table $2.7 .5-2$, herein. To account for the $\pm 15 \%$ peak broadening of the amplified response spectra, define the frequency band using $85 \%$ and $115 \%$ of the calculated best-estimate frequency.

2. Obtain the peak vertical acceleration, $\left(S_{N}\right)_{v}$, in the above frequency band from the SSI analyses for the vertical ground motion. The damping value shall be taken as $4 \%$ per Table 3.2 of the TSEP Guidelines.

3. Calculate $\mathrm{p}_{\mathrm{v}}(\eta)$ using Equation 2.7.5-22 and the value of $\left(S_{N}\right)_{v}$ obtained in step 2 above.

\subsection{EQUIPMENT LOADS}

Permanent and temporary equipment loads are addressed under dead and live load requirements given in Sections 2.3 and 2.4, respectively. The addition of new equipment shall be controlled and inventoried to ensure that the evaluated dome load limit is not exceeded when the combined weight of the new equipment and its associated installation equipment is combined with the current inventory of equipment on the tank.

\subsection{ACCIDENT LOADS}

Accident loads are extreme loads typically dynamic in nature and demand is typically compared to failure criteria rather than design criteria. The structural effect of accident loads on existing structures are typically evaluated from best-estimate predictions of how the structure will respond to the accident loading on a case-by-case basis. Potential release consequences are evaluated through appropriate safety analyses.

\subsubsection{Equipment Drops}

A postulated equipment drop shall be evaluated on a case-by-case basis for any equipment used either over or within the DSTs. The analysis shall consider effect of equipment drop on the DST structural integrity during installation and removal of the equipment. The drop weight shall include the weight of the equipment, the weight of waste material attached to or entrapped inside the equipment, lifting yoke, and any other components below the lifting rig hook used in handling the equipment. Equipment drops shall be postulated to impact on soil at grade level, on or within exposed pits in the equipment path, on exposed riser, and within riser in which equipment. If the structural integrity of the tank is vulnerable, special impact absorber equipment or special handling procedures shall be provided to protect the tank from failure. 


\subsubsection{Ignition of Flammable Gases}

The postulated ignition of hydrogen/flammable gases that may be released periodically from the waste could result in an internal pressure pulse within the primary tank. The time history of the pressure pulse shall be characterized on a case-by-case basis considering the estimated inventory of flammable gases within the tank of interest. Best-estimate and upper-bound pressure loads shall be established. Estimates of internal pressurization from a postulated burn event in tank 241SY101 have been characterized in Sullivan 1995 as part of the safety assessment for the proposed pump mixing operations to mitigate the episodic gas releases in this tank. The gas generation from within this tank is considered to be bounding for the Hanford underground waste storage tanks. 
Figure 2.7.5-1. Liquid Sloshing in a Tank.

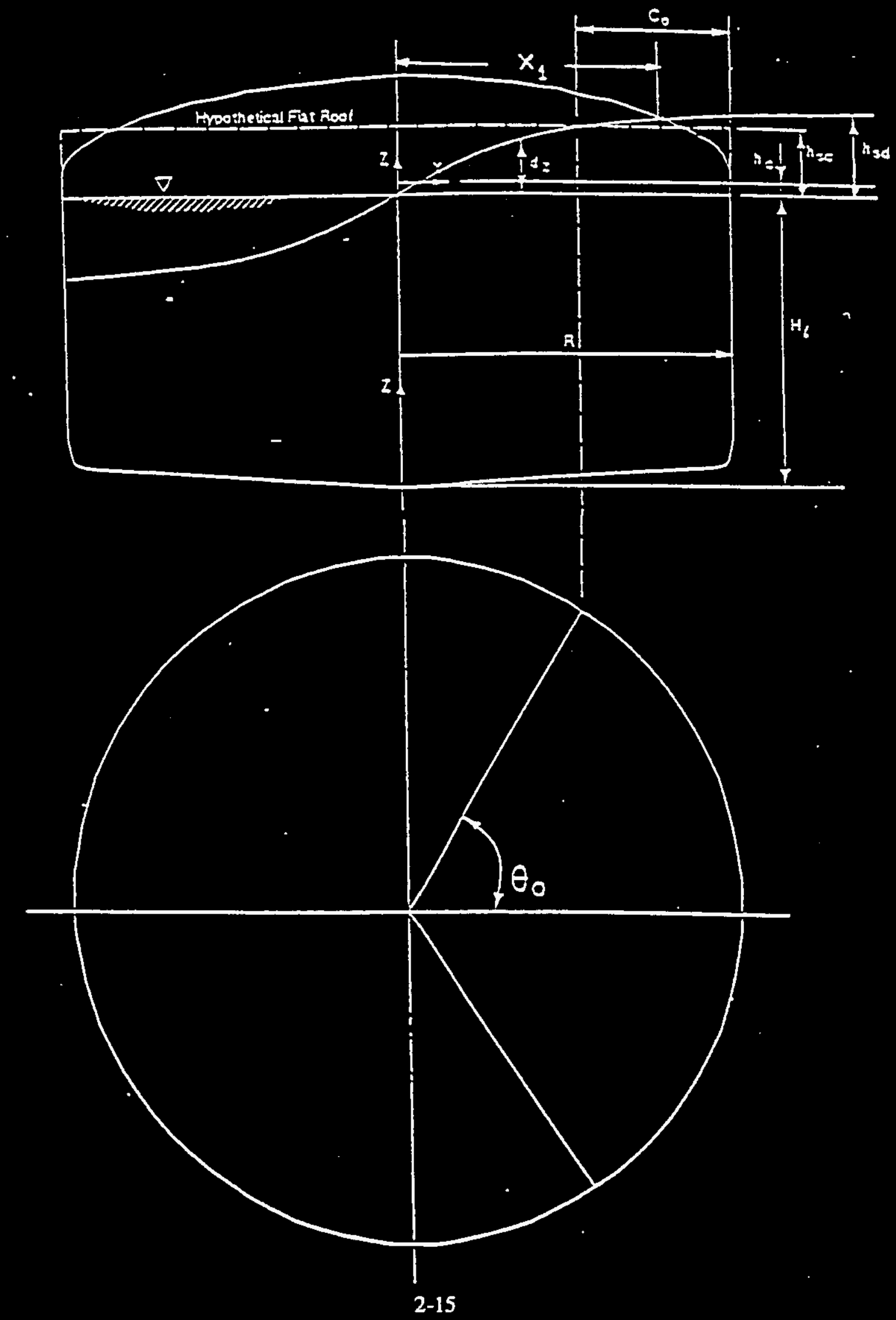




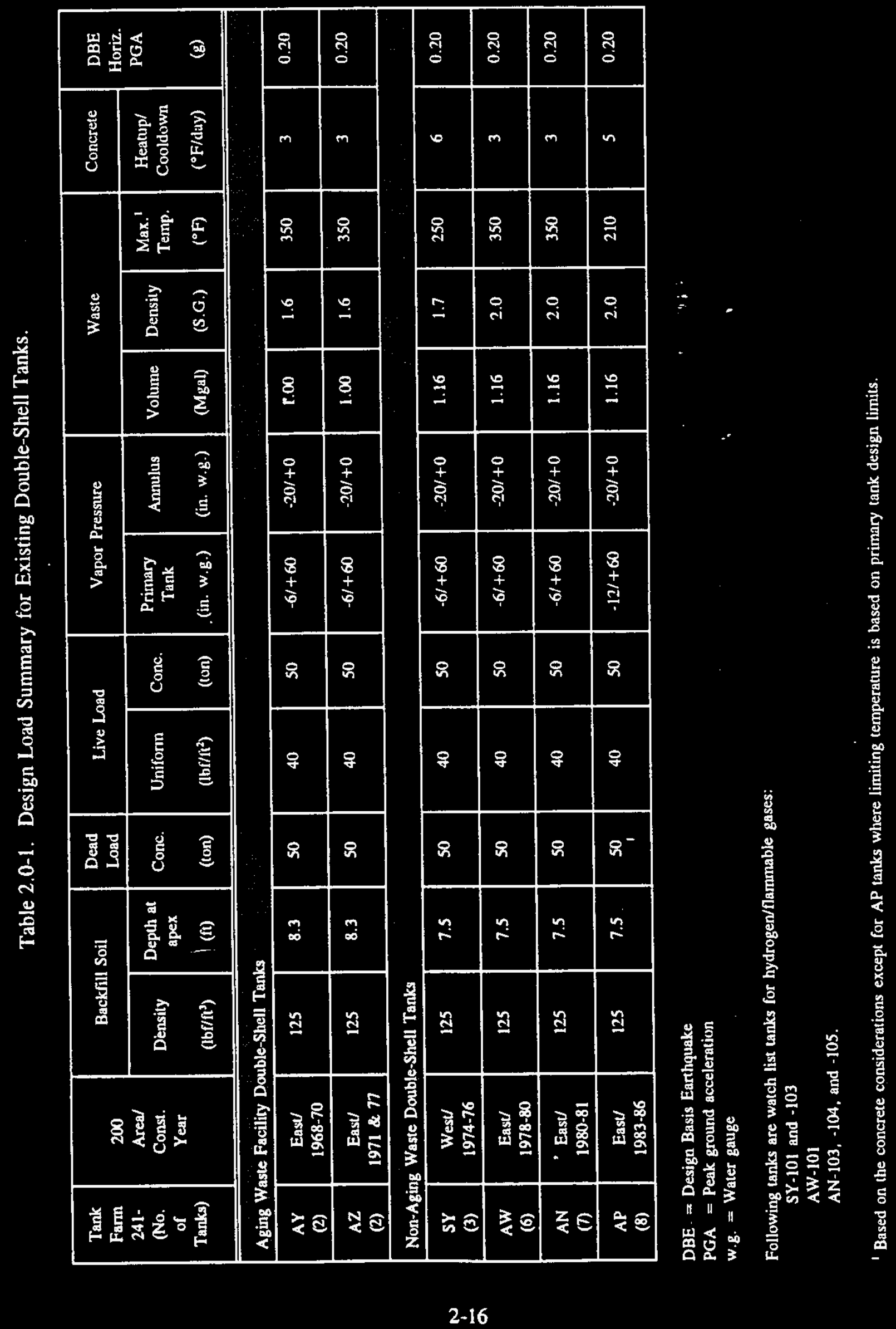


Table 2.7.2-1. Response Level and Damping.

\begin{tabular}{|c|c|c|c|}
\hline \multirow{2}{*}{ Type of Component } & \multicolumn{3}{|c|}{ Damping (\% of critical) } \\
\cline { 2 - 4 } & $\begin{array}{c}\text { Response } \\
\text { Level 1 }\end{array}$ & $\begin{array}{c}\text { Response } \\
\text { Level 2 }\end{array}$ & $\begin{array}{c}\text { Response } \\
\text { Level 3 }\end{array}$ \\
\hline Primary Tank (liquid containment metal tank) & \multicolumn{3}{|l}{} \\
\hline Impulsive mode & 2 & 3 & 4 \\
\hline Sloshing mode & 0.5 & 0.5 & 0.5 \\
\hline Secondary Tank (reinforced concrete structure) & 4 & 7 & 10 \\
\hline
\end{tabular}


Table 2.7.5-1. Values of Coefficient $\left(C_{i}\right)_{r}$ in Equation 2.7.5-4.

\begin{tabular}{ll}
$\mathrm{H}_{\mathrm{l}} / \mathrm{R}$ & $\left(\mathrm{C}_{\mathrm{i}}\right)_{\mathrm{r}}$ \\
\hline 0.20 & 0.0539 \\
0.25 & 0.0589 \\
0.30 & 0.0634 \\
0.35 & 0.0675 \\
0.40 & 0.0712 \\
0.45 & 0.0747 \\
0.50 & 0.0781 \\
0.55 & 0.0812 \\
0.60 & 0.0843 \\
0.65 & 0.0873 \\
0.70 & 0.0901 \\
0.75 & 0.0930 \\
0.80 & 0.0957 \\
0.85 & 0.0984 \\
0.90 & 0.1011 \\
0.95 & 0.1037 \\
1.00 & 0.1062
\end{tabular}

Table 2.7.5-2. Values of Coefficient $\left(C_{v}\right)_{r}$ in Equation 2.7.5-23.

\begin{tabular}{ll}
$\mathrm{H}_{1} / \mathrm{R}$ & $\left(\mathrm{C}_{\mathrm{v}}\right)_{\mathrm{r}}$ \\
\hline $\mathbf{0 . 2 0}$ & 0.0523 \\
0.25 & 0.0570 \\
0.30 & 0.0611 \\
0.35 & 0.0649 \\
0.40 & 0.0682 \\
0.45 & 0.0712 \\
0.50 & 0.0738 \\
0.55 & 0.0762 \\
0.60 & 0.0783 \\
0.65 & 0.0802 \\
0.70 & 0.0819 \\
0.75 & 0.0834 \\
0.80 & 0.0848 \\
0.85 & 0.0860 \\
0.90 & 0.0870 \\
0.95 & 0.0880 \\
1.00 & 0.0889
\end{tabular}




\subsection{FAILURE MODES}

Failure can be associated with loss of structural load-carrying ability or loss of function. The primary function of all the Hanford underground waste tanks is to contain high-level wastes without loss of inventory to the environment. Structural failure modes generally fall into two categories, local (L) and global (G). Global failures are characterized by structural instability, whereas local failures may or may not lead to a global failure but may lead to leakage. The following table identifies the structural failure modes that are applicable to the Hanford waste tanks and identifies their nature (local or global) and severity (leakage or structural instability) at the component level.

\begin{tabular}{lcccc}
\multicolumn{1}{c}{ Failure Mode } & $\begin{array}{c}\text { Steel Tank } \\
\text { or Liner }\end{array}$ & $\begin{array}{c}\text { Steel } \\
\text { Reinforcement }\end{array}$ & Concrete & Soil \\
\hline Buckling & $\mathrm{L} \rightarrow \mathrm{L}$ & & $\mathrm{G}$ & \\
Collapse & & & $\mathrm{G}$ & \\
Fatigue & $\mathrm{L} \rightarrow \mathrm{L}$ & $\mathrm{L} \rightarrow \mathrm{G}$ & $\mathrm{L} \rightarrow \mathrm{G}$ & \\
Fracture & $\mathrm{L} \rightarrow \mathrm{L}$ & & & \\
Bond-Slip & & $\mathrm{L} \rightarrow \mathrm{G}$ & & \\
Plastic Failure & $\mathrm{L} \rightarrow \mathrm{L}$ & $\mathrm{L} \rightarrow \mathrm{G}$ & $\mathrm{L} \rightarrow \mathrm{G}$ & \\
Bearing Failure & & & $\mathrm{L} \rightarrow \mathrm{L}$ & $\mathrm{L} \rightarrow \mathrm{L}$
\end{tabular}

\footnotetext{
$\mathrm{L} \rightarrow \mathrm{L}$ Local failure that could lead to leakage

$\mathrm{L} \rightarrow \mathrm{G}$ Local failure that could lead to a global instability failure

G Global instability failure
}

A local failure in the primary tank could lead to leakage if the failure resulted in a tear below the liquid level of the waste. The resulting leak would be contained by the secondary steel liner. In general, failure of the secondary concrete structure will lead to a catastrophic failure of the tank system because the concrete structure is the load bearing support structure against external soil loads.

\subsection{BUCKLING}

Buckling occurs when a structure is subjected to a compressive load and an infinitesimal increase in the load results in a large increase in the deflection of the structure or a large change in the equilibrium configuration of the structure. The load-carrying capacity of the structure may or may not decrease after buckling, but whether it does depends on the type of loading, the geometry of the structure, the post-buckled stress level, the boundary (support) conditions, etc. The mode of buckling may be characterized either by a split in the equilibrium path to an adjacent equilibrium configuration (bifurcation) or by a sudden jump to a new equilibrium configuration (snap-through) as the applied load is increased infinitesimally. In general for thin shell structures, the magnitude of the buckling load depends on the shell geometry, boundary restraints, material properties, and the type of load. The effects of large displacements and geometric imperfections are important considerations in correlating experimental results with theoretical analyses. In addition, for concrete shell structures the effects of inelastic behavior, creep, reinforcement, and cracking need to be considered. 


\subsubsection{Primary Steel Tank and Secondary Steel Liner Buckling}

The primary tank and secondary steel liner are not free standing but are displacement constrained by the secondary reinforced-concrete tank. Because of this constraint, the potential for buckling of either the primary tank or the secondary liner is greatly reduced and if buckling should occur it is not likely to lead to collapse. Even if buckling does not lead to collapse, the structure is weakened and local high stresses may develop within the buckled pattern that could contribute to stress corrosion cracking (SCC) and hence lead to leakage.

3.1.1.1 Elephant-Foot Buckling. Large size free-standing storage tanks suffer from various kinds of damage due to earthquake excitation. The elephant-foot buckling is one of the important ones which is caused by high vertical compressive membrane stresses resulting from overturning moment due to the horizontal earthquake excitation combined with hoop tensile stresses due to internal pressure. This mode of buckling is also called elastic-plastic buckling because the bulge formation near the bottom of the tank is by plastic collapse of the tank wall. The tensile hoop stress is generally very close to the yield limit.

Although, the Hanford DSTs are not strictly free-standing because the dome of the primary steel tank is anchored to the dome of the secondary concrete structure, elephant-foot buckling shall be addressed, particularly for seismic loading.

3.1.1.2 Diamond Buckling. The diamond or elastic buckling of the cylindrical walls of the primary tank is caused by high axial compressive forces. If the radius-thickness $(R / t)$ ratio is too large $(>300)$, the shell will fail by buckling at a critical longitudinal compressive stress well below the yield stress. At lower $R / t$ ratios, the cylindrical shells will fail by plastic yielding when the critical collapse stress is close to the yield stress.

The elastic buckling load is very sensitive to initial imperfection. Also, the axial membrane compressive stresses are generally not uniform over a given cross-section.

The current code criteria and most investigations of axially pressurized cylinders are for uniformly distributed loads. The codes generally provide acceptance criteria which is based on a theoretical critical axial compression load which is adjusted by knockdown factors to account for initial imperfections and material non-linearities and further reduced by a factor of safety. The ASME Code, Section III, Division 1 (ASME 1992a) and Section VIII, Divisions 1 (ASME 1992b) and 2 (ASME 1992c) apply a total reduction factor of nearly 10 to the theoretical critical stress to arrive at the allowable axial compression.

3.1.1.3 Harmonic Buckling. The strength of a circular cylindrical shell under negative pressure depends upon its length-diameter and thickness-diameter ratios and the physical properties of the material. Failure of the shell may occur in two ways. A short vessel with relatively thick wall fails because of stresses higher than the yield point while a long vessel collapses into two lobes by elastic buckling of the walls. The number of lobes, $n$, at collapse increases for intermediate cylinders with lengths less than the critical length which is defined as the minimum unsupported length beyond which the critical pressure is independent of the cylinder length. 
The quantity $n$ appears in all classical instability formulas. The buckling pressure is obtained by solving the instability equation with the condition that $n$ is an integer for which the applied pressure is minimum. The solution involves trial and error substitutions.

To eliminate the dependency on $n$ and to simplify the design procedure for vacuum vessels, the ASME Code uses U.S. Experimental Model Basin formula (Bednar 1986) which is independent of $n$ and is of sufficient accuracy. The Code design collapsing pressure is based upon a factor of safety of 3.0. This type of buckling is less sensitive to geometric imperfections.

3.1.1.4 Between Studs Buckling. As stated in Section 1.2.1, the primary tank dome is anchored at close intervals to the secondary concrete dome. Generally, anchor spacing in both circumferential and meridional directions is 24 in. or less. Similar anchor spacing is provided between the secondary steel liner and the secondary concrete tank.

Because the anchors are closely spaced, buckling of either the dome plate or secondary liner between the anchors is unlikely. The primary concern for the steel dome and secondary liner is that they must be able to accommodate deformations of the secondary concrete structure.

3.1.1.5 Flat Bottom Plate Buckling. The flat bottom of the primary tank could buckle under a net negative internal pressure. This condition could occur under a condition with either a low volume of waste present and a high negative internal pressure or if a significant positive pressure developed under the bottom of the primary tank. The development of a positive pressure under the primary tank could occur if a steam bubble was generated from entrapped water in the insulating refractory pad. However, this is not likely because any water driven out by elevated temperature is free to radially vent along the grooves provided in the insulating pad.

\subsubsection{Secondary Concrete Buckling}

In general, the mode of buckling for synclastic shells (principal curvatures of the same sign), such as the tank dome, can be related to that of a spherical cap and may be either bifurcation or snapthrough, depending on the relative shallowness of the cap as well as the extent of the applied load. There are two interacting modes of buckling that must be addressed for the cylindrical wall portion of the tank: buckling of the cylindrical wall under uniform axial compression and buckling of the cylindrical wall under external lateral pressure. Parameters of potential significance to the buckling capacity of the tank dome as well as the cylindrical wall of the tank include the following:

Type of loading: uniform, concentrated, axisymmetric or asymmetric

Post-buckling behavior

Initial geometric imperfection

Creep

Cracking and amount and type of reinforcement

Nonlinear behavior of concrete in compression.

\subsection{COLLAPSE}

Collapse is a global structural instability that may or may not be associated with buckling. Structural instability of components subjected to compressive loads is a function of the geometric 
configuration, loading and strain level. Gross structural instability (collapse) is addressed with a criterion that is based on overall structural instability and not on local failure.

\subsubsection{Primary Tank Collapse}

Collapse of the primary tank under axial compression and negative pressure has been discussed in Section 3.1.1. However, there may be other situations when the stress exceeds the yield strength of the material through the entire thickness or cross-section. In that case, prevention of failure is entirely dependent upon the strain-hardening properties of the material. The ASME Code provides allowable stress limits based on perfect plasticity with no strain-hardening. To prevent plastic collapse, the allowable membrane stress is limited to the lessor of two-thirds of the minimum yield strength or one-third of the minimum ultimate strength. As the code allowable stresses are based on consideration of this failure mechanism, no additional acceptance criteria is required.

\subsubsection{Secondary Concrete Collapse}

Collapse of the reinforced concrete structures is characterized by excessive yielding in the reinforcement bars or crushing of the concrete. At the design stage, such failures are precluded by checking for conformance with applicable ACI 349 and ASME code limits. However, determination of the actual load-capacity margin requires a more detailed analysis. Often, through plastic flow or other nonlinear response mechanisms, stresses will redistribute in such a way that the applied load can be carried, even though "simplified" calculations indicate that section capacity has been reached. When such redistribution occurs, however, a deformation-based criterion applied to nonlinear analysis results may be applied to identify the global mechanisms that lead to the onset of collapse.

This type of analysis is more common for frame structures and is commonly referred to as. Limit Analysis. Limit analysis is based on the development of plastic hinges. In an axisymmetric shell structure it is extremely difficult to determine the plastic hinge points. If one occurs in the meridional direction it counts as two because of the axisymmetry. For concentrated loads, the mechanism will develop in the dome, for uniform dome loads the mechanisms will develop in the haunch region. Several nonlinear collapse analyses have been utilized in the past to predict the actual collapse mechanisms. Currently, a reliable methodology for predicting the formation of plastic hinges and defining acceptable linear and rotational strain acceptance criteria precludes a formal collapse limit analysis.

\subsection{FATIGUE}

\subsubsection{Primary Tank}

Fatigue has been a major concern in the design of rotating machinery and aircraft where the expected number of loading/stress cycles is in the millions. In case of pressure vessels, the number of stress cycles during the specified life seldom exceeds 10,000. High-cycle fatigue involves little or no plastic action and therefore prevention of failure is achieved by keeping the stresses below the endurance limit. Low-cycle fatigue failure results from strains in excess of the yield strain. In the plastic region large changes in strain can be produced by small changes in stress. Fatigue damage is 
a function of plastic strain and therefore fatigue evaluation of pressure vessels should be based on strain. The ASME Code fatigue curves provide allowable number of cycles for any given stress amplitude. These stresses are fictitious and represent the strain value used in the test multiplied by the elastic modulus. This is necessary as the stresses calculated on the elastic basis can be directly used to obtain the allowable number of cycles.

The fatigue analysis of a vessel is time-consuming and thus engineering effort is not warranted if the vessel is not subjected to a large number of loading cycles. The ASME Code provides screening criteria to determine if a detailed fatigue analysis is required. Most Hanford double-shell tanks have undergone only few fill and drain cycles. However, some tanks have operated at much higher temperatures than the others. Therefore, whether fatigue analysis is required shall be determined on the basis of a tank's operating history and the ASME Code screening criteria. If such an analysis is required, it can be performed in accordance with the rules given in Appendix XIII of the ASME Code, Section III, Division 1.

\subsubsection{Secondary Liner}

In general, fatigue analysis of liners is not required because most stress and strain changes will occur only a small number of times. Also only minor fluctuations in stresses and strains will occur. The earthquake loading and the design basis accidents which are too infrequent will only produce a small number of stress-strain cycles and therefore will not control fatigue life of the liner.

\subsection{FRACTURE}

The existence of crack-like flaws cannot be precluded in any engineering structure. Under the proper conditions of flaw distribution, temperature, environment, and applied stress (cyclic or static) components made from certain materials are susceptible to premature failure at relatively low stress levels.

\subsubsection{Fracture of Low-Carbon Steel}

Fracture of Iow-carbon steel components depends on the state of stress, flaw size, temperature, material toughness, and material constraint (thickness). The fracture mode can be brittle or ductile depending on the temperature. The "transition-temperature" concept can be used to separate the brittle and ductile fracture modes of failure in low-carbon steel (Rolfe and Barsom 1977).

\subsubsection{Stress-Corrosion Cracking of Carbon Steel}

Stress-corrosion cracking (SCC) is defined as environmentally induced subcritical crack growth under the influence of static or dynamic tensile stress leading ultimately to a delayed brittle fracture of the component (Jones 1992). It requires the simultaneous interplay of a sustained tensile stress, a corrosive environment, and crack like flaws. Stress-corrosion cracking is particularly insidious in that catastrophic failure can occur even at relatively low stress levels and often with no warning.

Environments causing SCC can be so mild that no evidence of corrosion can be detected (Jones 1992). 


\subsubsection{Conerete Cracking and Spallation}

Concrete cracking is a local failure condition expected under service loads and can be accounted for in finite-element analysis but is not typically relied upon in the evaluation of reinforced concrete structures. Therefore, no consideration need be given to cracking as a state of structural failure. However, excessive cracking or spallation can affect the load transfer between the concrete and the reinforcement which would lead to rebar bond failure.

\subsection{REBAR BOND FAILURE}

Insufficient rebar bond or splice capacity results in local failure that can lead to a global failure of the structure. A fundamental proposition on which the mechanics of reinforced concrete is based is that the strain in the embedded reinforcing bar is the same as that of the surrounding concrete. That is, it is assumed that perfect bonding exists between the concrete and steel rebar at the interface, so that no slip can occur between the two materials. Smeared-crack reinforced-concrete constitutive models do not usually account for potential failure of the reinforcement bond. Because the ultimate capacity of reinforced concrete in tension relies on the integrity of the reinforcement bond, failure criteria for rebar bond and splices must be addressed to establish limits that assure the validity of the finite-element analysis in predicting global structural behavior.

The bond between the rebar and concrete can be thought of as the shearing stress between a bar and its surrounding concrete. Bond is made up of three components: adhesion, friction, and mechanical interaction between concrete and steel. The bond of plain (smooth) bars depends primarily on the first two elements, although there is some mechanical interlocking caused by the roughness of the bar surface. The bond failure common to plain rebar, which was used in the early years of concrete construction, is referred to as bond-slip failure. Deformed bars were introduced to overcome the limiting behavior associated with the bond-slip mechanism and thereby allow for more effective development of rebar-concrete interaction and the ultimate strength of a reinforced concrete cross section. Deformed bars depend primarily on mechanical interlocking for enhanced bond properties. The use of deformed bars can lead to bond failures as a result of concrete crushing at the bearing face of the deformations (i.e., lugs); shearing of the concrete around the outer perimeter of the bar; longitudinal splitting of the concrete cover in the vicinity of the bar; or a combination of these three failure modes.

With little confinement, the bond failure of large deformed bars may manifest itself by splitting of the concrete along the plane of the bar. This type of failure depends primarily on the load on the concrete, with bar stress and bar diameter (perimeter) being of little importance. As confinement around a bar improves, by virtue of increased cover or transverse reinforcement, the ultimate load depends increasingly on the bar diameter (perimeter). Therefore, small bars, top-cast bars, or bars that are confined to the extent that bond failure occurs by shear failure of the concrete lugs (between bar deformations) instead of splitting, will carry a maximum unit load proportional to the bar perimeter. Failures of the non-splitting type tend to be localized and not critical to the global integrity of the structure.

As depicted in Figure 3.5-1, the splitting bond failure relates to a system of forces developed as a result of the bearing of the rebar lugs on the concrete. The resulting system of forces is directed outwardly around the bar to form a hollow, truncated cone of pressure. These outward forces, like 
water pressure in a pipe, lead to splitting on weak planes in the concrete along the bar. Bond strength degradation may occur as a result of environmental (i.e., high temperature exposure or corrosion) or loading conditions (cyclic or sustained loads with applied-stress-to-strength ratio greater than approximately $\mathbf{0 . 8}$ ). Sufficient bond strength must be maintained during the operating life of the structure so that premature rebar bond failure does not reduce the ultimate capacity of the reinforced concrete section.

\subsection{PLASTIC FAILURE}

The failure mode associated with plastic failure is produced by the primary plastic strains which produce gross structural distortions or peak plastic strains that do not produce significant distortions but could lead to ductile tearing in steel components.

\subsection{CONCRETE CRUSHING}

Even unreinforced concrete is a composite material, comprising a matrix (cement) and aggregate. Compressive failures, except by hydrostatic compression, are the result of the propagation of microcracks under localized tensile stresses. Even in uniaxial compression tests, the failures are limited by the tensile stresses that develop from Poisson's ratio and friction induced confinement of the compression test platens. Therefore, concrete crushing is not usually measured. It is customary to use the uniaxial compressive tests to describe the compressive stress-strain behavior of concrete.

Crushing in this sense translates into strength reduction that occurs after the peak compressive stress is reached. The onset of crushing is signalled by the state of strain reaching the ductility strain limit, which is usually taken as $0.003 \mathrm{in}$./in. This strain occurs well after the strain associated with the peak compressive stress, usually taken as $\mathbf{0 . 0 0 2} \mathrm{in}$./in. Only under primary loading in structures which have no means of load redistribution does crushing follow the exceedance of the maximum compressive strength. The compressive strength is a strong function of confinement and therefore can only be accurately predicted by examining the deviatoric stress state.

\subsubsection{Crushing of Secondary Concrete}

Compressive stresses in the secondary concrete tank typically develop in the meridional direction of both the dome and wall. The membrane stresses in the dome contribute to the compressive stresses, but the meridional bending component causes the peak compressive stresses at the outside fibers of the section. Crushing, as traditionally defined, occurs as the peak compressive stress reaches the peak compressive strength. The post-peak compressive strength regime (compressive softening) allows for changes in the section neutral axis and load redistribution. Locations susceptible to crushing in the secondary concrete include the dome apex, the dome-haunch interface, and the haunch-wall interface.

\subsubsection{Crushing of Insulating Conerete}

The strength of insulating concrete is low compared to normal structural concrete. The only significant loads carried by the insulating concrete are those caused from the weight of the waste 
inventory. Even so, it is expected that the compressive stresses in the insulating concrete will approach the peak compressive strength. The significant confinement afforded by the sandwich geometry of the insulating concrete will normally allow compressive stresses larger than that associated with the uniaxial compressive strength test would indicate. The exception is near the outside radius of the insulating slab. This location, if subjected to significant compressive stresses will soften and could cause a lack of support to the primary steel tank. However, this condition would be mitigated by the presence of the circumferential steel support ring around the edge of the insulating concrete slab. This edge ring helps to confine the insulating concrete.

\subsection{SOIL FAILURE}

Equipment loads over or near the tank can lead to local soil bearing failures at the soil surface or at the tank footing. The Hanford sandy soil is not expected to have a failure problem when it is properly consolidated. Soil failure is not a concern for operational loads or code-based factored loads. However, checks for soil failure should be performed where additional surface loads are being considered. Checks for soil failure should be based on existing Hanford triaxial soil test data (see Section 6.5). 
Figure 3.5-1. Force System for a Splitting Bond Failure of Rebar (Ferguson 1988).

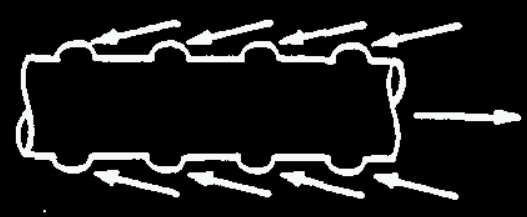

(a) On Bar

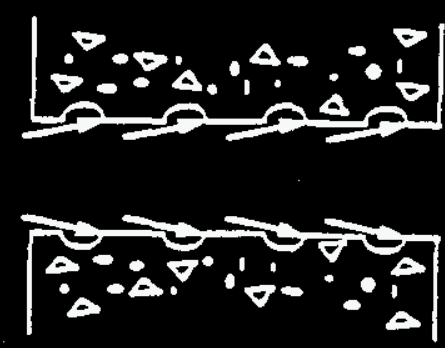

(b) On Concivio

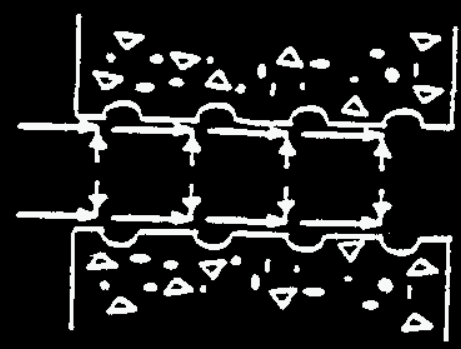

( $\theta$ Components on Concroto 
THIS PAGE TNTENTIONAULY

LEFT BLANK 


\subsection{PROTECTION AGAINST FAILURE}

Underground storage tank (UST) design at the Hanford has participated in a significant evolution of industry codes and standards. The first USTs at Hanford were single shell with steellined reinforced concrete construction. The Report of the Joint Committee on Standards for Specifications of Concrete and Reinforced Concrete (Joint Committee, 1924) was used as the design basis for the first tanks. This standard is a working stress method which is conducive to computing stresses with linear elastic methods. The first double-shell USTs (241-AY and 241-AZ) were also designed by the working stress method, as outlined by ACI 318-63. The next tank farm designed at Hanford abandoned the working stress method in favor of the ultimate strength method, as outlined in ACI 318-77.

The rationale for embracing the ultimate strength approach of the current $\mathrm{ACI}$ design codes to assess strength in lieu of the working stress approach of the original design code is, based to a large extent, on the following drawbacks of the latter as discussed by MacGregor (1976).

- The working stress approach does not account adequately for the variability in loading and resistance.

- It does not account adequately for variations in loadings that increase at different rates or have different signs. It assumes that all loadings will increase at approximately the same rate. This assumption becomes serious in the case of a highly variable load such as wind, earthquake, or soil pressure that causes forces opposite in sign to those resulting from relatively constant loads such as dead load.

- It does not attempt to evaluate the ultimate load capacity.

- It offers no rational method of considering such things as consequences of failure or type of failure.

The first Hanford double-shell tanks were designed at a time when the design-by-rule approach was prevalent in the ASME B\&PV code. This approach relied less on analysis and more on historical performance of standard practice. In 1969, the design-by-analysis approach was adopted by the ASME B\&PV code for Sections III and VIII, Division 2 (ASME 1969). The advantages of the design-by-analysis approach over the design-by-rule approach can best be described by an excerpt from an ASME code background document (ASME 1969):

The special committee to review the code stress basis was originally established to investigate what changes in code design philosophy might permit use of higher allowable stresses without reduction in safety. It soon became clear that one approach would be to make better use of modern methods of stress analysis. Detailed evaluation of actual stresses would permit substituting knowledge of localized stresses, and assignment of more rational margins, in place of a larger (safety) factor which really reflected lack of knowledge.

The ASME code now has explicit guidance for inelastic and collapse analysis as an alternative to meeting prescribed stress limits by linear elastic analysis. 
This is where the ASME code differs from the ACI code. The ACI code does not offer explicit guidance on inelastic or collapse analysis. Section 4.1 provides acceptance criteria for the primary steel tank and secondary steel liner, primarily on the basis of the ASME B\&PV code's design-by-analysis methodology. Section 4.2 provides acceptance criteria for the secondary concrete primarily on the basis of the ACI code's ultimate strength design approach. Section 4.3 is offered in part as an alternative method to meeting the $\mathrm{ACI}$ code's ultimate strength provisions through a nonlinear inelastic analysis that allows for load redistribution.

\subsection{ASME CODE-BASED PROTECTION AGAINST FAILURE}

ASME Code, Section III, Division 1 generally permits designers to choose between "design-byrule" and "design-by-analysis" Code methodologies to perform structural integrity evaluation of a pressure vessel. The "design-by-analysis" methodology utilizes the maximum shear stress theory for the strength criteria whereas "design-by-rule" is based upon the maximum normal stress theory.

The modes of failure addressed by the Code are related to structural integrity. The design rules provided by the Code do not assure operability. Also, no rules are provided for protection against environmental conditions such as corrosion and radiation effects. The "design-by-analysis" methodology requires detailed stress analyses of all applicable loadings. The resulting stresses are then grouped into the stress categories such as primary membrane, local membrane, primary bending, secondary, and peak stresses. The Code provides limits to these stresses to guard against the following failure modes (ASME, 1991):

Excessive plastic deformation: primary stress limits are provided to prevent excessive plastic deformation and to provide a nominal factor of safety on burst pressure.

Plastic instability: limits on primary plus secondary stresses are provided to prevent incremental collapse due to excessive plastic deformation.

Fatigue failure: A peak stress limit is provided to prevent fatigue failure due to cyclic operational' loads.

Elastic instability and excessive elastic deformation: special stress limits are provided for elastic and inelastic instabilities.

Brittle fracture: materials with adequate fracture toughness are required to be selected. However, the Code does not address the effects of environmental conditions on material ductility.

The "design-by-rule" methodology, on the other hand, does not require detailed stress analysis. Stress limits for design and service loadings are provided. However, stresses due to pressure and other mechanical loads only are required to be evaluated against these limits. There are no rules for thermal stresses and fatigue analysis. Localized secondary bending stresses at discontinuities are assumed to be within safe limits based upon industry experience that if the vessels are fabricated in accordance with the Code rules, the localized stresses are not excessive. Because detailed stress analyses are not required, the allowable stresses are lower than those permitted for design-by-analysis. 
The subarticle of the ASME Code, Section III, Division 1 which directly applies to the storage tanks is NC-3900. This subarticle provides the design and construction rules for $0-15 \mathrm{lbf} / \mathrm{in}^{2}$ tanks. The only other subarticle, NC-3800, applies to vertical cylindrical flat bottom atmospheric storage tanks and cannot be used for the Hanford tanks. The NC-3900 rules are generally applicable to above ground tanks, but may also be used for an underground tank provided the tank is not subjected to external pressure resulting from earth or fill. The Hanford underground primary tank configurations are significantly different from the above ground tanks commonly constructed per NC-3900 rules. For instance these tanks are vertically restrained at both top and bottom and the top heads are anchored to concrete at relatively close intervals. The stresses due to thermal effects and creep displacement of concrete, although secondary in nature, must be evaluated to limit them to an acceptable level. As NC-3900 does not address secondary stresses and fatigue damage due to cyclic stresses such as those due to thermal effects, the "design-by-analysis" methodology of NC-3200 (ASME 1992a) must be used to perform detailed stress evaluation. Secondary stresses will be evaluated using stress limits of Appendix XIII and fatigue evaluation shall be performed using Appendix XIV rules, if required.

The ASME Code, Section III, Division 2, Subsection CC (ASME 1992d) is the only national code which addresses the design and construction of liners. The liner is not considered a strength element and is required to accommodate the deformation of the concrete structure. Because the liner is not designed for load carrying purposes, the portions of the liner which are not backed by the concrete are required to be designed per Section III, Division 1 rules. The failure modes considered by Subsection $\mathrm{CC}$ include:

- General yield state under primary forces at a section.

- Liner tears at structural discontinuities such as penetrations, liner studs, and attachments etc. The Code provides strain limits to prevent excessive deformation at these locations. Also, the stud anchors are required to fail before tearing the liner.

- Progressive failure of the anchorage system.

\subsubsection{Stress Categories and Stress Limits for ASMIS Code Evaluations}

4.1.1.1 Stress Categories. The stress limits for NC-3200 design differ depending upon the stress category. The failure theory used is the maximum shear stress theory. Instead of using maximum shear stress directly, the code provides limits of "stress intensity" which is twice the maximum shear stress or the difference between the algebraically largest and the algebraically smallest of the three principal stresses at a point. The code establishes three basic categories of stresses according to the loads that cause them, their distribution, and their location:

i) Primary Stress: Primary stress is a normal stress developed by the imposed loading which is necessary to satisfy the laws of equilibrium of external and internal forces. This type of stress is not self-limiting. Primary stress is divided into two categories; general and local.

General Primary Stress: If this type of stress is considerably higher than the yield strength, failure will result. Any yielding through the entire shell thickness will not redistribute the stress but will result in gross distortions leading to failure. The code further divides this category into general membrane $\left(P_{\mathrm{m}}\right)$ and bending $\left(\mathrm{P}_{\mathrm{b}}\right)$ stresses. The membrane stress is uniformly distributed normal stress which is equal to the average stress across the thickness. 
High membrane stresses can cause collapse and, therefore, are limited by the code to values below material yield stress. The bending stresses are not uniform through the wall and local surface yielding will not result in collapse. Bending stresses, thus, have higher allowable than the membrane stresses.

Local Primary Stress: Local primary stress is localized at structural discontinuities and diminishes rapidly with distance. If local primary stress exceeds the yield point, the load is redistributed and carried by other parts of the shell. Although local primary stress has the characteristics of secondary stress, the ASME Code provides lower allowable stress to this type of stress than to secondary stress to prevent excessive distortion. Local primary stress can be divided into membrane stress and bending stress. Both, however, have the same stress intensity limit.

ii) Secondary Stress: Secondary normal and shear stresses (Q) are caused by the constraints of adjacent parts or self-constraint. For example, difference in geometry of cylindrical shell and connected spherical head causes bending stress at the shell-head junction due to differences in their free-radial expansion. Local yielding or minor distortion reduces the bending stress. Secondary stresses are self-limiting and less damaging and, therefore, the ASME Code has higher allowable for this type of stress. Secondary stresses are not further subdivided into membrane and bending components as the same stress limits apply to both components.

iii) Peak Stress: The peak stress $(F)$ is the highest stress at some local point under consideration. In case of failure, peak stress does not generate noticeable distortion, but it can be a source of fatigue crack, stress-corrosion, and delayed fractures. Generally, computation of peak stresses is required only for fatigue analysis.

ASME Table XIII-1130-1 provides some typical cases of stress intensity classification. Portions of the ASME table which are applicable to the primary tank are given in Table 4.1.1-1, herein.

4.1.1.2 Derivation of Stress Intensities. Article XIII-1130 of the ASME Code provides the following procedure for calculating stress intensities:

1. Choose an orthogonal set of coordinates at the point of interest and calculate the stress components, in this coordinate system, for each type of loading to which the part will be subjected.

2. Assign each set of stresses to one of the stress categories $P_{m}, P_{L}, P_{b}$, and $Q$.

3. For each stress category, combine stress components (algebraic sum if signs are known, absolute sum for unsigned stresses) resulting from different types of loading.

4. Calculate principal stresses for each of the applicable stress category and then the largest principal stress difference. This largest principal stress difference is the stress intensity. 
4.1.1.3 Stress Allowables. The Appendix XIII of the ASME Code, Section III provides the allowables given below for the four stress categories. These limits are applied when elastic analysis is performed.

General Primary Membrane Stress Intensity (SI): $\quad P_{m} \leq \mathbf{k S}_{\mathrm{m}}$

Local Primary Membrane SI:

$\mathrm{P}_{\mathrm{L}} \leq 1.5 \mathrm{kS}$

Primary Membrane plus Bending SI:

$\left(P_{m}\right.$ or $\left.P_{L}\right)+P_{b} \leq 1.5 k S_{m}$

Primary plus Secondary Stress SI:

$\left(P_{m}\right.$ or $\left.P_{L}\right)+P_{b}+Q \leq 3 S_{m}$

The primary plus secondary stress intensity limit, $3 \mathrm{~S}_{\mathrm{m}}$, applies to the range of stress intensity. Only cyclic loadings need to be considered in calculating the stress intensity range.

The stress intensity $k$ factors for various service levels are (from Table NC-3217-1):

$\begin{array}{lc}\text { Design and Level A } & 1.0 \\ \text { Level B } & 1.1 \\ \text { Level C } & 1.2 \\ \text { Level D } & 2.0\end{array}$

In addition to the above conditions, the algebraic sum of all three principal primary stresses should not exceed $4 \mathrm{~S}_{\mathrm{m}}$ and the condition of structural instability or buckling must be considered.

4.1.1.4 Plastic Analysis, Limit Analysis, and Shakedown Analysis. If the primary stress intensity or the primary plus secondary stress intensity at a specific location exceed the above allowables, the component can be qualified on the basis of plastic analysis, limit analysis, or shakedown analysis. The code requirements for these analyses are given below and can be found in Appendix XIII-1150.

Plastic Analysis (XIII-1151): If the local primary membrane stress intensity is exceeded at a specific location, the following procedure can be used:

(a) General primary membrane and general primary membrane plus primary bending stress intensities must be calculated on an elastic basis and compared against the allowables given above.

(b) In lieu of meeting the limits of local primary membrane and primary plus secondary stress intensities, plastic analysis may be performed to ensure that shakedown occurs.

(c) The numerically maximum principal total strain range is multiplied by one-half of the modulus of elasticity at the mean temperature of the cycle to obtain a stress amplitude which must be shown to be less than the fatigue allowables. 
Limit Analysis (XIII-1152): If at a specific location, the local primary membrane stress intensity or the primary membrane plus primary bending stress intensity exceeds the allowables given in Section 4.1.1.3, a limit analysis may be performed to show that the specified mechanical loading does not exceed two-thirds the lower bound collapse load.

Shakedown Analysis (XIII-1153): The $3 \mathrm{~S}_{\mathrm{m}}$ fimit on the range of primary plus secondary stress intensity can be exceeded if the range of primary plus secondary membrane plus bending stress intensity excluding the thermal bending stress is less than $3 \mathrm{~S}_{\mathrm{m}}$ and the following requirements are met:

(a) The value of stress amplitude, $S_{\mathrm{a}}$, used for entering the design fatigue curve is multiplied by the factor $K_{e}$, where

$$
\begin{aligned}
\mathrm{K}_{\mathrm{e}} & =1.0 & & \text { for } \mathrm{S}_{\mathrm{n}}<3 \mathrm{~S}_{\mathrm{m}} \\
& =1.0+[(1-\mathrm{n}) / \mathrm{n}(\mathrm{m}-1)]\left[\left(\mathrm{S}_{\mathrm{n}} / 3 \mathrm{~S}_{\mathrm{m}}\right)-1\right] & & \text { for } 3 \mathrm{~S}_{\mathrm{m}}<\mathrm{S}_{\mathrm{n}}<3 \mathrm{mS}_{\mathrm{m}} \\
& =1 / \mathrm{n} & & \text { for } \mathrm{S}_{\mathrm{n}} \geq 3 \mathrm{mS}_{\mathrm{m}}
\end{aligned}
$$

where $S_{\mathrm{n}}$ is the range of primary plus secondary stress intensity and for carbon steel $\mathrm{m}=3.0$ and $\mathrm{n}=\mathbf{0 . 2}$.

(b) A fatigue evaluation is performed per Appendix XIV of the Code.

(c) The thermal ratcheting requirements of Appendix XIV-1400, if applicable, are met.

(d) The ratio of minimum yield strength to minimum tensile strength must be less than 0.80 .

\subsubsection{Primary Tank Evaluation}

The primary tanks are cylindrical in shape and are approximately $75 \mathrm{ft}$ in diameter and $47 \mathrm{ft}$ above the basemat. The tanks rest on a layer of refractory concrete. There is no structural attachment between the tank and the refractory concrete. The primary tank dome is an ellipsoidal shell with a 4-ft radius knuckle ring. Except for the knuckle ring, the dome is backed by the concrete and is connected to the concrete dome with closely-spaced J-bolts. The lower knuckle connecting the bottom plate and the cylindrical tank has a 1-ft radius.

The Code rules discussed in this Section apply to those portions of the primary tank which are not attached to the secondary concrete structure. The ellipsoidal primary tank dome anchored to concrete shall be treated as a liner and the ASME Code, Section III, Division 2, Subsection CC rules discussed in Section 4.1.3 shall be used to evaluate this portion of the dome.

4.1.2.1 Design and Service Level A. Design loads, per ASME NCA-2142.1, are those pressure, temperature, and mechanical loads which are selected as the basis for design of the tank. Service level A loadings include those loads to which the tank may be subjected in the performance of its specified function. Although design specifications will provide specific information regarding service loads and load combinations for each service level, the following are some typical examples of loadings which are designated as Design and Service Level A loadings:

1. Design pressure for the vapor space above the maximum liquid level. 
2. Static liquid head below maximum liquid level.

3. Deadweight of the tank and its contents.

4. Design temperature for the tank. Note design temperature is more a design environmental condition than a design load. The specified design temperature is never less than the expected maximum mean metal temperature through the thickness. The normal industry practice is to select a design temperature $50^{\circ} \mathrm{F}$ higher than the maximum temperature of the operating fluid or the minimum temperature of the operating fluid for low-temperature (below $-20^{\circ} \mathrm{F}$ ) service vessels. This temperature is used to establish the minimum required wall thickness of a component and not considered in stress calculations.

If the primary tank is analyzed using a separate finite element model decoupled from the secondary concrete structure, the concrete dome displacements relative to the basemat shall also be included in this evaluation.

The combined effects of the above loadings shall be analyzed and the resulting stress intensities shall satisfy the limits provided in Section 4.1.1 using $S_{\mathrm{n}}$ at the design temperature from the ASME Code, Section II, Part D (ASME 1992e).

4.1.2.2 Service Level B. Service Level B loads are those loads which the tank must withstand without damage requiring repair. The designated loadings include loads occurring during normal operating conditions and those deviations from the normal conditions which have high probability of occurrence.

If the FDC does not specify mechanical loads other than those listed above for the Design and Service Level A, no primary stress intensity check is required for this service level as Service Level A primary stress intensity limits are lower than the Level B limits. However, Service Level B evaluation shall include steady state and transient thermal loadings and the effects of secondary tank deformations. The calculated primary plus secondary stress intensities shall be within the stress intensity limit provided in Section 4.1.1. If $3 \mathrm{~S}_{\mathrm{m}}$ limit cannot be met, fatigue evaluation shall be performed in accordance with the rules of Appendix XVI and the requirements of Appendix XIII-1153 listed in Section 4.1.1.4 shall be satisfied.

4.1.2.3 Service Level C. The loadings which can be designated under Service Level $\mathrm{C}$ have a low probability of occurrence and require shutdown for correction of conditions or repair of damage. The ASME Code service limits permit large deformations in the areas of structural discontinuities.

If the FDC specifies a Service Level C loading condition, the stress intensities shall be within the allowable given in Section 4.1,1. Note only primary stresses need to checked for Service Level C.

4.1.2.4 Service Level D. Those conditions associated with extremely low probability of occurrence and postulated events whose consequences are such that the integrity and operability of the component may be impaired are classified as Service Level D conditions. The ASME Code limits permit gross general deformations with some consequent loss of dimensional stability. The damage may require repair and removal of the component from service. 
Service Level D loadings will include the Service Level A loadings listed in Section 4.1.2.1 and any other loads postulated or specified in the FDC which are within the above definition of Service Level D loading. The earthquake induced loads and the design basis accident loads may be considered under this category. The earthquake loading and the accident loading, however, need not be considered simultaneously. The primary stress intensities shall satisfy the limits provided in Section 4.1.1. If the limit of $3 S_{\mathrm{m}}$ cannot be met, the stress limits of Appendix F-1330 or F-1340 may be applied. No secondary stress evaluation is required for Service Level D loadings. Appendix F has the following allowables:

\section{Evaluation Based on Elastic Analysis (F-1330)}

(a) The general primary membrane stress intensity, $P_{m}$, must be less than the lesser of $2.4 S_{m}$ and $0.7 S_{u} . S_{v}$ is the tensile strength of the material.

(b) $P_{L}$ is not to exceed $150 \%$ of the limit for $P_{m}$ given in (a) above.

(c) $P_{L}+P_{b}$ is not to exceed $150 \%$ of the limit for $P_{m}$ given in (a) above.

(d) The average primary shear stress across a section loaded in pure shear is not to exceed $0.42 \mathrm{~S}_{\mathrm{u}}$.

\section{Evaluation Based on Plastic Analysis (F-1340)}

(a) $P_{m}$ must be less than $0.70 S_{u}$.

(b) $P_{m}+P_{b}$ or $P_{L}+P_{b}$ must not exceed $0.90 S_{n}$.

(c) The average primary shear stress across a section loaded in pure shear is not to exceed $0.42 S_{\mathrm{u}}$.

4.1.2.5 Fatigue Evaluation. Fatigue analysis is not a mandatory requirement of Subsection NC if the tensile strength of the tank material is less than $80,000 \mathrm{lbf} / \mathrm{in}^{2}$ and the total number of loading cycles listed below does not exceed 1,000 .

(a) Expected design full range pressure.

(b) Expected service pressure cycles in which the range of pressure variation exceeds $20 \%$ of the design pressure.

(c) Changes in metal temperature between any two adjacent points in the pressure vessel including nozzles. Adjacent points are defined as follows:

For surface temperature difference, adjacent points in the meridional direction are less than $2(\mathbf{R t})^{1 / 2}$ apart where $\mathbf{R}$ is the radius measured normal to the surface from the axis of rotation to the midpoint of wall and $t$ is the wall thickness. In the circumferential direction and on flat parts, adjacent points are any two points on the same surface. For the through-thickness temperature difference, adjacent points are defined as any two points on a line normal to the surface.

The effective number of cycles are calculated by multiplying the number of changes in the metal temperature by the factor given below: 
Temperature Differential

$\left({ }^{\circ} \mathrm{F}\right)$
Factor

\begin{tabular}{lc}
\hline & \\
\cline { 2 - 2 } 50 or less & 0 \\
$51-100$ & 1 \\
$101-150$ & 2 \\
$151-250$ & 4 \\
$251-350$ & 8 \\
$351-450$ & 12 \\
excess of 450 & 20
\end{tabular}

Cycles of type (d) in NC-3219.2, Condition A are not applicable as Hanford tanks do not have welds between dissimilar materials.

The fatigue analysis is exempted for the nozzles with separate reinforcement and for nonintegral attachments if the total number of cycles of types (a), (b), and (c) above does not exceed 400 . However, type (b) cycles are counted if the pressure variation exceeds $15 \%$ of the design pressure rather than $20 \%$.

- For the existing DSTs, historical data regarding temperature cycles shall be obtained and number of cycles of future usage shall be estimated. Based on the temperature and usage data and the procedure outlined above, an evaluation shall be made if a fatigue evaluation is required. If required, the fatigue evaluation shall be performed in accordance with the rules of Appendix XIV of the ASME Code, Section III, Division 1. Note that a fatigue evaluation may be required for those cases where primary plus secondary stress intensity limit cannot be met although an evaluation per the above rules indicate that fatigue evaluation is non-mandatory.

4.1.2.6 Buckling Criteria for Cylindrical Tank. The primary tank shell, when subjected to axial compressive loading, must be evaluated against buckling limits. Because thermal stresses are self-relieving, the ASME Code does not require thermal loads to be considered in the buckling evaluation. As stated in Section 3.1.1, elephant-foot buckling (plastic buckling), diamond buckling, and harmonic buckling under a negative pressure are the buckling failure modes for the cylindrical portion of the primary tank that must be addressed.

4.1.2.6.1 Elephant-Foot Buckling. The ASME Code, Section III, Subsection NC does not address the elephant-foot mode of buckling, therefore, the compressive stress limit for elephant-foot buckling is taken from the TSEP Guidelines. The TSEP Guidelines provides the following compressive stress limit for this buckling:

$$
\sigma_{b e}=\frac{0.6 E_{t}}{\left(R / t_{t w}\right)}\left[1-\left(\frac{p_{m x} R}{S_{y} t_{t w}}\right)^{2}\right]\left[1-\frac{1}{1.12+k^{1.5}}\right]\left[\frac{k+\left(S_{y} / 36\right)}{k+1}\right]
$$

where

$$
\begin{array}{ll}
\mathbf{k} & =\mathbf{R} /\left(400 \mathrm{t}_{\mathrm{w}}\right) \\
\mathbf{R} & =\text { Primary tank mean radius }
\end{array}
$$


$t_{\mathrm{w}}=$ Nominal tank wall thickness minus the corrosion allowance at the location of the cylindrical wall of interest

$\mathrm{S}_{\mathrm{y}} \quad=$ Yield strength $\left(\mathrm{kip} / \mathrm{in}^{2}\right)$ of the material at the design temperature

$\mathrm{E}_{\mathrm{t}} \quad=$ Elastic modulus of the primary tank material at the design temperature

$\mathbf{p}_{\mathrm{mx}}=$ Maximum net internal radial pressure coincident with the compressive stress at the location of the cylindrical wall of interest.

Under seismic loading (Service Level D)

$$
p_{m x}=p_{s t}+p_{h}+0.4 p_{v}
$$

where

$p_{\mathfrak{n}} \quad=$ Total static pressure equal to the sum of the vapor pressure and the hydrostatic pressure for the liquid waste at the location of interest

$\mathrm{p}_{\mathrm{h}} \quad=$ Hydrodynamic pressure due to lateral seismic motion at the location of interest as given by Equation 2.7.5-21

$\mathrm{p}_{\mathrm{v}} \quad=$ Hydrodynamic pressure due to vertical seismic motion at the location of interest as given by Equation 2.7.5-22.

Once $\sigma_{b e}$ is determined, the axial compressive membrane stress allowable can be calculated from the following equation:

$$
\sigma_{a}=\frac{\sigma_{b e}}{\text { Factor of Safety }}
$$

where the factor of safety to be used in the above equation shall be as follows:

$\begin{array}{cc}\text { Service Level } & \text { Factor of Safety } \\ \text { A } & \\ \text { B } & 2 \\ \text { C } & 5 / 3 \\ \text { D } & 4 / 3\end{array}$

Note that the above allowable stress against elephant-foot buckling is a function of the location along the cylindrical wall because the wall thickness, temperature, and net internal pressure vary with axial position along the cylindrical wall of the primary tank.

4.1.2.6.2 Diamond Buckling. The current ASME Code criteria including those provided by the Code Case N-284 are for a cylinder subjected to compressive axial loads only and do not include the effects of internal pressure. As an alternative to the provisions of NC-3922 which apply to 0-15 lbf/in ${ }^{2}$ tanks, an ASME Code Case has been proposed to establish a more general criteria for allowable axial compressive membrane stress. This Code Case is based on recommendations of ECCS 1988. The allowable compressive stress can be determined following the procedure given below. 
The classical linear elastic buckling stress (compressive stress is positive) for a cylinder subjected to axial compression is given by:

$$
\sigma_{c t}=\frac{E}{\sqrt{3\left(1-v^{2}\right)}}\left(\frac{t}{R}\right)
$$

where $\mathrm{E}$ is the elastic modulus, $\nu$ is the Poisson's ratio, and $\mathbf{R}$ and $\mathrm{t}$ are the radius of the midsurface of the wall and the wall thickness; respectively.

Because the above equation provides the buckling stress for a perfect cylinder, a buckling capacity reduction factor, $\alpha_{0}$, must be applied to obtain a more realistic allowable. When the cylinder is simultaneously subjected to axial compression and internal pressure a capacity reduction factor, $\alpha_{p}$, must be used. These two factors are given by the following equations:

$$
\begin{aligned}
& \alpha_{0}=\frac{0.83}{\sqrt{1.0+0.01 \frac{R}{t}}} \text { for } R / t \leq 212 \\
& \alpha_{0}=\frac{0.70}{\sqrt{0.1+0.01 \frac{R}{t}}} \text { for } R / t>212
\end{aligned}
$$

and

$$
\alpha_{p}=\alpha_{0}+\left(1-\alpha_{0}\right) \frac{\rho}{\rho+0.007}
$$

where $\rho$ is a non-dimensional parameter given by

$$
\rho=\frac{p}{E}\left(\frac{R}{t}\right)^{\frac{3}{2}}
$$

and $\mathrm{p}$ is the net internal radial pressure coincident with the compressive stress at any location of the cylindrical wall. Under seismic loading

$$
p=p_{n t}+p_{h}-0.4 p_{v}
$$

which is determined at the vertical location of the cylindrical primary tank of interest. The hoop stress (tensile considered positive) resulting from this pressure is given by:

$$
\sigma_{h}=p \frac{R}{t}
$$


The lower bound effective buckling stress, $\sigma_{\text {eff }}$, is expressed by the following equation:

$$
\sigma_{e f f}=\sqrt{\sigma_{a, k}^{2}+\sigma_{h}^{2}+\sigma_{a, h} \sigma_{h}}
$$

where $\sigma_{\mathrm{a}, \mathrm{u}}$ is the lower bound for the axial membrane buckling stress (compressive stress is positive).

Two additional non-dimensional parameters are required to obtain the allowable compressive stress. These are given by the following equations:

$$
\beta=\frac{\sigma_{a, \mu}}{\sigma_{s f}}
$$

and

$$
\lambda_{p}=\sqrt{\frac{\beta S_{y}}{\alpha_{p} \sigma_{c l}}} .
$$

In the above equation, $S_{y}$, is the yield strength of the tank material. $\sigma_{\text {eff }}$, the material yield strength and the parameter $\lambda_{\mathrm{p}}$ are related as given in Equations 4.1.2-13a and 4.1.2-13b below:

$$
\frac{\sigma_{\text {ef }}}{S_{y}}=\frac{0.75}{\lambda_{p}^{2}} \quad \text { for } \lambda_{p} \geq 1.414
$$

and

$$
\frac{\sigma_{e f f}}{S_{y}}=\left(1.0-0.4123 \lambda_{p}^{1.2}\right) \quad \text { for } \lambda_{p}<1.414
$$

In order to solve these equations for the allowable compressive stress, Equation 4.1.2-10 can be written in an alternate form:

$$
\sigma_{a \mu h}=\sqrt{\sigma_{d f}^{2}-0.75 \sigma_{h}^{2}}-0.5 \sigma_{h}
$$

The following procedure may be used to solve for $\sigma_{\mathrm{a}, \mathrm{a}}$ :

1. Calculate $\alpha_{0}, \rho, \alpha_{\mathrm{p}}, \sigma_{\mathrm{cl}}$, and $\sigma_{\mathrm{h}}$ from Equations 4.1.2-4 to 4.1.2-9.

2. . Assume a value of $\beta$.

3. Calculate $\lambda_{\mathrm{p}}$ from Equation 4.1.2-12.

4. Calculate $\sigma_{\text {eff }}$ from Equation 4.1.2-13a or 4.1.2-13b whichever is applicable. 


\section{Obtain $\sigma_{\mathrm{a}, \mathrm{u}}$ from Equation 4.1.2-14.}

6. Calculate $\beta$ from Equation 4.1.2-11. If this value of $\beta$ is not within $2 \%$ of the assumed value in step 2 , repeat steps $2-6$.

Once $\sigma_{\mathrm{a}, \mathrm{u}}$ is determined, the axial compressive membrane stress allowable can be calculated from the following equation:

$$
\sigma_{a}=\frac{\sigma_{a, u}}{\text { Factor of Safety }}
$$

where the factor of safety to be used in the above equation shall be as follows:

$\begin{array}{cc}\text { Service Level } & \text { Factor of Safety } \\ \text { A } & \\ \text { B } & 2 \\ \text { C } & 5 / 3 \\ \text { D } & 4 / 3\end{array}$

Note that the above allowable stress against diamond buckling is a function of the axial location along the cylindrical wall because the wall thickness, temperature, and net internal pressure vary with axial position along the cylindrical wall of the primary tank. An alternate procedure for calculating the diamond buckling capacity of the cylindrical shell of the primary tank is given in the TSIP Guidelines.

4.1.2.6.3 Harmonic Buckling. When the tank is subjected to external (negative) pressure, design procedure provided in NC-3133.3 may be used to obtain the allowable external pressure. The Code uses "geometric chart" from which a "factor A" is determined. This factor is a function of length to diameter and diameter to thickness ratios for the cylinder under consideration. For the value of factor A obtained from the geometric chart, a "factor B" is determined from the "material chart". Using the value of $B$, the allowable pressure is calculated from the Code formula.

The primary tanks of the double-shell tanks have diameter to thickness ratios exceeding 1,000 and therefore are outside the range of the Code geometric chart. However, factor A can be calculated using the following formula (Bednar 1986):

$$
\text { Factor } A=1.30\left(\frac{t}{D_{0}}\right)^{\frac{3}{2}} \frac{D_{0}}{L}
$$

where $t, D_{0}$, and $L$ are the wall thickness, outside diameter, and the unsupported length of the cylinder, respectively.

Using the calculated value of A, the value of B can be read from the material chart applicable to the tank material. Then the allowable pressure can be calculated from the formula given below: 


$$
P_{a}=\frac{4 B}{3\left(\frac{D_{0}}{t}\right)} .
$$

For values of $\mathrm{A}$ falling to the left of the applicable material/temperature line, the allowable pressure can be calculated using the following equation:

$$
P_{a}=\frac{2 A E}{3\left(\frac{D_{0}}{t}\right)}
$$

4.1.2.7 Buckling Criteria for Dome and Lower Knuckle. The buckling criteria given in Section 4.1.2.6 apply only to cylindrical shells. As the primary tank dome and the lower knuckle of the tank are shells of double curvatures these rules are not applicable. Unfortunately, there are no reliable analyses available to predict a buckling failure of these types of shells of revolution.

The only available acceptance criteria for buckling of double curvature shells is delineated in paragraph NC-3922.3 which is the same as the one presented in API Standard 620 (API 1978) which provides rules for design and construction of large welded low pressure storage tanks. This criteria is for steels of 30,000 to $38,000 \mathrm{lbf} / \mathrm{in}^{2}$ yield strength and allowable tensile stress of $15,000 \mathrm{lbf} / \mathrm{in}^{2}$. A more realistic allowable buckling stress can perhaps be obtained from large-displacement finiteelement analyses which will provide critical compressive stresses for buckling failure. One can then apply the strength reduction factors and safety factors similar to those given in the ASME Code Case N-284 (ASME 1980).

4.1.2.8 Buckling of Bottom Plate Under Partial Vacuum. Both API 620 and NC-3900 require a limit on partial vacuum in the gas or vapor space of a storage tank not to exceed $1 \mathrm{oz} / \mathrm{in}^{2}$. However, larger negative pressures can be shown to be acceptable by analysis.

The allowable negative pressure for the cylindrical wall can be determined from the procedure outlined in Section 4.1.2.6.3. To obtain the allowable negative pressure for the bottom plate, largedisplacement, non-linear finite element analyses can be performed using a model with initial imperfection assuming the plate weightless. The resulting critical pressure with the appropriate safety factor (those given in Section 4.1.2.6.2) and the weight of the plate can be used to calculate the allowable negative pressure from the following equation:

$$
\boldsymbol{P}_{a}=w_{s}+\frac{\boldsymbol{P}_{a p}}{\text { Safety Factor }}
$$

where $w_{2}$ is the weight of steel per unit area of the bottom plate. No safety factor to $w_{1}$ needs to be applied as the weight of the plate can be determined accurately.

4.1.2.9 Slosh Height. The maximum vertical displacement (slosh height) of the liquid surface shall be calculated using the TSEP Guidelines. Considering only the fundamental sloshing mode, the slosh height is given by the following equation:

$$
h_{1}=R\left\{0.837\left(S_{A}\right)_{\mathrm{el}} / g\right\}
$$


where $\mathbf{R}$ is the tank radius, $\mathrm{g}$ is the gravitational acceleration, and $\left(\mathrm{S}_{\mathrm{A}}\right)_{\mathrm{cl}}$ is the fundamental sloshing mode spectral acceleration.

The slosh height demand shall be determined from the above equation by increasing the above response by a seismic load factor. Using a load factor equal to 1.15 in Equation 5.1 of the TSEP Guidelines, the slosh height demand (including 1.6 safety factor) is given by:

$$
\mathrm{h}_{\mathrm{rd}}=1.84 \mathrm{~h}_{\mathrm{s}} \text {. }
$$

The available slosh height capacity, $h_{n c}$, can be calculated from the following equation:

$$
h_{s c}=h_{c}+\left(h_{d} / 4\right)
$$

where $h_{c}$ is the cylindrical wall height above the liquid surface and $h_{d}$ is the dome height above the cylindrical wall.

If $h_{x}$ is less than $h_{x d}$, the effects of sloshing against the roof must be evaluated.

Section 2.7.5.2.1 provides the methodology to determine the tank wall pressure due to sloshing when the freeboard is inadequate.

4.1.2.10 Tank Sliding Capacity. The base shear demand and capacity shall be calculated using the following procedures which are based on Chapters 4 and 5 and Appendix F of the TSEP Guidelines.

4.1.2.10.1 Base Shear Demand. The impulsive mode hydrodynamic force at the base is given by Equation 4.1.2-23. This equation includes the mass of tank side walls and portion of the primary tank roof not directly supported by the concrete dome. Note Equation 4.31 of TSEP Guidelines neglects the effects of tank mass on base shear:

$$
V_{i}=\left[0.60\left(\frac{m_{i}}{m_{l}}\right) m_{l}+m_{i}\right]\left(S_{A}\right)_{i}
$$

where

$$
\begin{aligned}
& m_{\mathrm{i}}=\text { Impulsive component of liquid mass, } \\
& \mathrm{m}_{1}=\text { Total liquid mass, } \\
& \mathrm{m}_{\mathrm{i}}=\text { Mass of the tank side wall and the portion of the roof not directly supported by the } \\
& \text { concrete dome, and } \\
& \left(\mathrm{S}_{\mathrm{N}}\right)_{\mathrm{i}}=\text { Maximum horizontal spectral acceleration. }
\end{aligned}
$$

The ratio $m_{1} / m_{1}$ for a tanks is a function of the ratio of liquid height, $H_{1}$, and the tank radius $R$ and can be obtained from Table 4.2 of the TSEP Guidelines. 
The hydrodynamic force at the base for the convective mode may be expressed as (see Equation 4.31 of the TSEP Guidelines):

$$
V_{c l}=\alpha_{c l}\left(\frac{m_{c l}}{m_{l}}\right) m_{l}\left(S_{A}\right)_{c l}
$$

In the above equation $\mathrm{m}_{\mathrm{c} 1}$ is the liquid mass participating in the first convective mode of vibration and $\left(S_{A}\right)_{c 1}$ is the spectral acceleration. $\alpha_{c 1}$ and $m_{c 1} / m_{1}$ can be obtained from TSEP Guidelines Tables 4.4 and 4.2 , respectively for the appropriate ratio of liquid height and tank radius.

The total horizontal force at the base is then given by:

$$
V_{f}=V_{t}+V_{c I}
$$

Using a seismic load factor, $\mathrm{L}_{\mathrm{s}}=1.15$, and inelastic demand factor, $\mathrm{F}_{\mu \mathrm{D}}=1.25$, the horizontal force at the base is given by:

$$
\dot{V}_{\mathrm{d}}=1.15 \mathrm{~V}_{\mathrm{f}} / 1.25=0.92 \mathrm{~V}_{\mathrm{f}}
$$

4.1.2.10.2 Base Shear Capacity. The resistance to sliding is provided by friction between the tank bottom and the supporting concrete pad. Per TSEP Guidelines a coefficient of friction equal to 0.55 shall be used.

The vertical downward force acting on the tank bottom consists of the weight of the tank wall and unsupported roof, and hydrostatic and seismically induced hydrodynamic forces.

The effective minimum tank weight, $\mathrm{W}_{\mathrm{k}}$, is obtained by adjusting the actual weight by the following rule given in Appendix F of the TSEP Guidelines:

$$
W_{t e}=W_{t}\left[1-0.4 \frac{A_{v}}{g}\right]
$$

where, $A_{v}$ is the peak ground acceleration.

The downward acting force due to hydrodynamic effects is given by:

$$
F_{v p}=\pi R^{2} p_{a}
$$

where, $p_{a}=p_{s t}-0.4 p_{v}$ and $p_{a t}$ is the sum of design and hydrostatic pressure and $p_{v}$ is the hydrodynamic wall pressure due to vertical seismic motion. The total vertical force is then,

$$
F_{\mathrm{v}}=W_{\mathrm{te}}+\mathrm{F}_{\mathrm{vp}}
$$


Base shear capacity, $\mathrm{V}_{c}$, will be based on a coefficient of friction of 0.55 and a capacity reduction factor (due to uncertainty in coefficient of friction) of $0.75 . V_{c}$ is, then given by:

$$
V_{c}=(0.75)(0.55) F_{v}
$$

\subsubsection{Evaluation of Secondary Liner and Primary Tank Dome}

As the secondary liner is anchored to the secondary concrete structure, the rules of the ASME Code, Section III, Division 1, Subsection NC, cannot be applied to this component. Therefore, the ASME Code, Section III, Division 2, Subsection CC, Article CC-3000 rules will be used to assess the structural adequacy of the liner. A large portion of the primary tank dome is also attached to the concrete structure and, therefore, can be treated as a liner. Therefore, primary tank dome plates backed by concrete shall also be evaluated per Subsection CC rules.

The steel liner (primary or secondary), as described in ASME Section III,-Division 2, Subsection CC, when integrally connected to the concrete, is not considered a strength element and is only required to accommodate the deformation of the concrete structure. The failure modes considered by the Code include:

- General yield state under primary forces at a section.

- Liner tears at structural discontinuities such as penetrations, liner studs, and attachments, etc. The Code provides strain limits to prevent excessive deformation at these locations and imposes the requirement that liner stud anchors shall be designed to fail before tearing the liner.

- Progressive failure of the anchorage system.

4.1.3.1 Loads and Load Combinations. Three categories of loads, namely construction, service, and factored loads, are to be considered in design/evaluation. The Code provides stress allowables for construction loads but for service and factored loads the acceptance criteria are in terms of strain limit. For the evaluation of the existing Hanford DST domes and the secondary liners, only normal loads (under service load category) and factored loads are to be considered.

For the primary tank dome, the following normal and factored loads shall be analyzed

- Normal Loads: Under this category, the tank dead load, hydrostatic pressure, design pressure, thermal expansion, and thermal/creep dome displacements need to be included.

- Factored Loads: This category includes all of the above normal loads and seismically induced hydrodynamic pressures and the seismic displacements of the secondary concrete structures.

The liner analyses shall include the following loading conditions:

- Normal Loads: Under this category, design pressure, thermal expansion, and thermal/creep displacements of the secondary concrete structure need to be included. If the piping penetration design allows the loads to be transferred to the liner plate, such loads must also be considered in this load case. 
- Factored Loads: There are two cases which shall be considered in this category. The first case shall include all of the above normal loads and the seismic displacements of the secondary concrete structures. The second case shall address the abnormal event when the liner is flooded due to primary tank leakage. The loadings for this case shall be the pressure load (design pressure for the primary tank), hydrostatic pressure and dead load of liquid waste, thermal expansion, and thermal/creep deformation of the concrete structure.

The load combinations for the liner are specified in ASME Subsection CC-3230. The load factors for all load cases may be taken equal to 1.0. The applicable load combinations for the Hanford tank evaluation are listed in Table 4.1.3-1, herein.

4.1.3.2 Code Allowables. The Code requires the concrete-backed steel to be evaluated against the strain allowables. Separate sets of allowables exist for the normal and factored categories of loads. The liner stress and strain allowables are specified in the ASME Section III, Division 2, Subsection CC-3720. For the Hanford tank evaluation, only strain allowables are required which are listed in Table 4.1.3-2. The portion of the liner which is not backed by concrete shall be evaluated against ASME Section III, Division 1, Subsection NC requirements.

\subsubsection{Stud Evaluation}

The steel liner is anchored to the adjacent concrete by the use of embedded studs. The force and displacement allowables for the liner anchors are specified in ASME Section III, Division 2, Subsection CC-3730 (ASME 1992). The applicable force and displacement allowables from Table CC-3730-1 are listed in Table 4.1.4-1. The load combinations used for the liner anchor evaluation shall be those as shown in Table CC-3230-1 of ASME 1992 except that load factors for all load cases may be taken equal to 1.0. Load combinations which include earthquake effects shall be treated as being within the abnormal/extreme environmental category.

In accordance with Section CC-3123 of ASME 1992, the analysis shall demonstrate that the liner anchorage system is designed such that a progressive failure of the anchorage system is precluded in the event of a defective or missing anchor.

In accordance with Section CC-3800, the analysis used to predict loads and displacements for the liner anchors shall consider the effects of the following:

- Liner thicker than nominal due to the rolling tolerance given in SA-20. The thicker plate will impose greater forces and displacements on the anchorage system than a nominal thickness liner.

- Yield strength higher than the minimum specified due to the rolling processes and biaxial loading. Adequate consideration of yield strength in excess of the minimums may be provided by the following:

Converting liner strains to stress and membrane forces assuming the material remains elastic. 
- Conducting biaxial yield strength tests to establish the biaxial yield strength of materials used for the liner. Biaxial yield strength tests are required only when anchor designs rely on liner yielding to limit the forces applied to the anchors.

- Weld offset, structural discontinuities, and concrete voids behind the liner.

- Variation in anchor spacing. An effective anchor stiffiness should be used to account for any variations in anchor spacing used in analysis model and actual anchor spacing.

- Variation in anchor stiffness due to a variation of the concrete modulus.

- Local concrete crushing in the anchor zone. This may be addressed typically by assuring that the anchor stiffness includes the effects of local concrete crushing or by using a loaddisplacement profile (which includes the effects of local concrete crushing) to predict the response in the vicinity of the anchor.

- Stud anchors shall be designed to fail before tearing the liner.

The anchor allowables are in terms of forces and displacements. The anchor loads caused by mechanical loads which are not self-limiting have to meet a force allowable whereas the anchor deformations due to displacement-limited loads are required to be within the displacement allowables. Displacement-limited loads result from constraint of the structure or constraint of the adjacent material and are self-limiting or self-relieving.

As indicated in Section CC-3710 of ASME 1992, the yield $\left(F_{y}\right)$ and ultimate $\left(F_{v}\right)$ load capacities, and the ultimate displacements, $\delta_{u}$, should be obtained from test data that is directly applicable to the evaluated anchor, if available. Alternatively, capacity data provided in Nelson 1961, Ollgaard 1971, McMackin 1973, and Nelson 1977 may be used to develop the liner anchor allowables, provided that all assumptions are conservative and provided that use of such data that is not directly applicable to the anchor being evaluated is justified. The analyst should be aware that predicted loads and displacements may be sensitive to variations in the anchor stiffness which are affected by the anchor head geometry (e.g. headed anchors are stiffer than J-bolt anchor).

Information and data compiled from Nelson 1961, Ollgaard 1971, McMackin 1973, and Nelson 1977 were used to develop the information in Tables 4.1.4-2 and 4.1.4-3 for anchors with full embedment. Full embedment for tension loading is developed at an embedment depth of 8 to 10 times the anchor shank diameter. This ensures ductile behavior because the capacity of the concrete within the conical area of failure exceeds the tensile strength of the steel in the anchor. Similarly, full embedment for shear loading is developed at an embedment depth of approximately 4 times the anchor shank diameter. The full embedment depth values are based on the assumption that the studs are located, or spaced, so that there is sufficient surrounding concrete area for a full concrete shear cone to be developed. Based on a review of the double-shell tank drawings, it appears that the full embedment requirements are satisfied. However, limitations and corresponding reductions in allowables may be found in the literature (e.g. Nelson 1977) for those cases of partial embedment or where spacing requirements for edge conditions and adjacent anchors are not satisfied such that non-ductile behavior may occur. 
Table 4.1.4-2 provides relationships that may be used to determine $F_{y}$ and $F_{v}$ values for Nelson headed studs, Nelson headed-threaded studs, Nelson $90^{\circ}$ bent studs and Nelson $90^{\circ}$ bent flat bars with full embedment. Based on geometric considerations and based on the fact that $J$-bolt studs are expected to fail in the same manner as bent studs (by straightening of the stud), information and data for the bent studs may be used for evaluation of J-bolt studs. Similarly, Table 4.1.4-3 provides ultimate displacement values.

The evaluated displacements (for displacement-limited loads) should also be checked for consistency with the assumed load-displacement curves (tension and shear) that provide the bases for the allowables, $\delta_{\mathrm{u}}$. For example, if a linear stiffness value is used to represent the anchor, the corresponding displacements should be checked to ensure that the displacements correlate to the linear region on the load-displacement curves.

Ollgaard 1971 suggested the following empirical formula to describe the load-slip or loaddisplacement relationship for shear loading that includes the initial bond condition between the plate steel and the concrete:

$$
\mathrm{Q}=\mathrm{Q}_{0}\left(1-\mathrm{e}^{-18 \Delta}\right)^{2 / 5}
$$

where

$$
\begin{array}{ll}
\mathrm{Q} & =\text { Applied load } \\
\mathrm{Q}_{\mathrm{u}} & =\text { Ultimate load } \\
\Delta & =\text { Slip or displacement (in.). }
\end{array}
$$

For reloading conditions, where the initial bond condition no longer exists, the following relationship was found to provide a reasonable fit to the test data for shear loading:

$$
\mathrm{Q}=\mathrm{Q}_{\mathrm{u}} \mathrm{C} \Delta /(1+\mathrm{C} \Delta)
$$

where

$$
\mathrm{C}=80 \text {, an empirical constant. }
$$

The referenced literature does not provide similar equations for tension load data. However, based on a review of the data and load-displacement curves provided in the literature, Equations 4.1.4-1 and 4.1.4-2 also provide reasonable estimates of the load-displacement curves for tension loading for headed and headed-threaded studs.

Equation 4.1.4-1 has a vertical tangent at zero load, whereas Equation 4.1.4-2 has a slope of $80 \mathrm{Q}_{\mathrm{v}}$. Therefore, it may be desirable to use Equation 4.1.4-1 for primary loading (e.g. dead load) that is not displacement-controlled to conservatively predict higher loads at the anchor studs. Conversely, the use of Equation 4.1.4-2 may be preferred for displacement-controlled loading (e.g. thermal expansion) to conservatively predict higher displacements at the anchor studs. In addition, based on a review of the load-displacement curves provided in the referenced literature, a lower value for the Equation 4.1.4-2 coefficient $\mathrm{C}$, in the range of 40 to 60 , is recommended for bent studs (or $\mathrm{J}$ bolts). 
The allowable loads provided in Table 4.1.4-1 are for either tension loading only or shear loading only (uncombined). However, in many cases the embedded anchors may be subject to combined shear and tension forces. It has been shown (Nelson 1977) that, for combined shear and tension, an interaction curve of the following form provides a good fit for the test data:

$$
\left(\mathrm{P} / \mathrm{F}_{\mathrm{ap}}\right)^{\mathrm{S} / 3}+\left(\mathrm{S} / \mathrm{F}_{\mathrm{aas}}\right)^{\mathrm{s} / 3} \leq 1
$$

where

$\mathbf{P} \quad=$ Applied tension load

$S \quad=$ Applied shear load

$\mathrm{F}_{2 \mathrm{p}} \quad=\mathrm{F}_{\mathrm{a}}$ Allowable for an applied tension load

$F_{a} \quad=F_{a}$ Allowable for an applied shear load.

Similarly, for evaluating displacements, the following interaction equation should be used:

$$
\left(\delta_{\mathrm{p}} / \delta_{\mathrm{a}}\right)^{5 / 3}+\left(\delta_{\mathrm{q}} / \delta_{2}\right)^{5 / 3} \leq 1
$$

where

$\delta_{\mathrm{p}} \quad=$ Predicted tension displacement

$\delta_{\mathrm{s}} \quad=$ Predicted shear displacement

$\delta_{\mathrm{ap}}=\delta_{\mathrm{a}}$ Allowable for a predicted tension displacement

$\delta_{\mathrm{a}}=\delta_{\mathrm{a}}$ Allowable for a predicted shear displacement.

\subsubsection{Penetration Assemblies}

Penetration assemblies including nozzles, reinforcing plates, and penetration anchors shall meet the requirements of ASME Section III, Division 2, Subsection CC (ASME 1992) and shall be able to accommodate all design loads and deformations without loss of structural or leak-tight integrity. Effects such as temperature, concrete creep, and shrinkage shall be considered. The penetration assembly does not include the liner which is addressed in Section 4.1.3.

The penetration assemblies shall be evaluated using the same techniques and procedures used for metal containments in ASME Section III, Division 1, where applicable. The evaluation shall consider the concrete confinement for penetration sleeves embedded in the concrete containment.

The penetration assembly anchorage design shall be evaluated to the same requirements as those for the liner anchorage.

The penetration nozzle is that portion of the penetration assembly that is not backed up by concrete. The design allowables for the penetration nozzles shall be the same as those used for Division 1. For penetration nozzles which are not continuous through the liner, the allowable liner strength in the through-thickness direction shall be taken as one-half of that in the as-rolled direction.

The design allowables for the liner in the vicinity of the penetration shall be the same as those given in AISC, Specification for the Design, Fabrication, and Erection of Structural Steel for 
Buildings, for resisting mechanical loads for the service load category. For factored load categories, the allowables may be increased by a factor of 1.5 , except for impulse loads and impact effects.

The portion of the penetration sleeve backed by concrete shall be evaluated to meet the requirements of $\mathrm{CC}-3700$ and $\mathrm{CC}-3800$.

\subsection{ACI CODE-BASED PROTECTION AGAINST FAILURE}

This section considers ACI 349-90 Code provisions that are applicable to the evaluation of the secondary concrete structure. Section 4.2.1 considers appropriate load classifications, load combinations, and load factors. Special consideration is given to the application of load factors in nonlinear finite-element analyses. In Section 4.2.2, ACI-Code evaluation criteria are discussed for protection against failure under combined flexure and axial loads, twisting moments, transverse shear, in-plane shear, buckling, and impact loads. Special consideration is given to potential for rebar bond failure to assure that premature bond failure does not occur as a result of concrete degradation from high temperature exposure over time. Section 4.2.3 discusses code provisions applicable to the insulating concrete slab between the bottom of the primary tank and the secondary steel liner.

An important consideration in the structural evaluation of the waste storage tanks is the effect that the increased temperature from internal heat generation of the decaying radioactive waste material has on the concrete properties of the secondary concrete structure. In addition to creating thermal induced loads, concrete degrades in strength and modulus at temperatures greater than approximately $200{ }^{\circ} \mathrm{F}$. The ACI 349-90 temperature limit for normal or any long-term period of operation is $150^{\circ} \mathrm{F}$. However, higher temperatures are allowed for concrete if tests are provided to evaluate the reduction in strength and this reduction is applied to the design allowables. In addition, evidence shall be provided which verifies that the increased temperatures do not cause deterioration of the concrete either with or without load (ACI 349-90, Section A.4.3 of Appendix A, Thermal Considerations). The degraded concrete compressive strength should be used for capacity determinations for strength checks. In lieu of test data of the in-place concrete, temperature dependent degradation factors for concrete strength and modulus may be determined from available concrete test data normalized to the corresponding initial room temperature strength and modulus of the concrete test specimens. Because the degradation effects of temperature on concrete are not recovered on return to lower temperatures, the degradation factors shall be based on the maximum temperature attained within the concrete at the location of interest. If the analysis considers the actual service history for an existing tank then the degradation factors for each location within the concrete tank may be applied as monotonic increasing functions of the thermal history. Strength enhancement from long-term aging of concrete before exposure to temperatures above $200^{\circ} \mathrm{F}$ may be used if properly justified. The effect of temperature on rebar bond strength shall also be considered. Concrete strength and modulus degradation are presented as a function of temperature and time at temperature in Section 6.3.2. Temperature effects on bond strength are also discussed.

\subsubsection{Load Classification and Combinations}

The classification of load conditions or load events is key to determining the appropriate load combination that includes them and the application of proper load factors that reflect the variability in load. For this evaluation guideline loads are classified as normal loads, extreme environmental loads, 
and abnormal accident conditions which are included in the load combinations developed for high-energy pipe breaks.

ACI 349-90 (1992) uses the ultimate strength design approach. Structures and structural members shall have design strengths calculated for the factored loads and forces in such combinations as stipulated for the following loads combined in accordance with the provisions specified in Section 9.2 of ACI 349-90. The load combinations and load factors of Section 9.2 of ACI 349-90 reflect consideration of the likelihood of individual and combined-event occurrences as well as possible excess load effects such as variations in loads, assumptions in the structural analysis, and simplifications in the calculations.

Per Section 9.2 of $\mathrm{ACI}$ 349-90 the required strength, $\mathrm{U}$, shall be at least equal to the greatest of the following factored load combinations:

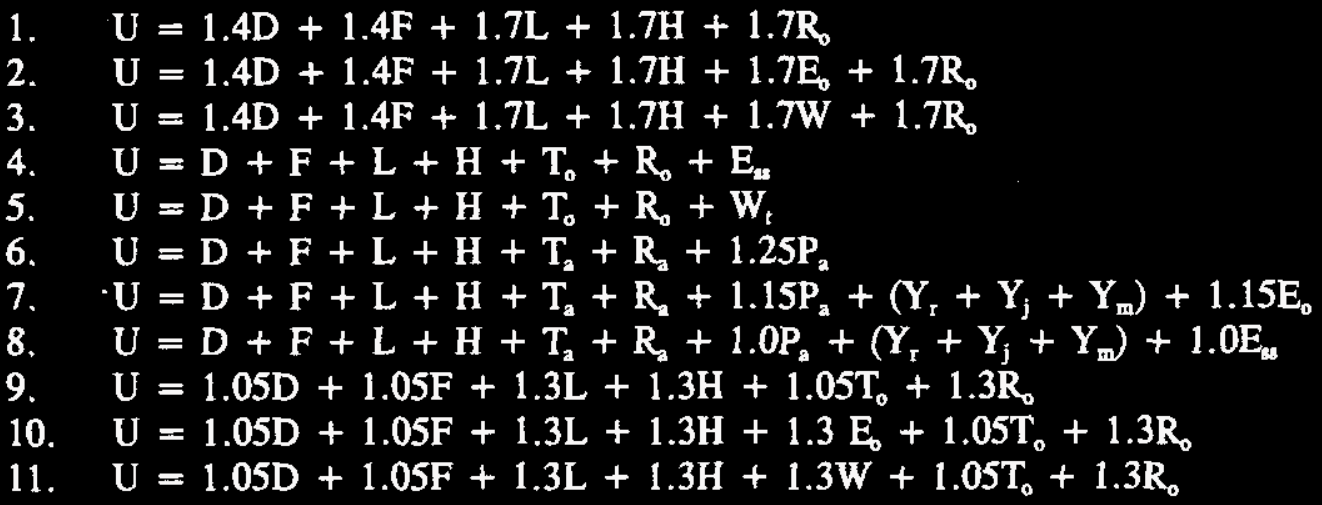

In the above load combinations the following load classifications and load definitions apply.

Normal loads encountered during operation and shutdown are:

$\mathrm{D}=$ Dead loads, including piping and equipment dead load

$\mathrm{L}=$ Live loads, including impact effects of moving loads

$F \quad=\quad$ Lateral and vertical pressure of liquids

$\mathbf{H}=$ Lateral earth pressure

$\mathrm{T}_{\mathrm{o}}=$ Internal moments and forces caused by temperature distribution within the concrete during normal operation and shutdown

$\mathbf{R}_{0}=$ Piping and equipment reactions under normal operation and shutdown (does not include dead load or earthquake reactions).

Included in normal loads, is consideration of forces induced from such effects as crane loads, vibration, impact, shrinkage, creep, unequal settlement of supports, construction, and testing.

Infrequent severe environmental loads are:

$\mathrm{E}_{\mathrm{o}} \quad=$ Operating Basis Earthquake (OBE) effects -- None defined

$\mathrm{W}=$ Operating Basis Wind (OBW) effects -- None defined 
Credible but improbable extreme environmental loads are:

$\mathrm{E}_{\mathrm{u}} \quad=$ Safe Shutdown Earthquake (SSE) effects $=$ DBE effects

$\mathrm{W}_{\mathrm{t}}=$ Design Basis Tornado (DBT) effects - None defined but other extreme accident loads such as internal pressure load from deflagration of flammable gases or equipment drop load could be considered here.

Abnormal high-energy pipe break accident loads are: -- None defined

$\mathbf{P}_{\mathrm{a}} \quad=\quad$ Differential pressure generated by a pipe break

$\mathrm{T}_{\mathrm{a}}=$ Internal forces and moments caused by temperature distributions within the concrete generated by a pipe break

$\mathrm{R}_{\mathrm{a}} \quad=$ Pipe and equipment reactions under thermal conditions of pipe break

$\mathrm{Y}_{\mathrm{r}} \quad=\quad$ Loads on the structure generated by reaction of the broken pipe

$\mathbf{Y}_{\mathrm{j}}=$ Jet impingement load on the structure generated by a pipe break

$\mathrm{Y}_{\mathrm{m}}=$ Missile impact load generated by a pipe break.

Where the structural effects of differential settlement, creep or shrinkage may be significant, they shall be included with the dead load $\mathrm{D}$ in load combinations 4 through 11 above.

-ACI 349-90 further instructs that other extreme environmental loads that may be specified for the structure shall be included in an additional load combination, with the additional extreme environmental load substituted for $W_{t}$ in load combination 5. Abnormal loads are not considered concurrently with these additional extreme environmental loads.

\section{Coefricient Modification}

ACI $349-90$ provides that within the load combinations, where any load reduces the effect of other loads, the coefficient shall be taken as zero unless; a) the load is always present or b) the load occurs simultaneously with the other loads. Then the coefficient shall be taken as 0.9 .

\section{Applicable Load Combingtions}

The full ACI 349-90 list of load combinations can be abbreviated to those load combinations applicable to the high-level waste tanks buried underground. All ACI loads not applicable to the concrete structure are identified as follows:

$r$ There is no high-energy piping within or adjacent to the tank structure. Therefore, all loads associated with high-energy pipe breaks can be disregarded.

- No OBE is defined for the Hanford Site. Only an SSE is defined.

- Wind loads impinge on the buried tanks only during construction. Therefore, these loads may be ignored in the evaluation of existing tanks.

Thermal states defined from historical operation and future normal operation and shutdown modes should be addressed. 
The load combinations cited by ACI $349-90$ can be reduced by considering only those loads found to be applicable to the Hanford USTs. For load combinations 1-3, representing normal loads and normal plus severe loads, no severe environmental loads are defined. Only load combination 1 applies. Thermal loads are not included.

1. $\mathrm{U}=1.4 \mathrm{D}+1.4 \mathrm{~F}+1.7 \mathrm{~L}+1.7 \mathrm{H}+1.7 \mathrm{R}_{\mathrm{b}}$.

For load combinations 4 and 5, involving extreme environmental loads, no tornado load is defined but internal pressure from deflagration of flammable gases or equipment drop load could be considered here. They will have to be examined for all temperature distributions in the concrete associated with normal operation.

4. $\mathrm{U}=\mathrm{D}+\mathrm{F}+\mathrm{L}+\mathrm{H}+\mathrm{T}_{0}+\mathrm{R}_{0}+\mathrm{E}_{\mathrm{u}}$

5. $\mathbf{U}=\mathrm{D}+\mathrm{F}+\mathrm{L}+\mathrm{H}+\mathrm{T}_{\mathrm{o}}+\mathbf{R}_{\mathrm{o}}+\mathrm{P}_{\text {defagration }} / \mathrm{P}_{\text {oquip. duop }}$

Load combinations 6,7 and 8 represent abnormal loads in combination with normal, severe and extreme environmental loads. ACI 349-90 defines abnormal loads as those associated with highenergy pipe break accidents which are not applicable to the Hanford waste tanks. However, if the thermal accident transients are identified as abnormal (rather than extreme) load conditions, these would be the appropriate load combinations to use. In that case, with no severe environmental load conditions defined, load combinations 6 and 8 apply. These will have to be examined for all temperature distributions in the concrete associated with abnormal accident conditions.

6. $\mathrm{U}=\mathrm{D}+\mathrm{F}+\mathrm{L}+\mathrm{H}+\mathrm{T}_{\mathrm{a}}+\mathrm{R}_{\mathrm{a}}+1.25 \mathrm{P}_{\mathrm{a}}$, which simplifies to

$\mathrm{U}=\mathrm{D}+\mathrm{F}+\mathrm{L}+\mathrm{H}+\mathrm{T}_{\text {abnormal }}+\mathrm{R}_{\mathrm{o}}$

because there are no abnormal piping and equipment reactions or pressure loads.

8. $U=D+F+L+H+T_{a}+R_{a}+P_{a}+Y_{r}+Y_{j}+Y_{m}+E_{u}$,

which simplifies to

$$
\mathrm{U}=\mathrm{D}+\mathrm{F}+\mathrm{L}+\mathrm{H}+\mathrm{T}_{\mathrm{abnomal}}+\mathrm{R}_{\mathbf{o}}+\mathrm{E}_{\mathbf{m}}
$$

because there are no abnormal piping or equipment reactions, pressure loads, or jet, missile or reaction loads.

Load combinations 9,10 and 11 are similar to 1,2 and 3 but include normal operation thermal loads. With no severe environmental loads defined, only load combination 9 will apply. This combination will have to be examined for all temperature distributions in the concrete associated with normal operation.

9. $\mathrm{U}=1.05 \mathrm{D}+1.05 \mathrm{~F}+1.3 \mathrm{~L}+1.3 \mathrm{H}+1.05 \mathrm{~T}_{0}+1.3 \mathrm{R}_{0}$ 


\section{Summary of Applicable Load Combinations}

In summary, applicable load combinations are:

1. $\mathrm{U}=1.4 \mathrm{D}+1.4 \mathrm{~F}+1.7 \mathrm{~L}+1.7 \mathrm{H}+1.7 \mathrm{R}_{\mathrm{o}}$

4. $\mathrm{U}=\mathrm{D}+\mathrm{F}+\mathrm{L}+\mathrm{H}+\mathrm{T}_{\mathrm{o}}+\mathrm{R}_{\mathrm{o}}+\mathrm{E}_{\mathrm{au}}$

5. $\mathrm{U}=\mathrm{D}+\mathrm{F}+\mathrm{L}+\mathrm{H}+\mathrm{T}_{\mathrm{o}}+\mathrm{R}_{\mathrm{o}}+\mathrm{P}_{\text {denegration }} / \mathrm{P}_{\text {equip. drop }}$

6. $\mathrm{U}=\mathrm{D}+\mathrm{F}+\mathrm{L}+\mathrm{H}+\mathrm{T}_{\text {abnomal }}+\mathrm{R}_{0}$

8. $\mathrm{U}=\mathrm{D}+\mathrm{F}+\mathrm{L}+\mathrm{H}+\mathrm{T}_{\text {abrormal }}+\mathrm{R}_{\mathrm{o}}+\mathrm{E}_{\mathrm{w}}$

9. $\mathrm{U}=1.05 \mathrm{D}+1.05 \mathrm{~F}+1.3 \mathrm{~L}+1.3 \mathrm{H}+1.05 \mathrm{~T}_{0}+1.3 \mathrm{R}_{0}$

Because some of the loads used in the above combinations are off-setting, the following group of loads should be considered with a 0.9 factor in combination with other fully-factored loads:

1. Soil over burden and tank dead load (with empty tank configuration)

2. Side soil pressure and temperature (with full tank configuration)

These additional load cases maximize the inward and outward radial wall deflection, respectively. Where live loads, L, reduces the effects of other loads, the corresponding load factors shall be taken as zero for $\mathrm{L}$.

\section{Apolication of Load Factors in Nonlinear Analysis}

Linear elastic analysis is usually employed in ACI code evaluations. When nonlinear analysis is employed, unlike linear analysis, the order of the application of the applied loads affects the final response. Similarly, for nonlinear analysis load factors that are applied directly to the service loads will cause a different response than that associated with factoring the response of unfactored loads. The strength-design approach is based on moments and forces calculated from elastic analysis of structures, whereas the strength evaluations of the cross sections involve inelastic action at the critical design sections. Ferguson et al. (1988) indicates that "The elastic analysis gives moments and shears generally on the safe side but their use involves at least a philosophical inconsistency. Although it is not usually computed, it also should be noted that the influence of the cracking of some of the members ... can modify the usual moments more than most designers realize" (p. 17).

Results obtained from analyses in which the load factor is applied to the load or to the response induced from the load are equivalent only when linear elastic analysis is used. However, the first approach is considered more appropriate where nonlinear analysis is used. The purpose of load factors in a linear elastic analysis is to account for the uncertainty of loads and the uncertainty of the structural response prediction. Nonlinear analyses in which load factors are applied directly to the loads, produces a response that more accurately predicts the structural response by accounting for load redistribution and other nonlinear effects such as cracking. Further, response from one type of load, e.g., thermal load, lateral earth pressure, cannot be isolated from the response resulting from another type of load in a nonlinear analysis; behavior is path dependent and superposition is invalid. Therefore, there are no means to apply different values of load factors to the response, as the contribution of each load to the overall response cannot be identified. 
Commentary on Code Requirements for Nuclear Safety-Related Concrete Structures (ACI 349-90) offers strong support for the applicability of nonlinear analysis techniques in assessing redistribution of loads for cracked, reinforced concrete shell structures. The "Commentary" on Chapter 19, paragraphs $19.2 .1,19.2 .2$ and 19.2.2, states:

Nonlinear analysis may be necessary when a cracked concrete section due to load combinations of thermal, earthquake, and others listed in [ACI 349] Section 9.2.1 is considered and the redistribution of stresses takes place in relationship to the depth of cracks. Tensile resistance of the cracked concrete is not relied on. The cracks could occur in meridional, hoop, or other directions depending on the reinforcement patterns and loadings.

The code does not intend to require the nonlinear crack analysis for all possible cracked conditions, but requires the Engineer to review the possibility of the resulting redistribution of forces and initiate analysis if deemed necessary.

Furthermore, for structures experiencing significant thermal loads, ACI 349 Committee Report ACI 349.1R-91 (1992), Reinforced Concrete Design for Thermal Effects on Nuclear Power Plant Structures, clearly states a preference for nonlinear analysis.

... Ideally, a sophisticated analysis of a frame or slab structure subject to both mechanical and thermal loads might consider concrete cracking and the resulting changes in member properties at many stages of load application. Such analysis would consider the sequential applications of the loads. ... In such an analysis, the thermal moments would be a result of member cracking occurring not only for mechanical loads, but also for thermal loads. ... The extent of cracking which the members experience under the total mechanical load (including the specified load factors) forms the basis for the cracked structure used for the thermal load analysis. (p. 4)

The type of analysis summarized above is consistent with the approach in Item 2 of Section A.3.3 of the "Commentary" to Appendix A. The "Commentary" on Section 3.3 of Appendix A to the ACI 349-90 code suggests three ways to handle thermal-stress problems; the second of the three described is of interest to this discussion.

Analyses may consider the cracking of concrete for all loads, mechanical and thermal.

Although this approach probably is the most accurate and generally results in the largest degree of self-relieving thermal stress, it is very complex, involving significant nonlinear analysis and iterative solutions not readily available to the Engineer.

Since the time Appendix A of ACI 349-90 was published, the availability of nonlinear analysis tools capable of predicting the response of reinforced concrete have become increasingly wide spread. Hence, the preferred approach is to factor the loads rather than the response. The following guidance is offered for developing the appropriate sequence for factored load application in a nonlinear analysis:

- Apply gravity loads to the tank and surrounding soil in a sequence that simulates that of the construction.

- Apply nominal operating loads in their naturally occurring sequence. If there is no "natural" sequence, apply loads simultaneously. 
Apply load factors on all loads simultaneously for each set of load factors starting from the nominal, unfactored condition.

\subsubsection{Secondary Concrete Tank - ACI Code Evaluation}

The most appropriate code for evaluating reinforced concrete containing nuclear material is ACI 349-90 (1992). Because the Hanford USTs have structural and functional attributes that are similar to reactor containments, the ASME B\&PV, Section III, Division 2 also can provide useful guidance. The loading conditions of Hanford USTs can include those not addressed explicitly by the ACI or ASME codes. To understand such conditions nonlinear analysis can be used to predict bestestimate behavior. The code check provides a measure of protection against local failure of members, but does not provide a measure of the structural capacity of the total system. The following subsections emphasize specific ACI code provisions that are a part of a comprehensive Code evaluation for DSTs.

4.2.2.1 Flexure and Axial Load Code Evaluation. The interaction between axial load and bending moment should be calculated according to ACI 349-90, Section 10, with an assumption that the behavior of rebar is elastic, perfectly plastic. In accordance with ACI 349-90, Section 14.4, the provisions of Section 10 are appropriate for a wall with combined flexure and axial load. A typical interaction diagram for axial load capacity $(P)$ and moment capacity $(M)$ of a section is illustrated in Figure 4.2.2.1-1. The heavy line bordering the shaded area in the figure represents the code-dictated capacity of a tied section. Although Hanford USTs may not have ties everywhere, Section 14.3.3 of ACI 349-90 states that vertical reinforcement in walls need not be enclosed by lateral ties if the vertical reinforcement area is less than 0.01 times the gross concrete area. Any point on the example $M-P$ interaction diagram that falls inside the shaded area represents an acceptable section demand. Several of key points of the M-P interaction diagram are described below. Point D represents the code limit for axial compression with zero bending moment; the value is computed by

$$
\alpha \phi P_{n o}=\alpha \phi\left[0.85 f_{c}\left(A_{g}-A_{s}-A_{s}^{\prime}\right)+f_{y}\left(A_{s}+A_{s}^{\prime}\right)\right]
$$

where

$$
\begin{array}{ll}
\alpha & =\text { Factor to account for a small eccentricity of the } \\
& \text { load (normally } 0.8) \\
= & \text { Capacity reduction factor (for a tied compression } \\
& \text { member }=0.7) \\
= & \text { Gross area of the section } \\
A_{g} & \text { Area of meridional rebar (both faces) } \\
A_{1}+A_{1}, \quad= & \text { Compressive strength of concrete adjusted for temperature } \\
f_{c} & \text { Yield strength of the rebar adjusted for temperature. } \\
f_{y} &
\end{array}
$$

Point 0 is Point $D$ without the $\alpha$ factor applied. Point $\mathrm{E}$ is the code limit for axial tension with zero bending moment. This tensile limit is $\phi\left(A_{t}+A_{1}\right) f_{y}$. Point $b$, the balance point, corresponds to the balanced loading condition for the section where crushing of the concrete $\left(\epsilon_{\mathrm{u}}=0.003 \mathrm{in} . / \mathrm{in}\right.$.) and yield of the tensile rebar $\left(\epsilon_{y}=f_{y} / E_{q}\right.$ where $f_{y}$ and Young's modulus of the rebar $E_{a}$ are adjusted for temperature) occur simultaneously. Figure 4.2.2.1-2 illustrates this balance condition. Note that the maximum compressive strength is assumed to occur at a strain of $0.002 \mathrm{in}$./in., hence the post-failure 
regime of the compressive stress-strain curve of the concrete is important in the ultimate strength method of analysis.

To determine this balance point, calculate the depth to the neutral axis $c_{b}$ from similar triangles and the strain profile,

$$
c_{b}=0.003 d /\left(0.003+f_{y} / E_{s}\right)
$$

Then, using the Whitney stress block approximation where $\beta_{1}$ is calculated in accordance with Section 10 of ACI 349-90 and using the degraded concrete compressive strength $f_{c}$, algebraically sum steel and concrete forces to determine the nominal balanced axial load $P_{b}$, and sum moments about the plastic centroid to determine the nominal balanced bending moment $\mathbf{M}_{\mathbf{b}}$. The plastic centroid of a section is the location of the resultant load that would give a uniform strain across the section (no bending). For a symmetric section, the plastic centroid lies at the geometric centroid. For an unsymmetric section subjected to net axial compression, the location of the plastic centroid as measured from the centroid of the steel designated $A_{4}$ in Figure 4.2.2.1-3 may be computed as:

$$
x_{p}=\left[0.85 f_{c} b h\left(h / 2-d^{\prime}\right)+A_{s}^{\prime} f_{y}\left(d-d^{\prime \prime}\right)\right] /\left[0.85 f_{c} b h+\left(A_{s}^{\prime}+A_{s}\right) f_{y}\right]
$$

Equation 4.2.2-3 is reduced to $x_{p}=h / 2-d$ ' when the section is symmetric, i.e., when $A_{\varepsilon}=A_{s}$ ' and $\mathrm{d}^{\prime}=\mathrm{d}^{\prime \prime}$.

The balanced axial load and moment are calculated as follows:

$$
\begin{aligned}
P_{b} & =\Sigma F=C_{c}+C_{s}-T \\
& =0.85 f_{c} b\left(\beta_{1} c_{b}\right)+A_{s}^{\prime} f_{s}^{\prime}-A_{s} f_{y}
\end{aligned}
$$

where

$$
f_{i}^{\prime}=0.003 E_{i}\left(c_{b}-d^{\prime \prime}\right) / c_{b} \leq f_{y} .
$$

Summing moments about the plastic centroid yields

$$
M_{b}=C_{c}\left(d-x_{p}-\beta_{1} c_{b} / 2\right)+C_{s}\left(d-x_{p}-d^{\prime \prime}\right)+T\left(x_{p}\right)
$$

Point $B$ on the M-P interaction diagram is determined by reducing the balanced axial load and moment by the $\phi$ factor $=0.7$. Connecting the points $\mathrm{O}$ and $\mathrm{B}$, and $\mathrm{B}$ and $\mathrm{E}$ with straight lines, creates an approximate interaction diagram. This three-point approximation is conservative except when approaching pure axial compression. Additional points to complete the interaction diagram are obtained as follows. Assume a location of the neutral axis. Using the linear strain profile with $\epsilon_{\mathrm{u}}=\mathbf{0 . 0 0 3}$, determine rebar strains. Calculate rebar stress from the rebar strain and Young's modulus adjusted for temperature (as strains are small, neglect strain hardening). Concrete stress is 
$0.85 \mathrm{f}_{\mathrm{c}}$ and the Whitney stress block is $\beta_{1} c_{b}$ deep. Sum concrete and steel forces to get $P_{n}$, and sum moments about the plastic centroid to get $M_{n}$. Apply the appropriate $\phi$ factors to $P_{n}$ and $M_{n}$ to obtain a point on the interaction diagram.

The $\phi$ factor is 0.7 for $P_{n}$ greater than $\left(0.1 f_{c} A_{g}\right) / 0.7$, and $\phi$ is 0.9 for $P_{n}$ less than zero. For other values of $P_{n}, \phi$ may be determined by linear interpolation. For a more in-depth discussion of combined flexure and axial load, refer to Reinforced Concrete Fundamentals (Ferguson et al. 1988).

4.2.2.2 Rebar Bond-Slip Failure. Inherent in the development of the M-P interaction diagram is the assumption that the bond between the concrete and reinforcement is maintained. There is experimental evidence that factors such as temperature, rate of loading, and cyclic type of loading contribute to degrade the nominal bond strength. For the USTs the most important consideration is the effect of temperature. In addition, smeared-crack concrete constitutive models typically used in finite-element analyses do not address rebar bond-slip. Rebar stresses must be checked separately to assure that bond is maintained throughout the finite-element analysis. That is, the rebar bond strength should not degrade below $1.2 \mathrm{f}_{\mathrm{y}}$, where $\mathrm{f}_{\mathrm{y}}$ is the yield strength of the rebar at the temperature of the concrete section where a rebar splice exists. The code requires this $20 \%$ increase above the rebar yield strength to assure flexural ductility when the steel stress exceeds the rebar yield strength (Ferguson et al. 1988).

A well-established theory for splitting bond failure, first proposed in Orangun et al. 1977, addresses the dependency of bond stress on such parameters as development length, bar size, bar cover, and clear bar spacings. The radial forces generated between the bar lugs and the surrounding concrete are treated as internal pressure acting on a thick-walled cylinder with an inner diameter equal to the bar diameter and a thickness, $\mathrm{C}$, that is the smaller of (1) the clear top/bottom or side cover $\mathrm{C}_{\mathrm{b}}$ and (2) one-half the clear spacing between adjacent bars, as shown in Figure 4.2.2.2-1. The capacity of the cylinder depends on the tensile strength of the concrete. With $\mathrm{C}_{b}$ greater than $\mathrm{C}_{\mathrm{a}} / 2, \mathrm{a}$ horizontal split develops at the level of the bars and is termed a "side-split" failure. With $\mathrm{C}_{\mathrm{l}} / 2$ greater than $\mathrm{C}_{\mathrm{b}}$, a "face-and-side split" failure forms with longitudinal cracking through the cover followed by splitting through the plane of the bars.

From the results of a number of development and splice tests, a regression analysis was used to develop an empirical equation in which the bond stress was expressed in terms of the concrete strength $f_{c}$, bar diameter $d_{b}$, thickness of concrete cylinder surrounding the bar $C$, length of anchored bar $l_{d}$ or $l_{s}$ and transverse reinforcement (Orangun et al. 1977). The tests were performed for $l_{\mathrm{s}} / d_{b}$ ratios varying from 10 to 80 . With this approach, the limiting rebar stress governing splitting bond failure, ignoring any contribution from transverse reinforcement, is determined for $C / d_{b} \leq 2.5$ as

$$
f_{s}=\frac{4 l_{s}}{d_{b}}\left(1.2+3 \frac{C}{d_{b}}+50 \frac{d_{b}}{l_{s}}\right) \sqrt{f_{c}}
$$

where

f, = Longitudinal rebar limit stress for bond failure $\left(\mathrm{lbf} / \mathrm{in}^{2}\right)$

$\mathrm{l}_{\mathrm{s}} \quad=$ Lap splice $\left(\mathrm{l}_{\mathrm{s}}\right)$ or development length $\left(\mathrm{l}_{\mathrm{f}}\right)$ of rebar (in.)

C $=$ Smaller of bottom cover dimension $\left(C_{b}\right)$ or $C_{t}=1 / 2$ of spacing between splices or rebar (in.) 
$\mathrm{d}_{\mathrm{b}} \quad=$ Rebar diameter (in.)

$\mathrm{f}_{\mathrm{c}} \quad=$ Compressive strength of concrete $\left(\mathrm{lbf} / \mathrm{in}^{2}\right)$ adjusted for temperature.

The increased capacity associated with transverse steel (ties and stirrups) has been neglected in Equation 4.2.2-7 because the transverse steel is not significant for the Hanford waste tanks. For top-cast rebar (reinforcement cast in a horizontal position with more than 12 in. of plastic concrete under the bar at the time the bar is embedded in concrete), a $23 \%$ reduction should be applied. This applies to the top reinforcement in the dome and basemat slab, as well as, to the circumferential reinforcement in the cylindrical wall if cast in lifts greater than $12 \mathrm{in}$. Where $\mathrm{C} / \mathrm{d}_{\mathrm{b}}$ exceeds 2.5, Equation 4.2.2-7 may be used with $\mathrm{C} / \mathrm{d}_{\mathrm{b}}=2.5$. This equation is valid for regions with a constant moment or with a moment gradient. However, there are indications that a splice may not perform as well in a region of high varying shear (Orangun et al. 1977). Equation 4.2.2-7 is conservative for side-to-bottom cover ratio $C_{b} /\left(C_{b} d_{b}\right)$ greater than $4 /$ in. For large clear spacing $\left(C_{a}>>C_{b}\right)$ the concrete outside the "minimum" cylinder surrounding the rebar tends to restrain splitting across the plane through the bars resulting in a "V-notch" type of failure through the concrete cover region.

Although the DSTs employ only round rebar, some of the single-shell tanks include square rebar. Because the tests that served as the basis for the empirical formula presented above were performed on conventional deformed, round rebar, additional consideration is needed to address the limits for the square rebar. An additional knockdown factor is derived in Julyk et al. 1994 to address square rebar.

Additional bond strength reduction factors may be required to account for other uncertainties. The original empirical bond failure relation given in Equation 4.2.2-7 did not account for cyclic or sustained load effects for a high stress-to-compressive-strength ratio. In addition, the effect of temperature was not directly considered since all tests were conducted at room temperature. Cyclic and sustained load effects are assumed to be accounted for through the application of the ACI load and $\phi$ factors since the Code writers were clearly aware of these effects. Because of the functional dependence of the bond strength on the compressive strength as shown in Equation 4.2.2-7, it appears logical that the effect of temperature on bond strength could be addressed by using the corresponding degraded compressive strength of the concrete in Equation 4.2.2-7.

However, there may be secondary temperature effects related to the difference in thermal expansion between the concrete and the steel reinforcement. The thermal expansion of carbon steel is typically on the order of $6 \times 10^{-6} \mathrm{in} / \mathrm{in}-{ }^{\circ} \mathrm{F}$ for the temperature range of interest. Measured values of the thermal expansion of Hanford concrete have been as low as $1.6 \times 10^{-6} \mathrm{in} / \mathrm{in}-^{\circ} \mathrm{F}$ with an average value of about $3.7 \times 10^{-6} \mathrm{in} / \mathrm{in}-^{\circ} \mathrm{F}$ (Winkel 1994). Changes in the concrete strength with temperature can be accounted for in Equation $4.2 .2-7$ by using the temperature degraded concrete compressive strength for $f_{c}$. Thermal induced stresses from the in-plane thermal expansion of the reinforcement relative to the concrete is accounted for directly in the finite element stress analysis. The development of these thermal stresses is also affected by the degradation in concrete modulus with temperature which can also be accounted for in the stress analysis. However, because the rebar is not typically modeled as a three-dimensional element, the thermal induced radial expansion of the reinforcement is not accounted for explicitly. This relative radial expansion of the reinforcement could contribute to additional degradation of the bond strength but this effect could also be mitigated by creep. Data related to bond strength at temperature is not always consistent and requires careful evaluation. For example, non-cyclic bond strength test results by Oland and Callahan (1978) for $4,000 \mathrm{lbf} / \mathrm{in}^{2}$ limestone aggregate concrete indicated little difference (within $3 \%$ ) in bond strength at 
$75^{\circ} \mathrm{F}$ and $300^{\circ} \mathrm{F}$ but the bond strength at $150^{\circ} \mathrm{F}$ was approximately $10 \%$ below the strength at $75^{\circ} \mathrm{F}$.

If the bond strength determined from Equation 4.2.2-7 should drop below 1.2f $\mathrm{f}_{\mathrm{y}}$ at a particular rebar-splice location within the structure, the lower allowable region below the balance point of the M-P interaction diagram in Figure 4.2.2.1-1 (line segment ECB) could be unconservative. This region of the M-P diagram would need to be adjusted to limit the stress in the rebar to below the bond strength rather than to the yield strength of the rebar. Such corrections to the M-P diagram because of reduction in the bond strength with increasing temperature as well as other potential effects are discussed further in Section 6.3.2.

4.2.2.3 Twisting Moment Code Evaluation. Twisting moments are manifested as a result of non-axisymmetric load application. ACI 349-90, Section 11.6.1 provides an equation to calculate a threshold value of factored torsion (twisting), above which torsional effects are to be included with shear and moment:

$$
T_{\text {trreatold }}=\phi 0.5\left(f_{c}\right)^{1 / 2} x^{2} y
$$

where

$$
\begin{array}{ll}
\phi & =\text { Strength reduction factor } \\
\mathbf{f}_{\mathrm{c}} & =\text { Compressive strength of concrete adjusted for temperature } \\
\mathrm{x} & =\text { Thickness of element (in.) } \\
\mathrm{y} & =\text { Width of element }=12 \mathrm{in} .
\end{array}
$$

4.2.2.4 Transverse Shear Code Evaluation. Because of the similarity of the tank's structural elements to slabs or footings (Section 11.5.5.1 of ACI 349-90) as well as the precedent established in paragraphs CC-3421.3 Shear and CC-3421.4 Radial Shear of ASME B\&PV Section III, Division.2, Subsection CC, there are no minimum shear reinforcement requirements. The shear capacity at each of the tank sections subject to axial compression is computed on the basis of concrete strength, in accordance with Section 11.3.1.2 of ACI 349-90, as follows:

$$
\text { Shear Capacity }=\phi V_{c}=2 \phi b d \sqrt{f_{c}}\left[1+N_{u} / 2,000 A_{g}\right]
$$

where

$$
\begin{aligned}
\phi & =\text { Capacity reduction factor for shear }=0.85 \\
b & =\text { Width of section }=12 \mathrm{in} . \\
\mathrm{d} & =\text { Distance from extreme compression fiber to centroid of tensile } \\
& \text { meridional reinforcement } \\
\mathrm{f}_{\mathrm{c}} \quad= & \text { Compressive strength of the concrete adjusted for temperature } \\
\mathbf{N}_{\mathrm{u}} \quad= & \text { Axial load (positive for compression) } \\
\mathrm{A}_{\mathrm{g}} \quad= & \text { Gross area of section. }
\end{aligned}
$$

Alternately, $\mathrm{V}_{\mathrm{c}}$ may be computed in accordance with the provisions of ACI 349-90, Section 11.3.2. 
Shear friction at construction joints should be checked according to ACI 349-90, Section 11.7, where the allowable shear across the construction joint is calculated as follows:

$$
\text { Shear-friction capacity }=\text { lesser of }\left\langle A_{v f} f_{y} \mu, \phi\left(0.2 A_{c}\right) f_{c}, \phi(800) A_{c}\right\}
$$

where

$$
\begin{array}{ll}
\phi & =\text { Capacity reduction factor for shear }=0.85 \\
A_{\mathrm{v}} & =\text { Area of shear friction reinforcement normal to the construction joint } \\
\mathbf{f}_{\mathrm{c}} & =\text { Compressive strength of concrete adjusted for temperature } \\
\mathrm{f}_{\mathrm{y}} & =\text { Yield strength of the rebar adjusted for temperature } \\
\mu & =\text { Coefficient of friction per ACI } 349-90 \text { Section } 11.7 .4 .3 \\
A_{\mathrm{c}} & =\text { Area of concrete section resisting shear transfer. }
\end{array}
$$

4.2.2.5 In-Plane Shear Code Evaluation. Although ACI 349-90 does not provide specific direction for the evaluation of in-plane shear of elements in a continuous structure such as a tank, the code requirements for in-plane shear in walls are adopted to provide a measure of adequacy.

Using ACI Section 11.10 equations, and in consideration of ACI Section 11.10.6 (Eqn 11-32),

$$
\phi V_{c}=\phi\left\{3.3\left(f_{c}\right)^{1 / h d}+N_{u} d / 4\left(L_{w}\right)\right\}
$$

where

$$
\begin{array}{ll}
\mathrm{V}_{\mathrm{c}} & =\text { Nominal shear strength provided by concrete (lbf) } \\
\phi & =\text { Strength reduction factor }=0.85 \\
\mathrm{f}_{\mathrm{c}} & =\text { Compressive strength of concrete adjusted for-temperature } \\
\mathrm{h} & =\text { Thickness of element (in.) } \\
\mathrm{d} & =\text { Width of element }=12 \mathrm{in} . \\
\mathbf{N}_{u} & =\text { Minimum factored axial load (compression positive, lbf) } \\
\mathrm{l}_{\mathrm{w}} & =\text { Width of element }=12 \mathrm{in} .
\end{array}
$$

The above ACI equation is expressed in terms of a global wall-check and limits " $d$ " to $0.81_{w}$ $\left(0.8^{*}\right.$ length-of-wall). The reduction factor on the wall length compensates for inaccuracies associated with the use of a strength-of-materials approach in predicting demand which ignores edge/boundary effects. In-plane shear demands are examined on an element basis using a finite-element analysis, therefore, peak values and edge effects should be considered instead of using an average "wall-shear." Furthermore, the tank shell is continuous, rather than comprising individual walls, so that there is no finite length-of-wall. For these reasons, it is appropriate to use an unreduced "d" value equal to a unit width consistent with the demand units.

In ACI Section 11.10.8, $\phi \mathrm{V}_{\mathrm{c}} / 2$ is identified as the maximum shear allowed without shear reinforcing requirements. Torsional moment (normal to shell mid-surface) is assumed to be low, as no such load is applied to the tank, so that ACI Equation 11-33 does not apply. 
4.2.2.6 Strength Reduction Factors. Strength reduction factors are given in Section 9.3 of ACI 349-90. Design strength shall be taken as the nominal strength multiplied by a strength reduction factor $\phi$, as follows:

(a) Flexure, without axial load

(b) Axial load

Axial load with flexure (multiply both axial load and moment nominal strength by appropriate single value of $\phi$ ) $\quad 0.9$ Axial tension, and tension with flexure

Axial compression, and compression with flexure spiral reinforcement conforming to ACI 349-90, Section 10.9.3 0.75 other reinforced members

(c) Axial compression, with or without flexure spiral reinforcement conforming to ACI 349-90, Section 10.9.3 0.75 $\begin{array}{ll}\text { other reinforced members } & 0.70\end{array}$

except that for low axial load, $\phi$ may be increased for $f_{y} \leq 60 \mathrm{kip} / \mathrm{in}^{2}$, with symmetric reinforcement and with $\left(h^{-}-d^{\prime}-d_{1}\right) / h \geq 0.7, \phi$ may be increased linearly to 0.9 as $\phi P_{n}$ decreases from $0.10 f_{c} A_{8}$ to zero.

For other reinforced members, $\phi$ may be increased linearly to 0.9 as $\phi P_{n}$ decreases from $0.10 f_{c} A_{g}$ or $\phi P_{b}$, whichever is smaller, to zero.

(d) Shear and torsion

(e) Bearing on concrete

4.2.2.7 Concrete Shell Buckling Code Evaluntion. Chapter 19 of ACI 349-90 requires the investigation of thin shells for instability, including the consideration of the possible reduction in buckling capacity caused by large deflections, creep effects, temperature, cracking, and deviations between the actual and theoretical shell geometry. By way of reference to the Commentary in Chapter 19 of ACI 318-83, ACI 349-90 identifies ACI SP-67, Concrete Shell Buckling (1981), as a source of approaches for determining the critical buckling loads of reinforced concrete shells. A practical procedure for determining critical buckling loads of reinforced concrete shells, as given by the International Association for Shell and Spatial Structures (IASS) Working Group No. 5, Recommendations for Reinforced Concrete Shells and Folded Plates, is discussed in the ACI SP-67 document. 
Scordelis (1981) summarizes the IASS recommendations in SP-67 with the following equations:

$$
\begin{aligned}
& P_{b}^{\text {red }}=\alpha_{1} \alpha_{2} \alpha_{3} \alpha_{4} P_{b}^{b i n}=\alpha P_{b}^{l i n} \\
& P_{b}^{\text {allow }}=P_{b}^{\text {red }} / S F_{b}
\end{aligned}
$$

where

$$
\begin{array}{ll}
P_{b}^{\text {ned }} & =\text { Reduced buckling load } \\
P_{b}^{\text {bn }} & =\text { Linear "classical" critical buckling load } \\
P_{b}^{\text {allow }} & =\text { Allowable buckling load } \\
\alpha_{1} & =\text { Geometric imperfection-sensitivity reduction factor } \\
\alpha_{2} & =\text { Creep reduction factor } \\
\alpha_{3} & =\text { Reduction factor to account for cracking and amount and } \\
\alpha_{4} & =\text { type of reinforcement } \\
\alpha & \text { Reduction factor to account for material nonlinearity of } \\
S_{\mathrm{SF}} & =\text { Combined buckling load-reduction factor }=\alpha_{1} \alpha_{2} \alpha_{3} \alpha_{4} \\
& =\text { Buckling safety factor. }
\end{array}
$$

Computation of the "classical" buckling load as predicted by linear buckling theory for an ideal shell geometry assuming gross uncracked concrete is based conservatively on the end-of-life degraded concrete modulus. The following provides equations which may be used to determine the linear buckling load for the dome and the cylindrical wall of the tank.

\section{Dome Buckling - $P_{b}^{\text {in }}$}

In lieu of an eigenvalue buckling analysis that considers the changing curvature and wall thickness of the tank dome, a conservative calculation of the dome linear buckling load, $\boldsymbol{P}_{b}^{\text {th }}$, can be obtained by idealizing the dome as a clamped spherical cap. For uniform pressure, $\boldsymbol{P}_{b_{k}}^{\text {th }}$, can be obtained by conservatively applying the following equation for a clamped spherical cap under uniform pressure with a shallowness parameter, $\lambda$, of 4 (Zarghamee and Heger 1983):

$$
P_{b_{a}}^{\lim }=0.66 E\left(\frac{t}{R}\right)^{2}
$$

where

$\mathrm{E} \quad=$ Young's modulus for concrete $\left(\mathrm{lbf} / \mathrm{in}^{2}\right)$ 
t $\quad=$ Dome minimum wall thickness (in.)

$\mathbf{R} \quad=$ Dome maximum mid-wall radius of curvature (in.).

The shallowness parameter, $\lambda$, is given by

$$
\lambda=\left[12\left(1-v^{2}\right)\right]^{\frac{1}{4}}\left(\frac{R}{t}\right)^{\frac{1}{2}} 2 \sin \frac{\phi}{2}
$$

where

$$
\begin{aligned}
& v \quad=\text { Poisson's ratio for concrete }=0.15 \\
& \phi \quad=\text { Half the included angle of the spherical cap. }
\end{aligned}
$$

According to Baker et al. 1972, for spherical caps with clamped edges under a concentrated loading, theory indicates that buckling will not occur if the shallowness parameter, $\lambda$, is less than about 8 . For values of $\lambda$ between 8 and 9 , axisymmetric snap-through is the expected buckling mode, with the shell continuing to carry increasing load. For larger values of $\lambda$, asymmetrical buckling is expected to occur first, but again the shell will continue to carry load. Baker cites experimental results that indicate that collapse loads of clamped spherical caps loaded over a small area are conservatively estimated by the load determined from Figure 4.2.2.7-1 (Baker at al. 1972). For a

concentrated load at the dome apex, $\alpha_{1} P_{b_{c}}^{\text {in }}$, for Hanford USTs can be obtained by conservatively applying the following equation for a clamped spherical cap loaded over a small area with a shallowness parameter, $\lambda$, of 4 to 8 (Figure 4.2.2.7-1):

$$
\alpha_{1} P_{b_{c}}^{\operatorname{lin}}=\frac{28 \pi D}{R}
$$

where

$$
\begin{array}{ll}
\mathrm{D} & =\frac{E t^{3}}{12\left(1-v^{2}\right)}=\text { Flexural stiffness of concrete shell } \\
\mathrm{E} & =\text { Young's modulus for concrete }\left(\mathrm{lbf} / \mathrm{in}^{2}\right) \\
v & =\text { Poisson's ratio for concrete }=0.15 \\
\mathrm{t} & =\text { Dome minimum wall thickness (in.) } \\
\mathrm{R} & =\text { Dome maximum mid-wall radius of curvature (in.). }
\end{array}
$$

The value of $a_{1} P_{b_{c}}^{\text {lin }}$, determined from Figure 4.2.2.7-1, is based on experimental determinations that are considered to include the effects of the geometric-imperfection factor $\alpha_{1}$. Baker's emphasis on the ability of the spherical cap under concentrated load to carry increasing load in the postbuckling regime is noteworthy with respect to establishing an appropriate safety factor as discussed under Safety Factors section below and in Section 8.0. 


\section{Cvlindrical Wall Buckling - $P_{b}^{l i n}$}

The linear buckling load for axial compression in the tank cylindrical wall, $P_{b_{c}}^{\text {lin }}$, is derived from the equation for the critical buckling stress presented by Seide (1981):

$$
\sigma_{b_{c}}=\frac{1}{\sqrt{3\left(1-v^{2}\right)}} E\left(\frac{t}{R}\right)
$$

which is transformed to the corresponding total dome load

$$
P_{b_{c}}^{l i n}=2 \pi R t \sigma_{b_{c}}^{\text {bin }}=\frac{2 \pi}{\sqrt{3\left(1-v^{2}\right)}} E t^{2}
$$

where

$$
\begin{array}{ll}
\mathbf{E} & =\text { Young's modulus for concrete }\left(\mathrm{bf} / \mathrm{in}^{2}\right) \\
\mathbf{v} & =\text { Poisson's ratio for concrete }=0.15 \\
\mathbf{t} & =\text { Tank cylinder minimum wall thickness (in.) } \\
\mathbf{R} & =\text { Tank cylinder mid-wall radius of curvature (in.) }
\end{array}
$$

The linear buckling load for external uniform lateral pressure on the tank cylindrical wall, $\boldsymbol{P}_{\boldsymbol{b}_{\boldsymbol{L}}}^{\mathrm{lin}_{\mathrm{h}}}$, is determined from the equation given by Timoshenko and Gere (1961) for a simply supported cylinder under uniform lateral pressure,

$$
\begin{aligned}
P_{b_{L}}^{b n}= & \frac{E}{1-v^{2}}\left(\frac{t}{R}\right) \frac{1-v^{2}}{\left(n^{2}-1\right)\left(1+n^{2} L^{2} / \pi^{2} R^{2}\right)^{2}} \\
& +\frac{E}{1-v^{2}} \frac{t^{3}}{12 R^{3}}\left(n^{2}-1+\frac{2 n^{2}-1-v}{1+n^{2} L^{2} / \pi^{2} R^{2}}\right)
\end{aligned}
$$

where

$\mathrm{E} \quad=$ Young's modulus for concrete $\left(\mathrm{lbf} / \mathrm{in}^{2}\right)$

$\nu \quad=$ Poisson's ratio for concrete $=0.15$

$\mathrm{t} \quad=$ Tank cylinder minimum wall thickness (in.)

R = Tank cylinder mid-wall radius of curvature (in.)

$\mathrm{L} \quad=$ Tank cylinder length (in.); taken as the actual cylinder length when the cylinder can be treated as simply supported; taken as twice the actual cylinder length when free conditions are taken at the lower boundary 
$=$ Positive integer, which corresponds to the number of circumferential waves into which the shell buckles, selected to minimize the lateral buckling pressure $\boldsymbol{P}_{\boldsymbol{b}_{\boldsymbol{L}}}^{\text {lin }}$.

Whereas the linear buckling load for external lateral pressure is determined for a uniform distribution along the length of the cylindrical wall, the actual distribution of pressure is linearly varying from a minimum value at the top to a maximum value at the base of the wall. Seide (1979) identifies theoretical results for a pressure distribution that varies linearly in the longitudinal direction. The critical equivalent uniform pressure is found to be the length average of the positive pressure distribution. If the lateral pressure is entirely positive along the full length of the cylinder, this corresponds to the average lateral pressure.

\section{Buckling Load-Reduction Factors}

The buckling load-reduction factor, $\alpha_{1}$, accounts for the imperfection sensitivity (i.e., deviation between the actual and theoretical shell geometry) of the structure. Seide (1981) develops a lowerbound correlation equation as a function of radius-to-thickness ratio $(R / t)$ based on experimental buckling data for axially loaded cylindrical shells. The use of this lower-bound correlation is appropriate when imperfections are unknown. Experimental values presented for axially compressed cylindrical shells, while exhibiting considerable scatter, indicate that the discrepancy between theory and experiment tends to increase as the $\mathrm{R} / \mathrm{t}$ of the shell increases. Seide attributes this phenomenon to decreased bending stiffness of the relatively thinner shells, which renders them more susceptible to imperfections during construction. Seide presents the following conservative design formula as a lower-bound representation of the experimental data:

$$
\alpha_{1}=1-0.9\left(1-e^{-\frac{1}{16} \sqrt{\frac{R}{t}}}\right)
$$

for cylinders with $100<R / t<3,000$ and $0.5<L / R<5$ where $L$ is the length of the cylinder. The applicability of knockdown factors developed for axially compressed cylinders to the dome under radial pressure is recognized by Popov and Medwadowski in their account of the IASS recommendations, wherein they state that if no solution is available for shells of a given geometry and load, the curves applicable to an axially compressed cylinder and a spherical cap should be used.

The upper-bound $\mathrm{R} / \mathrm{t}$ for the typical Hanford UST dome is 84 . Hence, conservatively taking $R / t=100, \alpha_{1}$ is calculated to be 0.58 . The $R / t$ for the Hanford UST cylindrical wall is 37 . Therefore, a calculated value for $\alpha_{1}$ of 0.58 is also a conservative lower bound for the wall under axial compression. A conservative value for $\alpha_{1}$ applicable to the wall under external lateral pressure is based on Seide's (1981) recommendation of 0.75 .

The buckling load-reduction factor, $\alpha_{2}$, is due to creep and is defined as $\mathrm{E}_{\mathrm{c} 2} / \mathrm{E}_{\mathrm{c}}$ where $\mathrm{E}_{\mathrm{c}}$ is the initial concrete modulus at the time of first loading and $E_{c 2}=E_{c} /\left(1+C_{v}\right)$ is the reduced concrete modulus resulting from creep. The ultimate creep coefficient for the concrete, $\mathrm{C}_{\mathrm{u}}$, is defined as the ratio of the ultimate creep strain to the initial elastic strain. In spite of the fact that for short-term loads such as live loads, the effect of creep is considered to be insignificant, $\alpha_{2}$ as determined above is applied conservatively to all loads being addressed during a particular service period of the tank. 
The values of $\mathrm{C}_{\mathrm{a}}$ should be based on a creep analysis of the structure. The creep analysis should use an upper-bound thermal history.

The buckling load-reduction factor, $\alpha_{3}$, is applied to account for the effect of cracking and the amount and type of reinforcement. Following the IASS procedure cited in SP-67, $n=E_{3} / E_{\infty 2}$ where $E_{a}$ is the modulus of elasticity of the steel reinforcement and $E_{\mathfrak{Q} 2}$ is the reduced concrete modulus caused by creep computed as before, except that a conservative initial concrete modulus corresponding to the end-of-life degraded concrete is applied. The steel ratio $\rho=A_{s} / A_{c}$ is determined, where $A_{s}$ is the total steel area per unit width of shell in one direction and $A_{c}$ is the concrete area. The product $n \rho$ is used to determine a $\Psi$ factor from Figure 4.2.2.7-2 (Scordelis 1981, p. 100). From Figure 4.2.2.7-3 (Scordelis 1981), a value of $w_{0} / h$ is selected that corresponds to $\alpha_{1}$. Finally, $\alpha_{3}$ is determined from Figure 4.2.2.7-4 (Scordelis 1981) as a function of $w_{0} / h$.

The buckling load-reduction factor, $\alpha_{4}$, is associated with material nonlinearity of the concrete under high stresses. The $\alpha_{4}$ is determined from the semi-quadratic interaction equation (Scordelis 1981):

$$
\left(\frac{P_{b}^{r e d}}{P_{u k}}\right)^{2}+\left(\frac{P_{b}^{r e d}}{P_{3}}\right)=1
$$

or

$$
\alpha_{4}^{2}\left(\frac{P_{3}}{P_{u t}}\right)^{2}+\alpha_{4}=1
$$

where

$$
\begin{aligned}
& P_{3}= \alpha_{1} \alpha_{2} \alpha_{3} P_{b}^{l m} \\
& P_{\text {ult }}= \text { Ultimate externally applied load that the shell can carry as } \\
& \text { governed by the ultimate strength of the reinforced concrete } \\
& \text { shell section, independent of any buckling consideration. }
\end{aligned}
$$

$\boldsymbol{P}_{\text {uk, }}$ for the UST dome under uniform pressure may be based on predictions from the collapse-load analysis for a uniform load applied at the soil surface.

$\boldsymbol{P}_{\boldsymbol{m b}}$ for the UST dome under concentrated loading is based on predictions from the collapse-load analysis for loads applied at the soil surface over a local region about the center of the tank.

$\boldsymbol{P}_{u b_{a}}$ for the UST cylindrical wall under axial compressive loading is computed based on obtaining a uniform circumferential compressive stress equal to the predicted degraded concrete compressive strength of the cylindrical wall at the end of its service. 
$\boldsymbol{P}_{u_{h_{L}}}$ for the cylindrical wall under uniform external lateral pressure is computed based on obtaining a uniform circumferential compressive stress equal to the predicted degraded concrete compressive strength of the cylindrical wall at the end of its service.

4.2.2.8 Code Evaluation for Impact Loads. Impact loads on the tank structure shall be evaluated in accordance with Appendix C of ACI 349-90 and Chapter 6 of ASCE Manual 58 (ASCE 1980).

\subsubsection{Insulating Slab - Code}

The insulating concrete slab is not considered a structural member. The only code evaluation that is necessary for this member is for bearing stress. In accordance with ACI 349-90 the allowable bearing stress is calculated as:

$$
\sigma_{\text {bearing }}=\phi 0.85 f_{c}^{\prime} A
$$

where $A$ is the contact area.

\subsection{ALTERNATE TECHNIQUES FOR MEETING ACI CODE REQUIREMIENTS FOR COMBINED FLEXURE AND AXIAL LOAD}

The Hanford waste tanks have, in many respects, a structural behavior that is analogous to that of both beams and slabs. The meridional response, especially in the haunch region, is similar to that of a frame. The mid-dome and wall regions respond in a biaxial fashion analogous to a two-way slab. For these reasons, Sections 10 and 11 of ACI 349-90 are the basis for code protection against flexure and axial load, in-plane shear, transverse shear, and twisting shear. These sections have traditionally relied on the response predicted by linear elastic analysis. However, for the Hanford waste tanks the most applicable section of the ACI $349-90$ code is Section 19, Shells and Folded Plate Members. Section 19 of ACI 349-90 also refers to Section 19 of ACI 318 . These sections do not provide the specific strength evaluation procedures as outlined in Sections 10 and 11, but imply that these sections need to be satisfied in addition to the requirements of Section 19.

Section 19 is the most explicit section on the need for and acceptance of inelastic (nonlinear) analysis. Inelastic analysis is endorsed because it provides a means of tracing the response and crack propagation of a reinforce-concrete shell through the elastic, inelastic and ultimate load ranges. Further, it provides a method of achieving the code's provisions by allowing for the possibility of load redistribution associated with the nonlinear behavior of reinforced concrete structures.

The concept of load redistribution from cracking and the development of plastic moments is one of the primary benefits of performing a limit analysis. Limit analysis is most beneficial when sufficient redundancy exists in the structure. Redundancy will occur naturally in a design that is required to accommodate a number of different load patterns. Hence, the design is less apt to reach a limit state at several locations simultaneously. Although there are no specific provisions in ACI 349-90 that give guidance for the application of yield-line theory, it is common practice in twoway slab design and is offered as an acceptable design method in the Section 13.3.1 of the ACl 349-90 commentary. 
The purpose of limit analysis is to determine the loads that cause structural instability (collapse). In a frame structure this is nominally accomplished by the incremental application of a load that causes the frame to develop a sufficient number of plastic hinges to form a mechanism. Both the yield-line method for slabs, and the formation of plastic hinges for frames can be performed manually. A computational collapse analysis, performed with an appropriate reinforced-concrete constitutive model, can provide the same if not better design information than is available by limit analysis or yield-line analysis. The primary advantage of a computational collapse analysis is the ability to account for the effects of multidimensional response, large deformation, load history, and thermal degradation. Structures that benefit most from collapse analysis are those that have redundant load paths. The Hanford waste tanks offer levels of redundancy in consideration of their biaxial behavior in the outer dome region, haunch, and upper wall where loads can be sustained by meridional flexure strength, hoop tensile strength, or both.

\subsubsection{Factored Limit-Analysis for Flexure and Axial Load Code Evaluation}

The provisions of the $\mathrm{ACl}$ code provide conservatism in a number of ways. In addition to the implied safety factors manifested in the load factors and strength reduction factors, the code requires intentional limits on the strength of reinforced concrete sections. It is understood that analytical models used to predict section demands will be capable of predicting demands that exceed those allowed by the ACl code. The simplest example of this is the prediction of demands on the basis of a linear elastic model. Clearly, this model will be capable of predicting demands that exceed the code limits.

In flexure, for example, the $\mathrm{ACI}$ code determines the ultimate strength of a reinforced concrete section on the basis of the following conservative stress state approximations:

Reinforcement is treated as elastic perfectly plastic.

Sections are treated as orthotopic.

Maximum compressive stress does not exceed $0.85 \mathrm{f}_{\mathrm{c}}$ to account for the difference in the rate of load application between the test cylinders and real structures.

Strength reduction factors are applied to reduce the section capacity.

If flexure and axial load demands are greater than capacities as described in Section 4.2.2.1, a more consistent code-based approach is to model the structure in a way that does not permit the structural elements from sustaining more load than the code allows.

\section{Code Softening Approach}

One way to accomplish consistency between the analysis approximations and the code approximations is to specify material behavior that represents the codes prescribed stress state approximations. Reinforcement can be specified as elastic perfectly plastic. The specified compressive strength can be reduced by the product of 0.85 and the appropriate strength reduction factor. A computational model, with appropriate reinforced-concrete constitutive relations, would 
then be subjected to the full spectrum of factored loads. The results of such an analysis would be incapable of sustaining greater loads than the code allows.

The ACI code evaluation for flexure and axial load would then comprise a check of the maximum outside-fiber compressive strain. The structure meets the intent of the code if the maximum outside-fiber compressive strain is less than $0.003 \mathrm{in}$./in. The maximum bending strain of $0.003 \mathrm{in}$./in. is based on the ultimate strength design methodology which requires the maximum strain to coexist with the other stress state approximations discussed previously.

As an example in steel structures, in the limit analysis as prescribed by the ASME B\&PV Code, several acceptable methods are described as alternatives to meeting the stress limits by linear analysis. One of these methods requires that the analysis model behave elastic-perfectly plastic at a yield strength of $2 / 3 S_{y}$. This modeling approach clearly results in a softening of the structural response thereby allowing load redistribution to take place at lower loads than with best-estimate material properties.

An international handbook on limit analysis for reinforced concrete structures (Ghanekar and Jain 1990) provides even more specific endorsement of the code softening approach. For flexure and axial load, the handbook suggests that the stress-strain behavior of concrete be redefined such that the maximum compressive strength, $\mathbf{f}_{c}$, is reduced by a strength reduction factor and a load factor. This reduced maximum compressive stress is assumed to occur at a strain of $\mathbf{0 . 0 0 2}$ and remain perfectly plastic to a strain of $\mathbf{0 . 0 0 3 5}$. This example of code softening is even more dramatic than the method proposed herein because of load factor inclusion in the artificial strength reduction.

Unlike structural steel, concrete is a strain softening material. Concrete exhibits a distinct maximum compressive stress after which the stress decreases gradually with increasing strain. When a concrete cylinder is tested in a load controlled testing machine, the cylinder will fail at this maximum stress. However, when a displacement controlled machine is used, the specimen can sustain a stress as much as one-quarter of its maximum at strains as much as eight times that at maximum stress. While the internal failure mechanism of concrete may be brittle on a micro-scale, it is not brittle on a macro-scale (Barnard 1964). At large compressive strains a certain amount of cracking will develop. However, even the slightest confinement offered by a real structure will mitigate spalling.

\section{Auremented Logd Factor Approgch}

Another way of accomplishing consistency between analysis approximations and code assumptions is to consider the $\mathbf{0 . 8 5}$ and strength reduction factors as inverted safety factors. The inverse of these factors can be used to augment the load factors. For a number of years, the ACI Code did not separate the safety factors that are applied to loads and those that are applied to capacities. The application of these augmented load factors to a model that represents the bestestimate concrete properties will result in demands that are consistent with the Code's state of stress assumptions without the approximations previously mentioned. Because it is not clear how to augment the load factors to address reinforcement strain hardening, the reinforcement should be modeled as elastic perfectly plastic. This method is more appealing than the code softening method because the response is essentially a best-estimate response, there is no artificial softening, and it treats all of the various forms of safety factors in a consistent manner (applied to loads). 
Again, the ACI Code evaluation for flexure and axial load would then comprise a check of the maximum outside-fiber compressive strain. The structure meets the intent of the ACI Code if the maximum outside-fiber compressive strain is less than $0.003 \mathrm{in}$./in. While the code softening approach can be used on an element-by-element basis or on the entire structure, the augmented load factor approach can only be applied to the entire model.

In shear, the ACI Code's ultimate strength based requirements are more empirical than for flexure and less attributable to stress state approximations. Therefore, no attempt is made herein to identify physical assumptions and modeling approximations that would provide consistency between modeled limit states and Code limit states.

\subsubsection{Step-Wise Limit Analysis to Demonstrate Structural Redundancy}

If the codes capacities of Section 4.2.2 are exceeded for demands at a given location of the structure, that structure cannot be said to be code qualified. However, if it can be shown that the locations that have excessive demands need not be relied upon by the remaining structure to meet the Code limits, then the structure as a whole can be said to be sufficiently redundant to meet the intent of the Code. Redundancy can be tested by removing those areas of the structure (or reducing their stiffness dramatically), in which the demand exceeds that permissible by the Code. Recheck the remaining structure for code compliance in the usual way to determine whether the remaining structure can sustain the loads. It is possible that as local areas are removed or softened, other areas which passed the code evaluation previously, now do not. These local areas would have to be removed and the process repeated in a step-wise manner until the remaining structure is shown to be sufficient to carry the applied loads or in fact is not sufficient.

A practical application to underground tanks is a slab-footing shear failure. Depending on the soil stiffness, the basemat slab demand may exceed the ACI Code limit. The footing will likely have the capacity to carry the entire load without the slab. The slab would still need to carry the load applied directly to it but not that imposed by settling of the footing. This configuration is analogous to a construction joint separating the slab from the footing. Assuming a slab shear failure at the footing would however require investigating the effects of the discontinuous support on the secondary liner. It may be that subsequent nonstructural failures, such as leaking, cannot be ruled out but the stability of the structure may still be maintained.

\subsection{PRIMARY TANK - STRAIN LIMIT FAILURE CRITERION ${ }^{5}$}

The methodology described herein is directed at determining the "best-estimate" failure load of the structure under extreme loading conditions. Best-estimate material properties are used. A strain limit criterion is provided for the evaluation of extreme accident load conditions, such as in the deflagration of flammable gases within the primary tank.

The strain limit failure criterion presented herein was developed to predict the failure loading on the primary steel tank. The failure mode is associated with plastic failure produced by the primary plastic strains which produce gross structural distortions or peak plastic strains that do not produce significant distortions. The acceptance criterion for plastic failure is based on a combination of two

'This section extracted in part from WSRC 1994. 
methods; the first was developed by Miller 1990 for steel tank rupture, and the second was developed by Connelly (Davis and Connelly 1959) and Manjoine 1975 for ductility reduction due to triaxial loading conditions. Because the Miller, Connelly and Manjoine criteria produce the strain limit for failure, a section is included on factor of safety to address the specific safety function and loading frequency of the component. The combined failure criterion is expressed as:

$$
\epsilon_{c} \leq \frac{\epsilon_{u}}{R F_{T}}
$$

where

$$
\begin{aligned}
& \epsilon_{\mathrm{c}} \quad=\text { Maximum calculated von Mises equivalent membrane strain } \\
& \epsilon_{\mathrm{u}} \quad=\text { Maximum uniform strain from uniaxial test data } \\
& \mathbf{K} \quad=\mathbf{K}_{1} \mathbf{K}_{2} \mathbf{K}_{3} \text { : Combined knockdown factor } \\
& \mathbf{K}_{1}=\text { Knockdown factor for analysis sophistication } \\
& \mathbf{K}_{2} \quad=\text { Knockdown factor for as-built configuration } \\
& \mathrm{K}_{3} \quad=\text { Knockdown factor for material considerations } \\
& \mathrm{F}_{\mathrm{T}} \quad=\text { Triaxial ductility reduction factor. }
\end{aligned}
$$

\section{Knockdown Factor Ouantification}

Knockdown factors to account for strains which are not calculated by the finite-element method (FEM) or for conditions which reduce the material strain at failure can be quantified as shown below. An example of a condition which produces $\mathbf{a} \mathbf{K}_{1}$ knockdown factor is a local structural discontinuity that is not included in the FEM; such as, penetrations, liner-stud interaction, or liner thickness transition. An example of a condition which produces a $\mathrm{K}_{2}$ knockdown is the ductility reduction produced by postweld heat treatment of components which have significant cold work fabrication strains. Because these two conditions affect different parameters, the equations which produce the values of the knockdown factors are different.

Quantification of the $\mathrm{K}_{1}$ factor for strain which is not included in the FEM is based on the calculated strain value $\left(\epsilon_{\mathrm{c}}\right)$ and the increase in strain produced by the local effect $\left(\epsilon_{\mathrm{p}}\right)$ as shown in the following equation:

$$
K_{1}=\frac{\epsilon_{c}+\epsilon_{p z}}{\epsilon_{c}}=\frac{\epsilon_{\text {peat }}}{\epsilon_{\text {global }}}
$$

where

$$
\begin{aligned}
& \mathbf{K}_{1}=\text { Knockdown factor for FEM sophistication } \\
& \epsilon_{\mathrm{c}} \quad=\text { Maximum calculated equivalent membrane strain }\left(=\epsilon_{\mathrm{gibaa}}\right) \\
& \epsilon_{\mathrm{pl}} \quad=\text { Local peak membrane strain increment } \\
& \epsilon_{\mathrm{peak}} \quad=\text { Local peak membrane strain }\left(=\epsilon_{\mathrm{c}}+\epsilon_{\mathrm{p}}\right) .
\end{aligned}
$$

When the combined knockdown factor $(K)$ is divided into the uniform strain limit $\epsilon_{2}$ to calculate the allowable strain limit, the uniform strain will be reduced by the ratio of the maximum local strain over the FEM calculated strain. 
Quantification of the $\mathrm{K}_{2}$ factor for ductility reduction produced by postweld heat treatment of components which have significant cold work fabrication strains is based upon the ratio of the reduction in strain $\left(\epsilon_{1}\right)$ from the uniaxial tensile test data as shown in the following equation.

$$
K_{2}=\frac{\epsilon_{u}}{\epsilon_{u}-\epsilon_{r}}
$$

where

$\mathrm{K}_{2} \quad=$ Knockdown factor for as-built configuration

$\epsilon_{\mathrm{u}} \quad=$ Uniform strain from uniaxial test data

$\epsilon_{\mathrm{T}} \quad=$ Ductility reduction due to post weld heat treatment.

When the combined knockdown factor $(\mathbf{K})$ is divided into the uniform strain limit to calculate allowable strain limit, the uniform strain will be reduced by the amount of strain that the strain at failure is reduced. Because some knockdown factors are local, there will be different values for the knockdown factor at different locations.

\section{Analrsis Sophistication Knockdown Factor $\left(\mathbf{K}_{1}\right)$}

The $K_{1}$ knockdown factor is developed to account for the level of sophistication of the FEM. This is done by identifying the detail and completeness of the geometry, element refinement, appropriateness of boundary conditions, and other assumptions made or implied in the FEM. Any differences between the FEM and the actual geometry are quantified and related to the calculated strain to produce the value for $K_{1}$. The $K_{1}$ knockdown factor varies with location in the FEM and is typically a function of the magnitude of the global strain near the local region of interest. The determination of $K_{1}$ typically requires a detailed local-effects analysis of the local discontinuity of interest.

\section{As-Built Confifouration Knockdown Factor $\left(\mathrm{K}_{2}\right)$}

The as-built configuration knockdown factor $\left(\mathrm{K}_{2}\right)$ is based on the difference between the structural information available to the analyst and actual construction configuration. In order to quantify the value for $\mathrm{K}_{2}$, the important parameters related to the knockdown factor are evaluated by using the original design drawings as the basis. The parameters that contribute to the value of the knockdown factor are:

\footnotetext{
Materials used in construction

Weld quality

$\neg \quad$ Fabrication tolerances

Post weld heat treat

Fabrication residual stresses

- Fabrication details

- Plate thickness and thickness transitions.
}

The evaluation of these parameters is based on information form the Quality Assurance (QA) records prepared during construction. Any structural deviation from the original design configuration is either included in the FEM or quantified and include in the $\mathrm{K}_{2}$ factor. The range of the knockdown factor, $\mathrm{K}_{2}$, is from 1 to 1.25 . This range applies to structures constructed to the ASME code rules. 


\section{Material Considerations Knockdown Factor $\left(\mathbf{K}_{\mathbf{a}} \mathbf{l}\right.$}

The material considerations knockdown factor $\left(\mathbf{K}_{3}\right)$ is based on the effect that material property variations and degradation have on the strain at failure and the structural loading of the component. Parameters that contribute to the value of the knockdown factor include:

r. Material property variations

Corrosion, pitting and cracking

$r$ Aging

r Hydrogen embrittlement

$r \quad$ Radiation damage.

The range of knockdown factor that accounts for variations in material properties is from 0.85 to 1.15 where 1.0 represents the mean (best estimate) value of material properties.

\section{Multiaxial Strain Duttility Reduction Factor $\left(\mathbf{E}_{\mathrm{T}} \mathbf{2}\right.$}

The ductility reduction in the material, or decrease in the strain level at failure, due to multiaxial loading effects is addressed by using the triaxiality factor approach. The triaxiality factor $\left(\mathrm{F}_{\mathrm{T}}\right)$ was originally proposed by Davis and Connelly (1959), and is written as

$$
F_{T}=\frac{\sqrt{2\left(\sigma_{1}+\sigma_{2}+\sigma_{3}\right)}}{\sqrt{\left(\sigma_{1}-\sigma_{2}\right)^{2}+\left(\sigma_{2}-\sigma_{3}\right)^{2}+\left(\sigma_{3}-\sigma_{1}\right)^{2}}}
$$

where

$$
\begin{aligned}
& F_{\mathrm{T}}=\text { Triaxiality factor } \\
& \sigma_{\mathrm{i}}=\text { Principal stresses }(\mathrm{i}=1,2,3) .
\end{aligned}
$$

It has been empirically determined by Manjoine (1975) that the maximum principal strain at failure under the multiaxial load divided by the triaxiality factor, as shown below.

$$
\epsilon_{f}=\frac{\epsilon_{u}}{F_{T}}
$$

where

$$
\begin{array}{ll}
\epsilon_{\mathrm{f}} & =\text { Equivalent strain at failure for multiaxial loading } \\
\epsilon_{\mathfrak{u}} & =\text { Maximum uniform strain for uniaxial loading. }
\end{array}
$$

It is noted that for a uniaxial tensile test, the $F_{T}$ is unity and the failure strain is equal to the maximum uniform strain from the test. However, this method will over predict the failure strain for small values of $\mathrm{F}_{\mathrm{T}}$. For example, the $\mathrm{F}_{\mathrm{T}}$ is zero for a torsion test $\left(\sigma_{1}=\tau / 2\right.$ and $\left.\sigma_{2}=-\tau / 2\right)$, and the 
method predicts infinite failure strain. To ensure a reasonable limiting value, Manjoine (1982) proposed the following formulation.

$$
\epsilon_{j}=\epsilon_{u}\left(2^{1-F_{\tau}}\right)
$$

In addition, Manjoine (1982) proposed the use of the minimum strain limit from two preceding equations, as shown below

$$
\epsilon_{f}=\min \left[\frac{\epsilon_{u}}{F_{T}}, \epsilon_{u}\left(2^{1-F_{r}}\right)\right]
$$

To combine these equations into one which produces the correct triaxiality factor for use with the previously developed knockdown factors, Equation $4.4-7$ is rearranged as follows:

$$
F_{T}=\max \left[F_{T}, \frac{1}{2^{1-F_{T}}}\right]
$$


Figure 4.2.2.1-1. Typical Concrete Interaction Diagram for Bending-Plus-Axial Load.

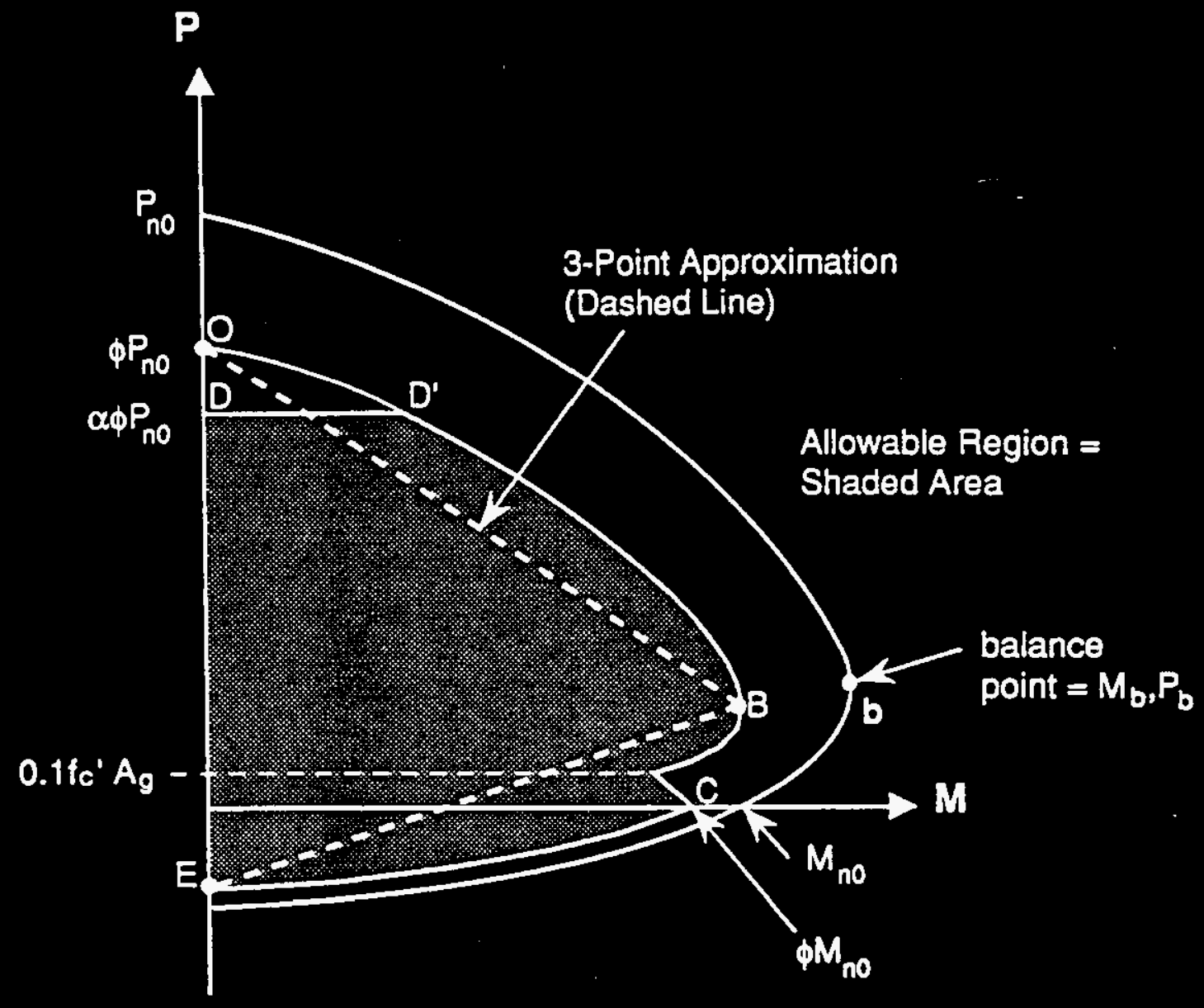


Figure 4.2.2.1-2. Balanced Condition for Reinforced Concrete Section.

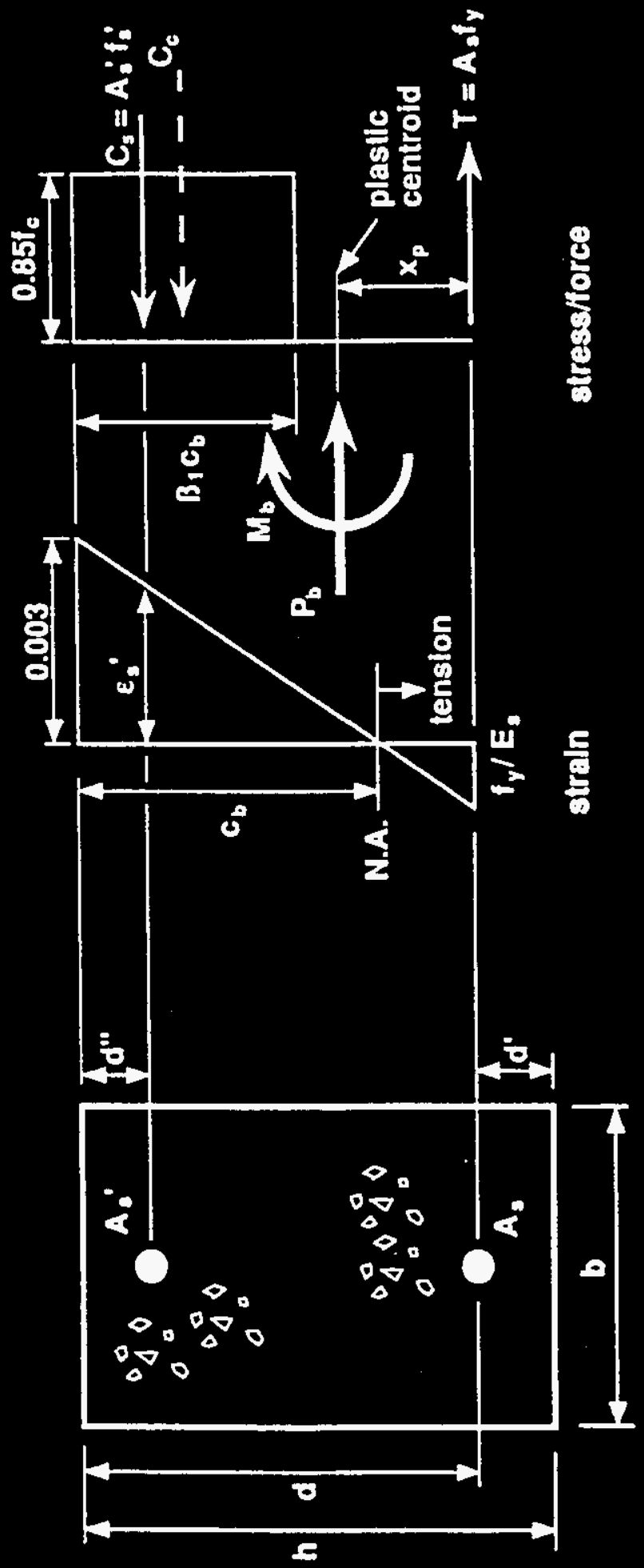


Figure 4.2.2.1-3. Force Balance for Axial Compression without Bending in Reinforced Concrete Section.

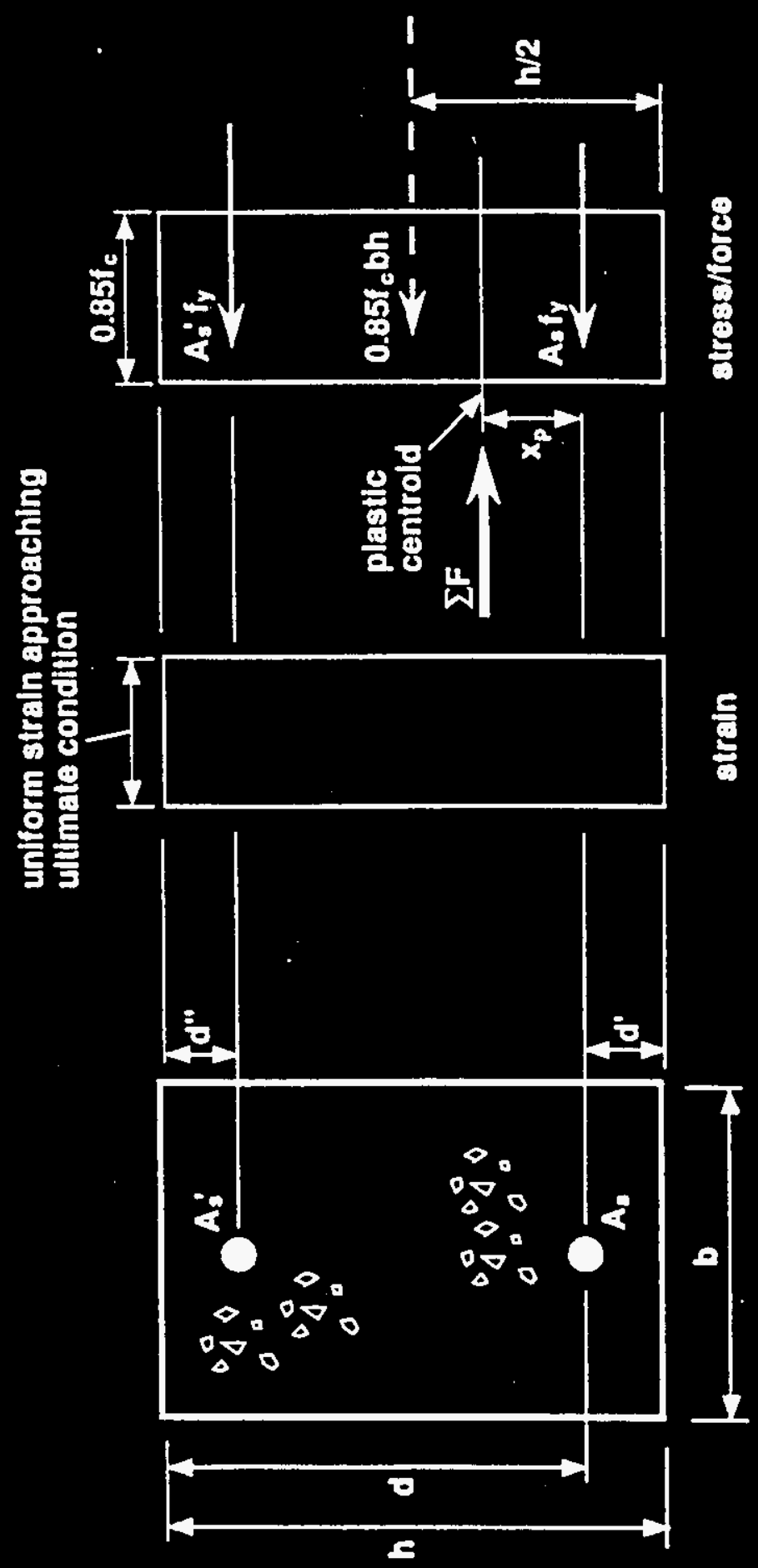


Figure 4.2.2.2-1. Theory of Splitting Bond Failure of Rebar - Failure Surfaces (Ferguson 1988).

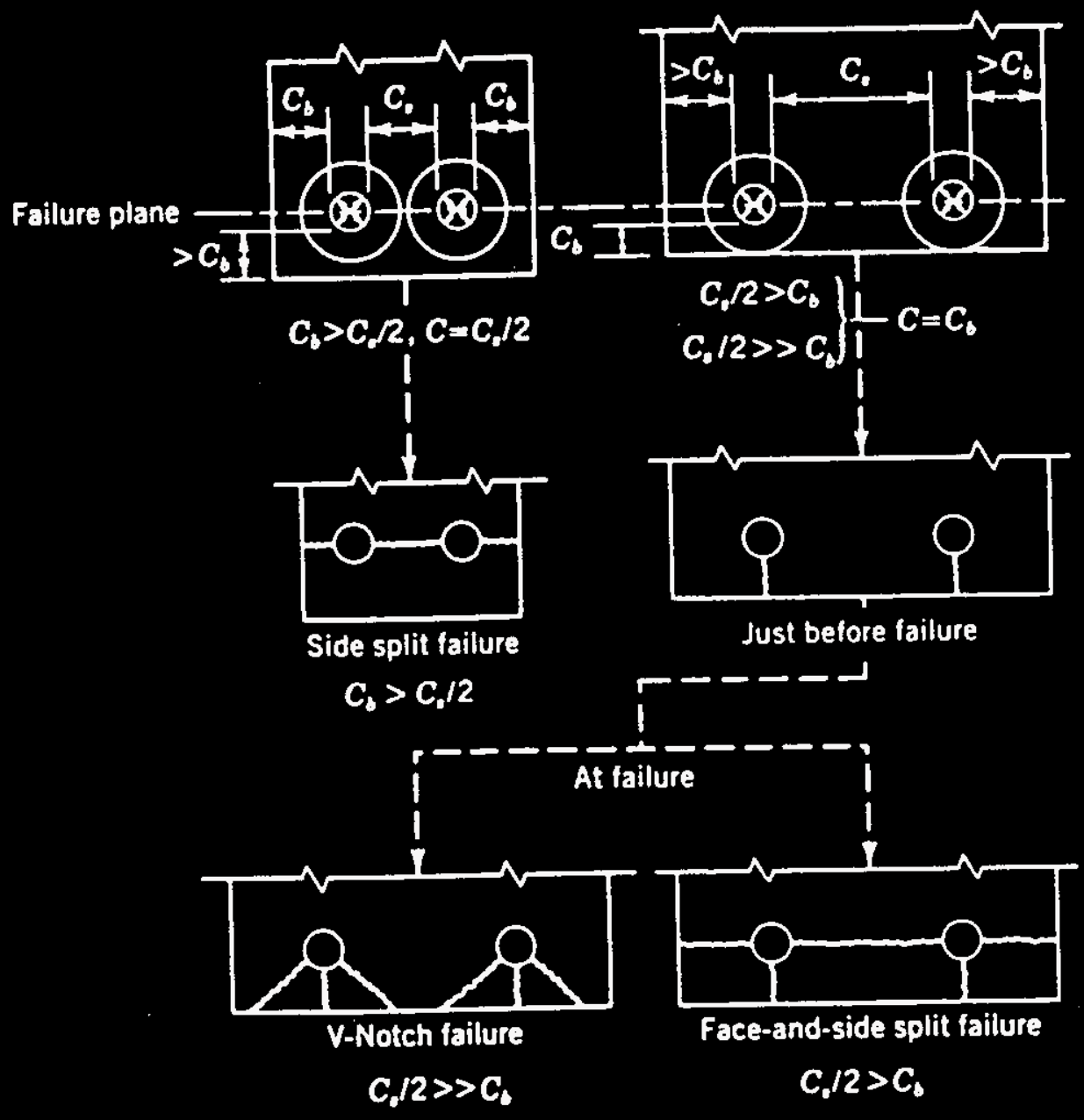


Figure 4.2.2.7-1. Theoretical Buckling Loads for Clamped Spherical Cap Under Concentrated Load (Figure 10-34 of Baker et al. 1972).

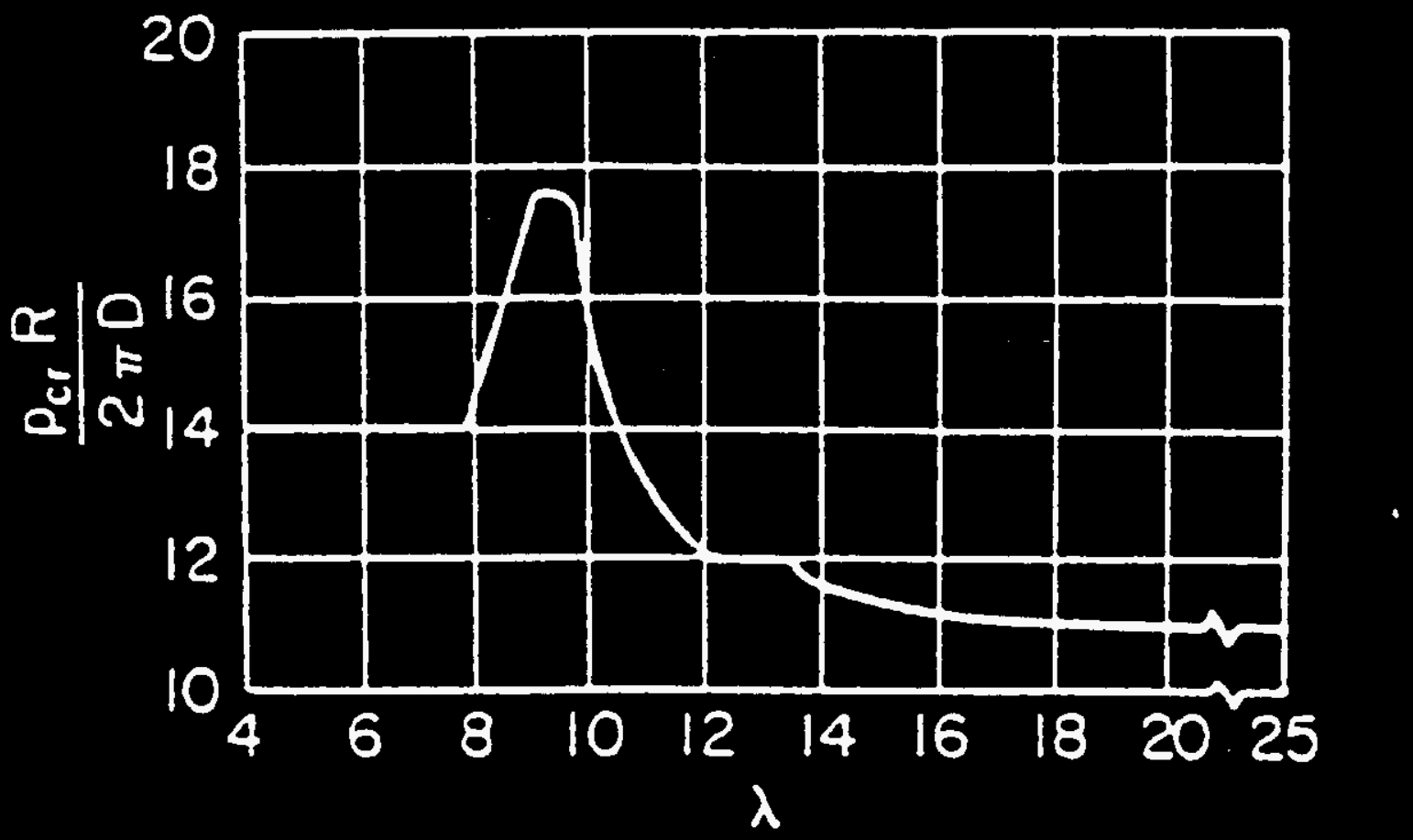


Figure 4.2.2.7-2. Values of $\psi$ for Effect of Concrete Cracking and Amounts and Type of Reinforcement (Figure 4 of Scordelis 1981).

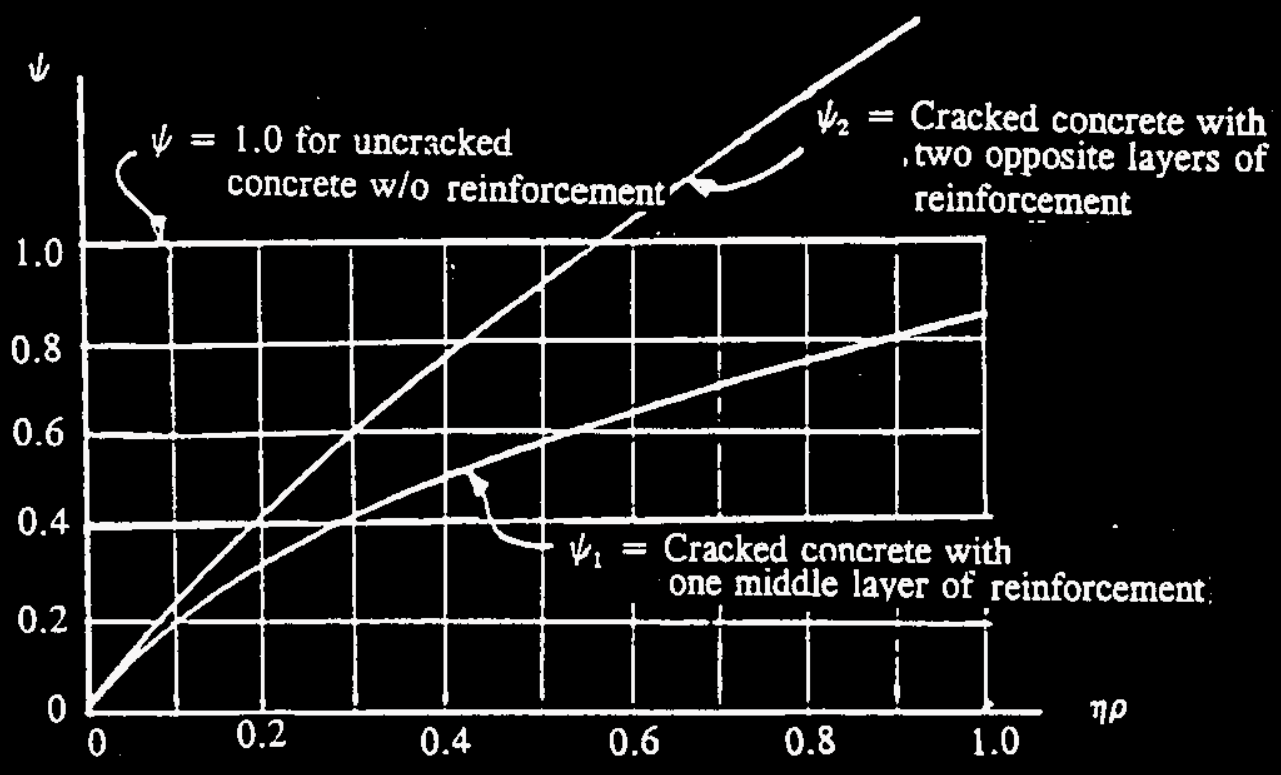


Figure 4.2.2.7-3. Effect of Geometric Imperfections on Buckling Load (Figure 3 of Scordelis 1981).

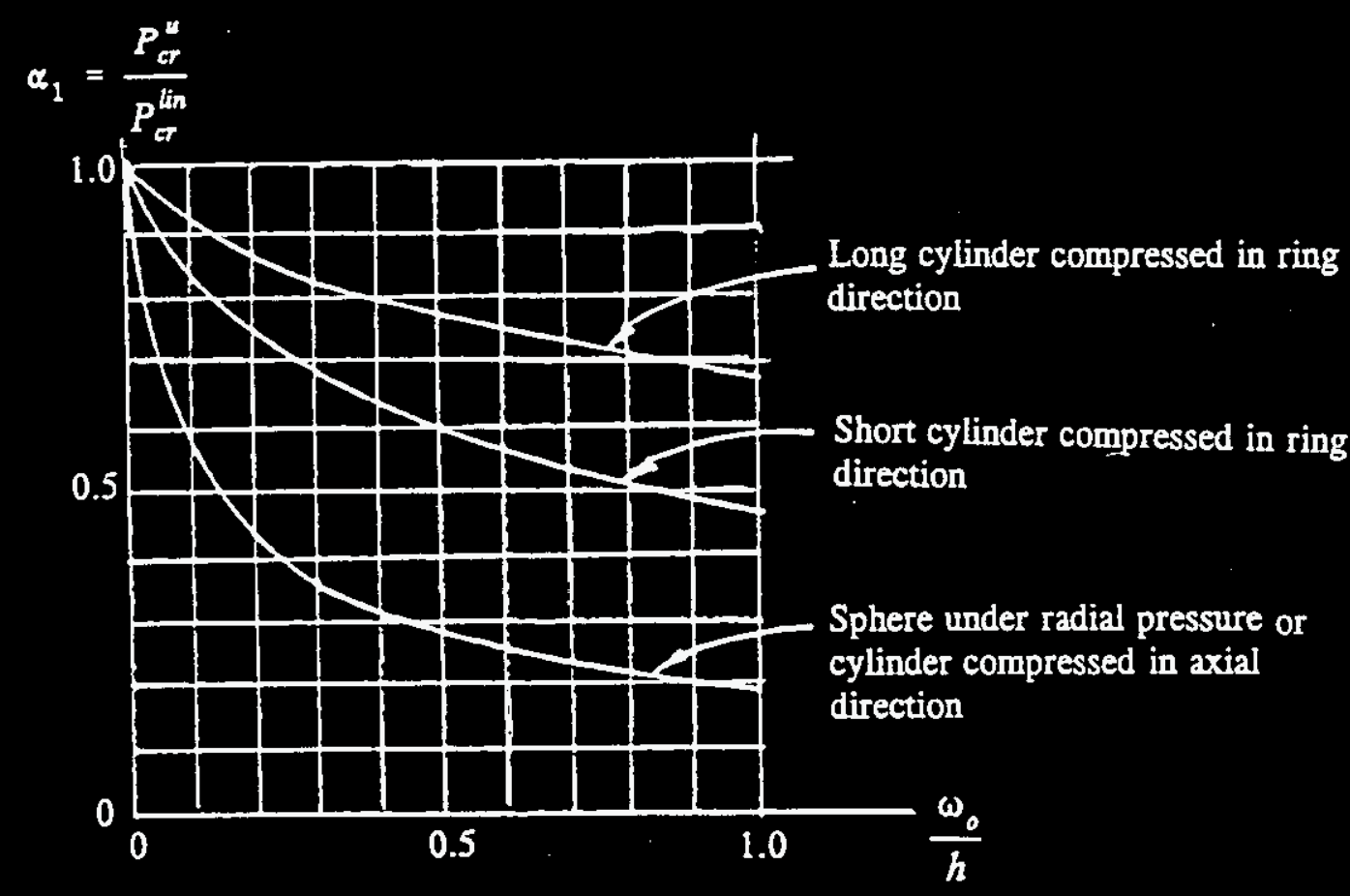


Figure 4.2.2.7-4. Reduction Factor $\alpha_{3}$ for Concrete Cracking and Amounts and Type of Reinforcement (Figure 5 of Scordelis 1981).

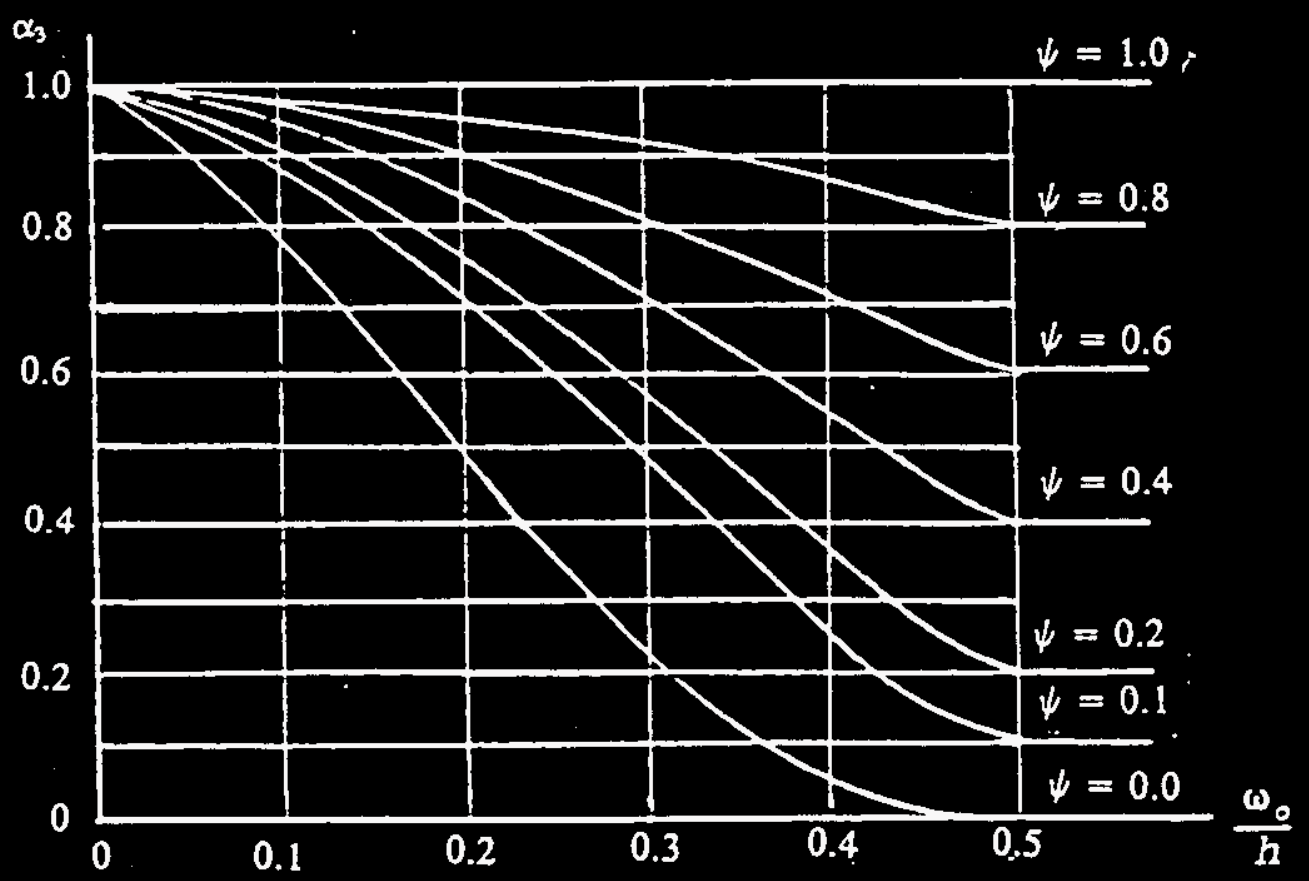


Table 4.1.1-1. Stress Intensity Classification.

\begin{tabular}{|c|c|c|c|c|}
\hline Vessel Component & Location & Origin of Stress & Type of Stress & Classification \\
\hline \multirow[t]{3}{*}{$\begin{array}{l}\text { Cylindrical or } \\
\text { Spherical Shell }\end{array}$} & \multirow[t]{2}{*}{$\begin{array}{l}\text { Shell plate remote } \\
\text { from discontimuity }\end{array}$} & Internal Pressure & $\begin{array}{l}\text { General Membrane } \\
\text { Gradient through plate } \\
\text { thickness }\end{array}$ & $\begin{array}{l}\mathbf{P}_{\mathbf{m}} \\
\mathbf{Q}\end{array}$ \\
\hline & & $\begin{array}{l}\text { Axial Thermal } \\
\text { Gradient }\end{array}$ & $\begin{array}{l}\text { Mernbrane } \\
\text { Bending }\end{array}$ & $\begin{array}{l}\mathbf{Q} \\
\mathbf{Q}\end{array}$ \\
\hline & $\begin{array}{l}\text { Junction with head } \\
\text { or flange }\end{array}$ & Internal Pressure & $\begin{array}{l}\text { Membrane } \\
\text { Bending }\end{array}$ & $\begin{array}{l}P_{L} \\
Q\end{array}$ \\
\hline \multirow[t]{4}{*}{ Any Shell or Head } & \multirow[t]{2}{*}{$\begin{array}{l}\text { Any section across } \\
\text { entire vessel }\end{array}$} & $\begin{array}{l}\text { External load or } \\
\text { moment, or internal } \\
\text { pressure }\end{array}$ & $\begin{array}{l}\text { General membrane } \\
\text { averaged across full } \\
\text { section }\end{array}$ & $\mathbf{P}_{\mathbf{m}}$ \\
\hline & & $\begin{array}{l}\text { External load or } \\
\text { moment }\end{array}$ & $\begin{array}{l}\text { Bending across full } \\
\text { section }\end{array}$ & $\mathbf{P}_{\mathbf{m}}$ \\
\hline & $\begin{array}{l}\text { Near nozzle or other } \\
\text { openings }\end{array}$ & $\begin{array}{l}\text { External load or } \\
\text { moment, or internal } \\
\text { pressure }\end{array}$ & $\begin{array}{l}\text { Local membrane } \\
\text { Bending }\end{array}$ & $\begin{array}{l}\mathbf{P}_{\mathrm{L}} \\
\mathbf{Q}\end{array}$ \\
\hline & Any location & $\begin{array}{l}\text { Temperature } \\
\text { difference between } \\
\text { shell and head }\end{array}$ & $\begin{array}{l}\text { Membrane } \\
\text { Bending }\end{array}$ & $\begin{array}{l}\mathbf{Q} \\
\mathbf{Q}\end{array}$ \\
\hline \multirow[t]{2}{*}{$\begin{array}{l}\text { Dished Head or } \\
\text { Conical Head }\end{array}$} & Crown & Internal pressure & $\begin{array}{l}\text { Membrane } \\
\text { Bending }\end{array}$ & $\begin{array}{l}\mathbf{P}_{\mathbf{m}} \\
\mathbf{P}_{\mathbf{b}}\end{array}$ \\
\hline & $\begin{array}{l}\text { Kmuckle or junction } \\
\text { to shell }\end{array}$ & Internal pressure & $\begin{array}{l}\text { Membrane } \\
\text { Bending }\end{array}$ & $\begin{array}{l}\mathbf{P}_{\mathbf{L}} \text { (Note 1) } \\
\mathbf{Q}\end{array}$ \\
\hline
\end{tabular}

Note: 1) Consideration shall also be given to the possibility of wrinkling and excessive deformation in vessels with Iarge diameter-thickness ratio. 
Table 4.1.3-1. Load Combinations for Liner.

\begin{tabular}{|l|c|c|c|c|c|c|c|c|}
\hline Category & $\mathrm{D}$ & $\mathrm{L}$ & $\mathrm{T}_{\mathrm{o}}$ & $\mathrm{E}_{\mathrm{a}}$ & $\mathrm{W}$ & $\mathrm{R}_{\mathrm{o}}$ & $\mathrm{P}_{\mathrm{v}}$ & $\mathrm{H}_{\mathrm{a}}$ \\
\hline \multicolumn{7}{|c|}{ Service Load Category } \\
\hline Normal & 1.0 & 1.0 & 1.0 & & & 1.0 & 1.0 & \\
\hline \multicolumn{1}{|c|}{ Factored Load Category } \\
\hline $\begin{array}{l}\text { Extreme } \\
\text { Environmental }\end{array}$ & 1.0 & 1.0 & 1.0 & 1.0 & & 1.0 & 1.0 & \\
\hline Abnormal & 1.0 & 1.0 & 1.0 & & & & 1.0 & 1.0 \\
\hline
\end{tabular}

D $\quad=$ Dead Loads

L = Live Loads

$\mathrm{T}_{\mathbf{0}} \quad=$ Operating Temperature

$\mathrm{E}_{\mathrm{ss}} \quad=$ DBE Earthquake

W $=$ Wind Loads

$\mathbf{R}_{0} \quad=$ Operating Pipe Reaction

$\mathbf{P}_{\mathrm{v}} \quad=$ Pressure Loads

$\mathrm{H}_{\mathrm{a}} \quad=$ Secondary Tank Flooding Loads - Hydrostatic Gradient 
Table 4.1.3-2. Liner Strain Allowables.

\begin{tabular}{|c|c|c|}
\hline Strain Type & \multicolumn{2}{|c|}{$\begin{array}{l}\text { Strain Allowable } \\
\text { (in./in.) }\end{array}$} \\
\hline \multicolumn{3}{|c|}{ Service Load Category } \\
\hline Membrane & $\begin{array}{l}\epsilon_{\mathrm{ac}}=\epsilon_{\text {comprentive mum }} \\
\epsilon_{\mathrm{ut}}=\epsilon_{\text {tensile strain }}\end{array}$ & $\begin{array}{l}=0.002 \\
=0.002\end{array}$ \\
\hline $\begin{array}{l}\text { Membrane plus } \\
\text { Bending }\end{array}$ & $\epsilon_{\mathrm{sc}}$ & $\begin{array}{l}=0.004 \\
=0.004\end{array}$ \\
\hline \multicolumn{3}{|c|}{ Factored Load Category } \\
\hline Membrane & $\begin{array}{l}\epsilon_{x c} \\
\epsilon_{n t}\end{array}$ & $\begin{array}{l}=0.005 \\
=0.003\end{array}$ \\
\hline $\begin{array}{l}\text { Membrane plus } \\
\text { Bending }\end{array}$ & $\begin{array}{l}\epsilon_{\mathrm{sc}} \\
\epsilon_{\mathrm{st}}\end{array}$ & $\begin{array}{l}=0.014 \\
=0.010\end{array}$ \\
\hline
\end{tabular}


Table 4.1.4-1. Liner Anchor Allowables.

\begin{tabular}{|l|c|c|}
\hline \multirow{2}{*}{ Category } & \multicolumn{2}{|c|}{ Force and Displacement Allowables } \\
\cline { 2 - 3 } & $\begin{array}{c}\text { Mechanical Loads, } \\
\text { Lesser of: }\end{array}$ & $\begin{array}{c}\text { Displacement } \\
\text { Limited Loads }\end{array}$ \\
\hline \hline $\begin{array}{l}\text { Normal, } \\
\text { Extreme Environmental }\end{array}$ & $\begin{array}{c}\mathrm{F}_{\mathrm{a}}=0.67 \mathrm{~F}_{\mathrm{y}} \\
\mathrm{F}_{\mathrm{a}}=0.33 \mathrm{~F}_{\mathrm{u}}\end{array}$ & $\delta_{\mathrm{a}}=0.25 \delta_{\mathrm{u}}$ \\
\hline Abnormal & $\mathrm{F}_{\mathrm{a}}=0.90 \mathrm{~F}_{\mathrm{y}}$ & $\delta_{\mathrm{a}}=0.50 \delta_{\mathrm{u}}$ \\
& $\mathrm{F}_{\mathrm{a}}=0.50 \mathrm{~F}_{\mathrm{u}}$ & \\
\hline
\end{tabular}

$\mathrm{F}_{\mathrm{a}} \quad=$ Allowable force

$F_{y} \quad=$ Force to reach anchor yield strength

$\mathbf{F}_{\mathrm{u}} \quad=$ Force to reach anchor ultimate strength

$\delta_{\mathrm{a}} \quad=$ Allowable displacement

$\delta_{\mathrm{u}}=$ Displacement at ultimate strength. 
Table 4.1.4-2. $F_{y}$ and $F_{v}$ Relationships for Nelson Studs with Full Embedment (Ductile Behavior).

\begin{tabular}{|c|c|c|c|c|}
\hline \multirow[t]{2}{*}{ Nelson Anchor Type } & \multicolumn{2}{|c|}{$F_{y}(l b f)$} & \multicolumn{2}{|c|}{$F_{v}(b f)$} \\
\hline & Tension & Shear & Tension & Shear \\
\hline Headed Stud & \multirow{3}{*}{$A_{s} f_{y}$} & \multirow{3}{*}{$\mathbf{A}_{\mathbf{f}} \mathbf{f}_{\mathrm{y}}$} & \multirow{3}{*}{$0.9 \mathrm{~A}_{\mathrm{s}} \mathrm{f}_{\mathrm{u}}$} & \multirow{4}{*}{$\begin{array}{c}\text { Lesser of: } \\
0.9 \mathrm{~A}_{\mathrm{z}} \mathrm{f}_{\mathrm{u}} \\
5.66 \mathrm{~A}_{\mathrm{g}} \mathrm{f}_{\mathrm{c}}^{0.3} \mathrm{E}_{\mathrm{c}}^{0.44}\end{array}$} \\
\hline Headed-Threaded Stud & & & & \\
\hline Bent Flat Bar & & & & \\
\hline $\begin{array}{l}\text { Bent Stud } \\
\text { (or J-bolt) }\end{array}$ & $\begin{array}{l}\text { Lesser of: } \\
\qquad A_{s} f_{y} \text {, } \\
1 / 2 A_{8} f_{u}\end{array}$ & $A_{8} f_{y}$ & $2 / 3 A_{i} f_{u}$ & \\
\hline
\end{tabular}

$A_{1}=$ Cross sectional area of the anchor shank $\left(\mathrm{in}^{2}\right)$

$\mathrm{f}_{\mathrm{y}} \quad=$ Yield strength of the anchor material ( $\mathrm{lbf} / \mathrm{in}^{2}$ )

$\mathrm{f}_{\mathrm{u}} \quad=$ Tensile strength of the anchor material $\left(\mathrm{lbf} / \mathrm{in}^{2}\right)$

$\mathrm{f}_{\mathrm{c}}=$ Compressive strength $\left(\mathrm{lbf} / \mathrm{in}^{2}\right)$ of concrete adjusted for temperature

$\mathrm{E}_{\mathrm{c}}=$ Concrete modulus of elasticity $\left(\mathrm{lbf} / \mathrm{in}^{2}\right)$ adjusted for temperature. 
Table 4.1.4-3. Ultimate Displacements for Nelson Studs with Full Embedment (Ductile Behavior).

\begin{tabular}{|c|c|c|c|c|c|}
\hline \multirow{3}{*}{$\begin{array}{c}\text { Nelson } \\
\text { Anchor } \\
\text { Type }\end{array}$} & \multirow{3}{*}{$\begin{array}{l}\text { Anchor } \\
\text { Size } \\
\text { (in.) }\end{array}$} & \multicolumn{4}{|c|}{$\delta_{\mathrm{u}}$ (in.) } \\
\hline & & \multicolumn{2}{|c|}{ Tension } & \multicolumn{2}{|r|}{ Shear } \\
\hline & & $\begin{array}{l}\text { Test } \\
\text { Data }\end{array}$ & $\begin{array}{c}\text { Recommended } \\
\text { (1) }\end{array}$ & $\begin{array}{l}\text { Test } \\
\text { Data }\end{array}$ & $\begin{array}{c}\text { Recommended } \\
\text { (1) }\end{array}$ \\
\hline \multirow{5}{*}{$\begin{array}{l}\text { Headed } \\
\text { Stud }\end{array}$} & $1 / 4$ & 0.220 & \multirow{5}{*}{0.220} & (2) & 0.042 \\
\hline & $3 / 8$ & 0.42 & & (2) & 0.094 \\
\hline & $1 / 2$ & 0.5 & & 0.167 & 0.167 \\
\hline & $5 / 8$ & 0.5 & & 0.299 & 0.220 \\
\hline & $3 / 4$ & 0.227 & & 0.341 & 0.220 \\
\hline \multirow{2}{*}{$\begin{array}{c}\text { Headed- } \\
\text { Threaded } \\
\text { Stud }\end{array}$} & $1 / 2$ & 0.233 & \multirow[t]{2}{*}{0.220} & (3) & 0.167 \\
\hline & $5 / 8$ & 0.284 & & (3) & 0.220 \\
\hline \multirow{4}{*}{$\begin{array}{l}\text { Bent Stud } \\
\text { (or J-bolt) }\end{array}$} & $1 / 2$ & $>0.44$ & \multirow{4}{*}{0.220} & (3) & 0.167 \\
\hline & $5 / 8$ & $>0.42$ & & (3) & 0.220 \\
\hline & $3 / 4$ & $>1.0$ & & (3) & 0.220 \\
\hline & 1 & $>1.5$ & & (3) & 0.220 \\
\hline $\begin{array}{c}\text { Bent Flat } \\
\text { Bar }\end{array}$ & All Sizes & $>1.5$ & 0.220 & (3) & 0.220 \\
\hline
\end{tabular}

\section{Notes}

(1) Recommended values are based on the lesser of the minimum test value and a value such that $0.25 \delta_{\mathrm{u}}$ does not significantly exceed the displacement on test data plots that corresponds to the yield point of the test anchor (i.e. the initial linear portion of the load-displacement curve).

(2) Test data not available. Based on the data for the larger studs, factoring $\delta_{1}$ for the $1 / 2$-in. stud by the area ratio $A_{<r_{2}-\text { in. }} / A_{y_{2}-\text { in. }}$, to obtain $\delta_{n}$ for the smaller studs is conservative.

(3) Test data not available. Use of headed stud recommended values is conservative. 


\section{THIS PAGE INTENTIONALLY}

LEFT BLANK 


\subsection{CODE RECONCILIATION}

It is acceptable to apply the provisions of the Code of Record (COR) as the design basis of existing structures. However, it may be desirable to apply a new code or later edition of the original code. Further, any modifications to existing facilities must be designed and evaluated with respect to the provisions of the codes identified by the current governing DOE Orders. Differences between the current code provisions and those of the COR should be identified by directly comparing the COR to the current code being used. Using code commentaries and other references. The reasons for the differences generally can be categorized into the following:

- The change from the COR design specification is associated with updates in material standards or changes in material specifications;

- The change from the COR design specification is associated with new or revised construction/fabrication techniques;

- The change from the COR design specification is associated with an improved understanding of structural behavior;

- The reason for change from the COR design specification is not clear; however, the reason is unrelated to material specifications.

Modification of the form or format of a code provision without a change in the meaning or intent does not qualify as a true "change" in code requirements.

Provisions of code editions subseguent to the COR may be used in place of the COR provisions whenever any changes in the provisions can be attributed solely to an improved understanding of . structural behavior or when the updated provisions fall into any of the above categories and are more stringent than those of the COR. Changed provisions which fall into the above categories that are less stringent than the COR provisions may not be used.

\section{ASME BRPV Code Reconciliation}

The tank steel liners (primary and secondary) are governed by either ASME Section III or Section VIII as indicated in Table 5.0-1. The salient issues that should be addressed in a code reconciliation include:

- Material

- Openings and Reinforcement Details

- Penetration Details

- Connections

- Welds

- Anchor Details

- Fabrication Requirements

- General Design and Analysis Considerations

- Strength and Serviceability Requirements

- Loads

- Combined Stresses 
Discontinuity Effects

- High Temperature and Creep Effects

- Fatigue Requirements.

- Allowable Stresses

Buckling Modes

$r \quad$ Impulse and Impact Effects

r Corrosion

\section{ACL Code Reconciliation}

The secondary tank concrete is governed by ACI 318 and ACI 349 as indicated in Table 5.0-2. The salient issues that should be addressed in a code reconciliation include:

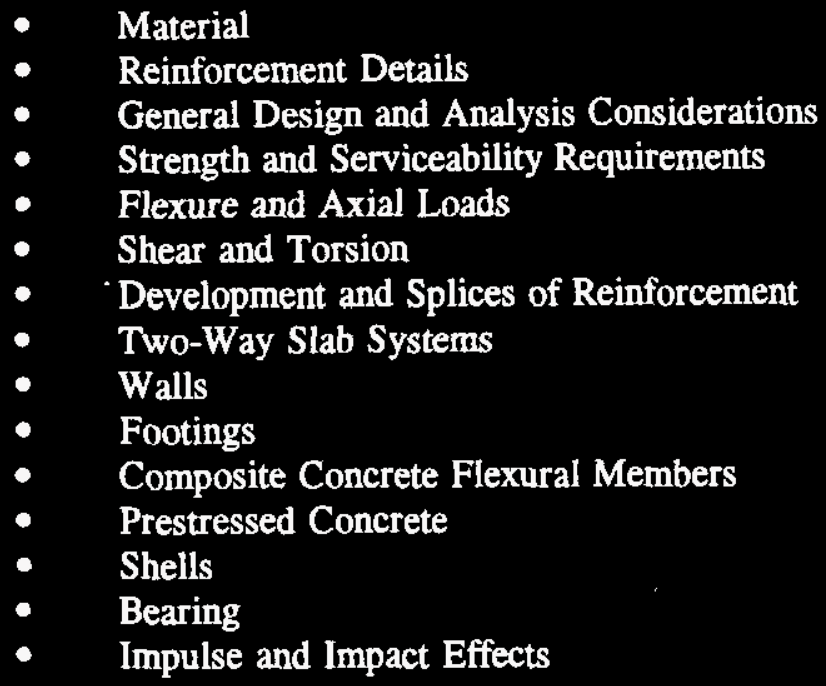

\section{AISC Code Reconciliation}

Although most of the tank components are not designed to the AISC code, some of the supporting facilities, such as pits, penetrations and surface equipment may be. New construction may be analyzed using the most current AISC standards and does not require a code reconciliation. For the existing supporting components, the Codes of Record which may be used in code reconciliation has varied over the course of their construction history and may be found in the existing analyses for the components under consideration. The code reconciliation should focus on the following issues:

Dimensions and Properties of Rolled Shapes and Tubing Material

Allowable Stresses

- Structural Steel

- $\quad$ Rivets, Bolts, Threaded Parts

- Welds

Combined Stresses

Stability/Slenderness Ratios

Width-Thickness Ratios 
WHC-SD-WM-DGS-003

Revision 0

- $\quad$ Plate Girders and Rolled Beams

- Composite Construction

- Gross and Net Areas

- Connections

- Rivets and Bolts

- Welds

- Built-up Members 
Table 5.0-1. Summary of Hanford Double-Shell Tank Codes of Record for Primary Tank and Secondary Steel Liner.

\begin{tabular}{|c|c|c|c|c|c|c|c|}
\hline \multirow{2}{*}{$\begin{array}{l}\text { Tank } \\
\text { Farm } \\
241-\end{array}$} & \multirow{2}{*}{$\begin{array}{l}\text { Const. } \\
\text { Year }\end{array}$} & \multirow{2}{*}{$\begin{array}{l}\text { Hanford } \\
\text { Construction } \\
\text { and Design } \\
\text { Specification }\end{array}$} & \multicolumn{2}{|c|}{ Design Code } & \multirow{2}{*}{$\begin{array}{c}\text { Steel Spec. } \\
\text { ASTM } \\
\text { Yield } \\
\text { Strength } \\
\left(10^{3} \text { lb } / / \mathrm{in}^{2}\right)\end{array}$} & \multicolumn{2}{|c|}{ Welds } \\
\hline & & & $\begin{array}{l}\text { Primary } \\
\text { Tank }\end{array}$ & $\begin{array}{l}\text { Secondary } \\
\text { Steel } \\
\text { Liner }\end{array}$ & & Proc. & Qual. \\
\hline $\mathbf{A Y}$ & $1968-70$ & $\begin{array}{l}\text { HWS-7789 to } \\
\text { HWS-7791 }\end{array}$ & \multicolumn{2}{|c|}{$\begin{array}{l}\text { ASME Section VIII } \\
\text { Div. } 2 \text { (1965) }\end{array}$} & $\begin{array}{l}A 515-65 \\
G_{\text {r. }} 60 \\
S_{y}=32\end{array}$ & $-\cdots$ & $\begin{array}{c}\text { ASME } \\
\text { Section IX }\end{array}$ \\
\hline $\mathbf{A Z}$ & $1971 \& 77$ & $\begin{array}{l}\text { HWS-8981 } \\
\text { HWS-8982 }\end{array}$ & \multicolumn{2}{|c|}{$\begin{array}{c}\text { ASME Section III } \\
\text { (1968) }\end{array}$} & $\begin{array}{l}\text { As15-69 } \\
\text { Gr. } 60 \\
S_{y}=32 \\
\end{array}$ & - & $\begin{array}{c}\text { ASME } \\
\text { Section IX }\end{array}$ \\
\hline $\mathbf{S Y}$ & $1974-76$ & $\begin{array}{c}\mathrm{B}-101- \\
\mathrm{C} 1, \mathrm{C} 2, \& \mathrm{C} 3\end{array}$ & \multicolumn{2}{|c|}{$\begin{array}{l}\text { ASME Section III } \\
\text { Div. } 1 \text { (1971 with } \\
1973 \text { Addenda) }\end{array}$} & $\begin{array}{c}\text { AS16-65 } \\
\text { Gr. } 65 \\
S_{y}=35\end{array}$ & HPS-220-W & $\begin{array}{c}\text { ASME } \\
\text { Section } \mathbf{X}\end{array}$ \\
\hline AW & $1978-80$ & $\begin{array}{c}\mathrm{B}-120- \\
\mathrm{C} 3, \mathrm{C} 4, \mathrm{C} 5, \& \mathrm{D} 1\end{array}$ & \multicolumn{2}{|c|}{$\begin{array}{l}\text { ASME Section VIII } \\
\text { Div. } 2 \text { (1974) }\end{array}$} & $\begin{array}{c}\text { A537-74a } \\
\text { Class } 1 \\
S_{y}=50 \\
\end{array}$ & HPS-220-W & $\begin{array}{c}\text { ASME } \\
\text { Section } \mathrm{X} \\
\text { HPS-210-W }\end{array}$ \\
\hline AN & $1980-81$ & $\begin{array}{c}\mathrm{B}-130- \\
\mathrm{C} 3, \mathrm{C} 4, \mathrm{C}, \& \mathrm{D} 1\end{array}$ & \multicolumn{2}{|c|}{$\begin{array}{l}\text { ASME Section VIII } \\
\text { Div. } 2 \text { (1974 with } \\
1976 \text { Addenda) }\end{array}$} & $\begin{array}{l}\text { A } 537-75 \\
\text { Class } 1 \\
S_{y}=50\end{array}$ & HPS-220-W & $\begin{array}{c}\text { ASME } \\
\text { Section DX } \\
\text { HPS-210-W }\end{array}$ \\
\hline $\mathbf{A P}$ & $1983-86$ & $\begin{array}{l}\text { B-340- } \\
\text { C3, C4, D1, \& } \\
\text { RHO } 1986\end{array}$ & \multicolumn{2}{|c|}{$\begin{array}{l}\text { ASME Section VIII } \\
\text { Div. } 2 \text { (1980 with } \\
\text { Winter } 1981 \text { Addenda) }\end{array}$} & $\begin{array}{c}\text { A537-80,79 } \\
\text { Class } 1 \\
S_{y}=50 \\
\end{array}$ & AWS D1.1 & $\begin{array}{c}\text { ASME } \\
\text { Section IX }\end{array}$ \\
\hline
\end{tabular}

ASME = American Society of Mechanical Engineers

ASTM = American Society of Testing and Materials

AWS = American Welding Society

HPS = Hanford Plant Standard 
Table 5.0-2. Summary of Hanford Double-Shell Tank Structural Concrete Design Basis.

\begin{tabular}{|c|c|c|c|c|c|c|c|c|}
\hline \multirow{3}{*}{$\begin{array}{l}\text { Tank } \\
\text { Farm } \\
241-\end{array}$} & \multirow{3}{*}{$\begin{array}{l}\text { Const. } \\
\text { Year }\end{array}$} & \multicolumn{4}{|c|}{ Design Code } & \multirow{2}{*}{\multicolumn{3}{|c|}{ Reinforcing Steel }} \\
\hline & & \multicolumn{4}{|c|}{$\begin{array}{l}\text { Specified 28-day Compressive Strength } \\
\qquad\left(10^{3} \mathrm{lb} / \mathrm{in}^{2}\right)\end{array}$} & & & \\
\hline & & $\begin{array}{l}\text { Dome \& } \\
\text { Haunch }\end{array}$ & Wall & $\begin{array}{l}\text { Basemat } \\
\text { Foundation }\end{array}$ & $\begin{array}{l}\text { Insulating } \\
\text { Concrete }^{1}\end{array}$ & $\begin{array}{l}\text { Rebar } \\
\text { (ASTM) }\end{array}$ & $\begin{array}{c}\text { Cross- } \\
\text { Ties } \\
\text { (ASTM) }\end{array}$ & Welds \\
\hline \multirow[t]{2}{*}{ AY } & \multirow[t]{2}{*}{$1968-70$} & \multicolumn{3}{|c|}{ ACI 318 (1963) } & & \multirow{2}{*}{$\begin{array}{c}\text { A15-65 } \\
\text { FDN Gr. } 40 \\
\text { A432-66 } \\
\text { Shell Gr. } 60\end{array}$} & \multirow{2}{*}{$\begin{array}{l}\text { A432-66 } \\
\text { Gr. } 60\end{array}$} & \multirow[t]{2}{*}{--} \\
\hline & & $\begin{array}{c}3 \\
\text { (Type III) }\end{array}$ & $\begin{array}{c}3 \\
\text { (Type II) }\end{array}$ & 3 & 0.200 & & & \\
\hline \multirow[t]{2}{*}{$\mathbf{A Z}$} & \multirow[t]{2}{*}{$1971 \& 77$} & \multicolumn{3}{|c|}{ ACI 318 (1963) } & & \multirow{2}{*}{$\begin{array}{l}\text { A615-68 } \\
\text { Gr. } 60\end{array}$} & \multirow{2}{*}{$\begin{array}{l}\text { A615-68 } \\
\text { Gr. } 60\end{array}$} & \multirow[t]{2}{*}{--} \\
\hline & & 3 & 3 & $\stackrel{3}{(T y p e ~ V)}$ & 0.200 & & & \\
\hline \multirow[t]{2}{*}{$\mathbf{S Y}$} & \multirow[t]{2}{*}{$1974-76$} & \multicolumn{3}{|c|}{ ACI 318 (1971) } & & \multirow{2}{*}{$\begin{array}{l}\text { A615-72 } \\
\text { Gr. } 60\end{array}$} & \multirow{2}{*}{$\begin{array}{l}\text { A615-72 } \\
\text { Gr. } 40\end{array}$} & \multirow[t]{2}{*}{ AWS D12.1 } \\
\hline & & $\begin{array}{l}4.5 \\
\text { (Type III) }\end{array}$ & $\begin{array}{c}4.5 \\
\text { (Type II) }\end{array}$ & $\begin{array}{l}3(4.5)^{2} \\
\text { (Type V) }\end{array}$ & 0.130 & & & \\
\hline \multirow[t]{2}{*}{$\mathbf{A W}$} & \multirow[t]{2}{*}{$1978-80$} & \multicolumn{3}{|c|}{ ACI 318 (1971) } & & \multirow{2}{*}{$\begin{array}{c}\text { A615-76a } \\
\text { Gr. } 60\end{array}$} & \multirow{2}{*}{$\begin{array}{c}\text { A615- } \\
768 \\
\text { Gr. } 40\end{array}$} & \multirow{2}{*}{$\begin{array}{l}\text { AWS D12.1 } \\
\text { HPS-220-W }\end{array}$} \\
\hline & & $\begin{array}{c}5 \\
\text { (Type III) }\end{array}$ & $\begin{array}{c}5 \\
\text { (Type II) }\end{array}$ & $\begin{array}{l}4.5 \\
\text { (Type II) }\end{array}$ & 0.130 & & & \\
\hline \multirow[t]{2}{*}{ AN } & \multirow[t]{2}{*}{ 1980-81 } & \multicolumn{3}{|c|}{ ACI $318(1971)$} & & \multirow{2}{*}{$\begin{array}{l}\text { A615-75 } \\
\text { Gr. } 60\end{array}$} & \multirow{2}{*}{$\begin{array}{l}\text { A615-75 } \\
\text { Gr. } 40\end{array}$} & \multirow{2}{*}{$\begin{array}{l}\text { AWS D12.1 } \\
\text { HPS-220-W }\end{array}$} \\
\hline & & $\begin{array}{c}5(4.5)^{3} \\
\text { (Type III) }\end{array}$ & $\begin{array}{c}5(4.5)^{3} \\
\text { (Type II) }\end{array}$ & $\begin{array}{c}4.5 \\
\text { (Type II) }\end{array}$ & 0.130 & & & \\
\hline \multirow[t]{2}{*}{$\mathbf{A P}$} & \multirow[t]{2}{*}{$1983-86$} & ACI 34 & (1976) & ACI 318 & & A615-81a & A615- & AWS D1.4 \\
\hline & & 5 & 5 & $\begin{array}{c}4.5 \\
\text { (Type II) }\end{array}$ & 0.130 & & Gr. 60 & \\
\hline
\end{tabular}

${ }^{1}$ The insulating concrete material is a cast-in-place lightweight refractory concrete material.

2 From H-2-37704

${ }^{3}$ From H-2-71907

Nomenclature

ACI = American Concrete Institute

ASTM $=$ American Society of Testing and Materials

ASW $=$ American Welding Society

FDN = Foundation (basemat)

HPS = Hanford Plant Standard

Type II = Low-alkali portland cement - used where moderate exposure to sulfate attack is anticipated. Type II cement is in common use in western U.S. Type II cement gains strength a little more slowly than general-purpose Type I cement but ultimately attains strength of Type I cement.

Type III = High-early-strength cement - develops in 7 days the same strength that is achieved at 28 days for concrete made from Type I or II cement but may not achieve the long-term strength of Type I or II.

Type V = Sulfate-resisting cement - strength characteristics are equivalent to Type II. 
THIS PAGE INTENTIONALIY

LEFT BLANK 


\subsection{MATERIAL CHARACTERIZATION}

The environmental conditions, both historical and anticipated for the future, is an important factor in determining the useful life of the existing Hanford double-shell tanks. The undegraded specified material properties summarized in the following sections should be used as a starting point in addressing the environmental factors that have an altering effect. Guidance is provided on methods of addressing the behavior of material properties over time. Consensus properties are provided for cases where testing records of the original materials may not be available.

\subsection{STEEL LINERS PROPERTIES}

The primary tank and secondary steel liner materials specified for the DSTs are listed in Table 5.0-1. The design stress intensity values, $S_{m}$, are given in Tables I-1.1 of Section III of the ASME Code or Section II, Part D, Subpart 1 (for Section VIII analyses). Typical values are provided in Table 6.1-1. Values of the coefficients of thermal expansion are given in Table I-5.0 of Section III of the ASME Code or in Tables TE-1 through 5 in Section II, Part D (for Section VIII analyses). Typical values are provided in Table 6.1-2. Values of the moduli of elasticity are given in Table I-6.0 of Section III of the ASME Code or in Tables TM-1 through 5 of Section II, Part D (for Section VIII analyses). Typical values are provided in Table 6.1-3. The density of steel shall be taken as $490 \mathrm{lb} / \mathrm{ft}^{3}$. Poisson's ratio shall be taken as 0.30 for elastic analysis unless another value is shown and documented to be more appropriate. Corrosion is the dominant aging mechanism (see Section 6.6).

\subsection{REINFORCEMENT STEEL PROPERTIES}

Reinforcement rebar and cross-ties materials specified for the DSTs are listed in Table 5.0-2. Both Grade $\mathbf{4 0}$ and Grade $\mathbf{6 0}$ bars are specified. The material properties are summarized in Table 6.2-1 (Mirza and MacGregor 1979). Typical stress-strain curves for non-tensioned reinforcing bars (consistent with the minimum specified yield strength) are given in Nilson et al. 1982.

Corresponding mean stress-strain curves are shown in Figure 6.2-1 obtained by shifting minimum specified yield strength to the mean yield strength.

\subsection{REINFORCED CONCRETE PROPERTIES}

The nonlinear behavior of reinforced concrete complicates the number of material properties requiring definition to properly model its structural behavior. There are uncertainties associated with the original (as-constructed) properties as well as the mathematical models used to characterize the response to loads and environmental conditions. Table $5.0-2$ provides a summary of the specified concrete materials used in the construction of the Hanford double-shell waste tanks. To address the nonlinear behavior of reinforced concrete a number of constitutive model characteristics are provided below that are necessary to predict reinforced concrete response. Recommended expressions that describe material property changes with time and the environment are provided. Modeling aspects that are limited by the state-of-the-art are addressed in a manner that provides qualitatively the effects that are not explicitly modeled. 


\subsubsection{Initial Properties}

Specified 28-day concrete compression strengths $\left(\mathrm{f}_{\mathrm{c}} \mathrm{)}\right.$ ) for the DSTs are listed in Table 5.0-2. In lieu of actual test data, the corresponding initial modulus of elasticity can be calculated from the empirical ACI equation from Section 8.5.1 of ACI 318-89 (1992) for normal-weight (145 lbf/ $\left.\mathrm{ft}^{3}\right)$ concrete:

$$
E_{c}=57,000 \sqrt{f_{c}}
$$

where

$\mathrm{E}_{\mathrm{c}} \quad=$ Initial modulus of elasticity $\left(\mathrm{bf} / \mathrm{in}^{2}\right)$ defined as the slope of the line drawn from a stress of zero to a compressive stress of $0.45 \mathrm{f}_{\mathrm{c}}$.

$\mathrm{f}_{\mathrm{c}} \quad=$ Specified concrete compression strength $\left(\mathrm{lbf} / \mathrm{in}^{2}\right)$.

The modulus for concrete is sensitive to the modulus of the aggregate; measured values range typically from 120 to $80 \%$ of the calculated value from Equation 6.3.1-1. The tensile strength, $f_{t}$, is taken approximately as $0.10 \mathrm{f}_{\mathrm{c}}$ at room temperature for Hanford concrete (RHO 1981). The coefficient of thermal expansion is taken as $3.7 \times 10^{-6} \mathrm{in} / \mathrm{in}-{ }^{\circ} \mathrm{F}$ (Winkel 1994). Poisson's ratio, $v_{\mathrm{c}}$, for Hanford concrete at room temperature ranges from 0.15 to 0.19 which is within the typical range of 0.15 to 0.20 for normal weight concrete. Poisson's ratio for concrete remains constant until approximately $0.8 \mathrm{f}_{\mathrm{c}}$, at which stress the apparent Poisson's ratio begins to increase and in the unstable crushing phase exceeds 0.5 . Strength and modulus properties can be affected by loading rate, temperature, time, and repeated or cyclic loading.

\subsubsection{Thermal and Aging Effects}

An important consideration in the structural evaluation of the waste storage tanks is the effect that the increased temperature from internal heat generation of the decaying radioactive waste material has on the concrete properties of the secondary concrete structure. A review of the effects of elevated temperature on the behavior of concrete is given in Kassir 1993. In Moore 1995a constitutive models for concrete and the effects of temperature on the behavior of concrete are reviewed further. Specific guidance is provided on strength and modulus degradation factors. The degradation factors are a function of temperature and time at temperature though most of the damage occurs over a short period of time. The degradation factors were developed from a reassessment (Peterson 1994) of the Hanford concrete test database (RHO 1981). The effect of temperature on bond strength is also addressed in Moore 1995a. The effect of temperature on the stress-strain curve of concrete is discussed in Kassir 1993 and Moore 1995a. Changes in concrete peak strength and ductility are apparent. Thermal cycling causes progressive degradation of concrete with increasing number of cycles though most of the damage occurs in the first few cycles (Kassir 1993). In general, there is a wide variation in the effect of elevated temperature on the behavior of concrete because of the many inherent variables that effect the behavior of concrete. Hence, upper and lower bounds of the degraded properties at temperatures applicable to the environments of the waste storage tanks need to be considered in assessing the structural integrity of the tanks. Recommendations and guidance in establishing such bounds are given in Kassir 1993 and Moore 1995a. 


\subsubsection{Creep and Shrinkage}

Creep and shrinkage of concrete are also important considerations in determining the behavior of the behavior of the waste storage tanks, particularly for the elevated temperatures environment of the tanks. Although the effect of concrete creep on the structure is generally favorable in that it redistributes the stresses from the concrete to the reinforcement, under conditions of high sustained loads it can lead to an accelerated time-dependent failure. Concrete creep and shrinkage behavior with increasing temperature are characterized in Kassir 1993 and in Moore 1995a from a review of available data. A wide variation in behavior is exhibited. Hence, upper and lower bounds of the creep and shrinkage behavior at temperatures applicable to the environments of the waste storage tanks need to be considered in assessing the structural integrity of the tanks. Guidance in establishing such bounds are given in Kassir 1993 and Moore 1995a.

\subsection{INSULATING CONCRETE PROPERTIES}

In accordance with the corresponding construction specifications, the insulating concrete for the AY and AZ tanks has a minimum specified compressive strength of $200 \mathrm{lbf} / \mathrm{in}^{2}$ and for the $S Y, A W$, AN, and AP tanks has a minimum specified compressive strength of $130 \mathrm{lbf} / \mathrm{in}^{2}$ (see Table 5.0.2). The above compressive strength requirements are for the minimum compressive strength of the insulating concrete after stress relieving of the primary tank with the insulating concrete in place. The insulating concrete is specified as a cast-in-place refractory concrete material. The bulk density is estimated to be approximately $50 \mathrm{lb} / \mathrm{ft}^{3}$ for this compressive strength range per Table $2.1 \mathrm{~b}$ of ACI 547R-79 (1992) which corresponds to a lightweight refractory concrete material. In lieu of actual test data, the corresponding initial modulus of elasticity can be estimated from the empirical ACI equation from Section 8.5.1 of ACI 318-89 for concrete:

$$
E_{c}=33\left(w_{c}\right)^{1.5} \sqrt{f_{c}}
$$

where

$$
\begin{aligned}
& \mathrm{E}_{\mathrm{c}}=\text { Initial modulus of elasticity }\left(\mathrm{lbf} / \mathrm{in}^{2}\right) \text { defined as the slope of the line drawn from a } \\
& \text { stress of zero to a compressive stress of } 0.45 \mathrm{f}_{\mathrm{c}} . \\
& \mathrm{w}_{\mathrm{c}} \quad=\text { Weight density of concrete }\left(\mathrm{lbf} / \mathrm{ft}^{3}\right) \\
& \mathrm{f}_{\mathrm{c}} \quad=\text { Specified concrete compression strength }\left(\mathrm{bf} / \mathrm{in} \mathrm{n}^{2}\right) .
\end{aligned}
$$

This equation was developed form data for concrete densities in the range of 90 to $155 \mathrm{lbf} / \mathrm{ft}^{3}$. However, the data provided in ACI 523.1R-86 (1992) and ACI 523.3R-75 (1992) suggest that Equation 6.3.1-2 can be used as a fist approximation for concretes having $\mathrm{w}_{\mathrm{c}}$ values between 23 and $90 \mathrm{lbf} / \mathrm{ft}^{3}$. The tensile strength, $f_{t}$, is taken approximately as $0.10 \mathrm{f}_{\mathrm{c}}$. The reversible thermal expansion of lightweight refractory concrete varies from $2.5 \times 10^{-6}$ to $3.5 \times 10^{-6}$ in/in- ${ }^{\circ} \mathrm{F}$ (ACI 547R-79). Poisson's ratio is assumed to be approximately 0.15 in lieu of test data. Generally, lightweight concretes designed for insulating purposes should not be subjected to impact, heavy loads, abrasion, erosion or other physical abuse. 


\subsection{SOIL PROPERTIES AND STRUCTURAL ANALYSIS CONSIDERATIONS}

\subsubsection{Soil Properties}

The soils in which the Hanford waste storage tanks are buried range from sandy fine gravel to a coarse sand. An overview of existing Hanford Site geotechnical studies is given in Giller 1992. Results of geotechnical investigations on soil for the proposed Multi-Function Waste Tank Facility (MWTF) in the 200 East and 200 West Areas are reported in Shannon \& Wilson 1995a and 1995b, respectively. Available soil density data of in-place backfill over existing tanks is compiled in Pianka 1994. Static, dynamic, and thermal properties of Hanford Site soil and relevant open literature soil test data are reviewed in Moore $1995 \mathrm{~b}$.

\subsubsection{Soil-Structural Interaction Analysis Considerations}

Previous analyses have shown that the Hanford Site tank designs are sensitive to the soil modeling characterization, particularly at the wall-foundation interface. Guidelines for static and dynamic (seismic) soil-structure interaction analyses are provided in Moore $1995 \mathrm{~b}$. Various soil constitutive models are reviewed for their ability to adequately model soil behavior. In addition, the proper application of available soil test data in the development of simplified soil-spring models and complex finite-element soil continuum models is addressed.

\subsection{CORROSION CONSIDERATIONS ${ }^{6}$}

Corrosion is the most probable degradation mechanism of the steel liners resulting from aging in both the SSTs and DSTs. Corrosion results from contact with liquid, liquid-vapor, solid, and vapor phases of the waste. The most important types of tank liner corrosion are believed to be one or more of three localized corrosion mechanisms

Pitting corrosion (PC)

Crevice corrosion (CC)

Stress-corrosion cracking (SCC)

and one general or uniform corrosion (UC) mechanism. Future in-tank mixing may lead to erosioncorrosion (EC); EC rates as high as $4 \mathrm{mil} / \mathrm{yr}$ have been estimated (Smith 1992, Schwenk 1992).

Other failure mechanisms, such as chemical attack or elevated temperature degradation and cracking of the concrete surrounding the SST and subsequent corrosion of rebar within that concrete, are important because of the possible relationship between degraded concrete, increased stresses on the adjacent liner, and increased stresses in the rebar. Chemical attack and corrosion of the rebar is less likely for DSTs because direct contact of the liquid or vapor phase of the waste with the concrete is prevented by the primary tank and the secondary steel liner containment barriers.

\footnotetext{
6 This section was taken from WHC $1993 \mathrm{~b}$.
} 


\subsubsection{Uniform Corrosion}

UC is considered to be the least likely failure mode for waste-wet regions of DSTs. Initial control of the composition of the waste ensures the inhibition of UC. UC could occur, however, in the vapor-phase region. Here, explicit inhibition controls are not possible, although the high $\mathrm{pH}$ of the liquid waste may have had a beneficial inhibiting effect on the vapor. Also, UC could occur in areas where possible variations in waste concentration may have occurred, e.g., if bottom-adhering crustal deposits occurred, they could have changed the local fluid composition and concentration.

The UC data from Divine and Bowen (1984) indicate that, for the compositions and concentrations tested, nearly all the UC rates were less than $1 \mathrm{mil} / \mathrm{yr}$.

\subsubsection{Pitting Corrosion and Crevice Corrosion}

PC and CC appear to be most likely to occur in at least three locations: (1) in the splash zone (waterline region) where alternate wetting and drying can occur and cause the formation of adherent deposits, (2) at the waterline where airborne $\mathrm{CO}_{2}$ could lower the $\mathrm{OH}$ concentration (Zapp 1990), and (3) under bottom-lying layers of porous corrosion products or possible solid forms of the waste.

Because no leaks have been detected in a DST, these two failure modes either do not yet exist, are in their incubation stage, or are progressing slowly through-wall.

\subsubsection{Stress-Corrosion Cracking}

The weld regions of the DSTs are not of principal concern regarding SCC since the entire inner tank was post-weld heat treated during construction. SCC in DSTs appears most likely to occur in regions of high hydraulic-pressure-induced tensile stress. Such high stresses could exist in the meridional direction within the lower knuckle region (Shurrab 1991). Because no leaks have yet been detected in a DST, this failure mode is probably still in an incubation stage, which could last until the tank is retired from service. The possible incubation of SCC is based on the assumption that proper control of chemical inhibitor species $\mathrm{OH}^{-}$and $\mathrm{NO}_{2}^{\circ}$, can always be maintained. If the knuckle-region tensile stresses are in the neighborhood of tensile yield stress (Shurrab 1991), and the lowest (worst case) value of the applied stress intensity factor to produce $S C C$ growth $\left(\mathbf{K}_{\mathrm{Iscc}}\right)$ due to imbalanced corrosion inhibitor chemicals is $15 \mathrm{ksi} \sqrt{\mathrm{in}}$ (Beavers 1987), the eventual formation of a sharp inside surface flaw or crack - say by CC or intergranular corrosion -- nominally less than 0.1 in. deep by about 1 in. long, may initiate SCC. The literature data however, suggest that $\mathbf{K}_{\mathrm{scc}}$ may be in the neighborhood of 25-30 ksi/in (Donovan 1977); consequently the critical flaw size to initiate SCC could be nominally as large as about 0.2 in. deep by about 2 in. long. Based on SCC growth rates that are typical of $\mathrm{NO}_{3}{ }^{-} \mathrm{SCC}$ in carbon steel, either initial crack size could penetrate the 0.875 -in. thick knuckle in less than 9 months (Schwenk 1992). 
Figure 6.2-1. Steel Reinforcing Bar Adjusted Mean Stress-Strain Curves.

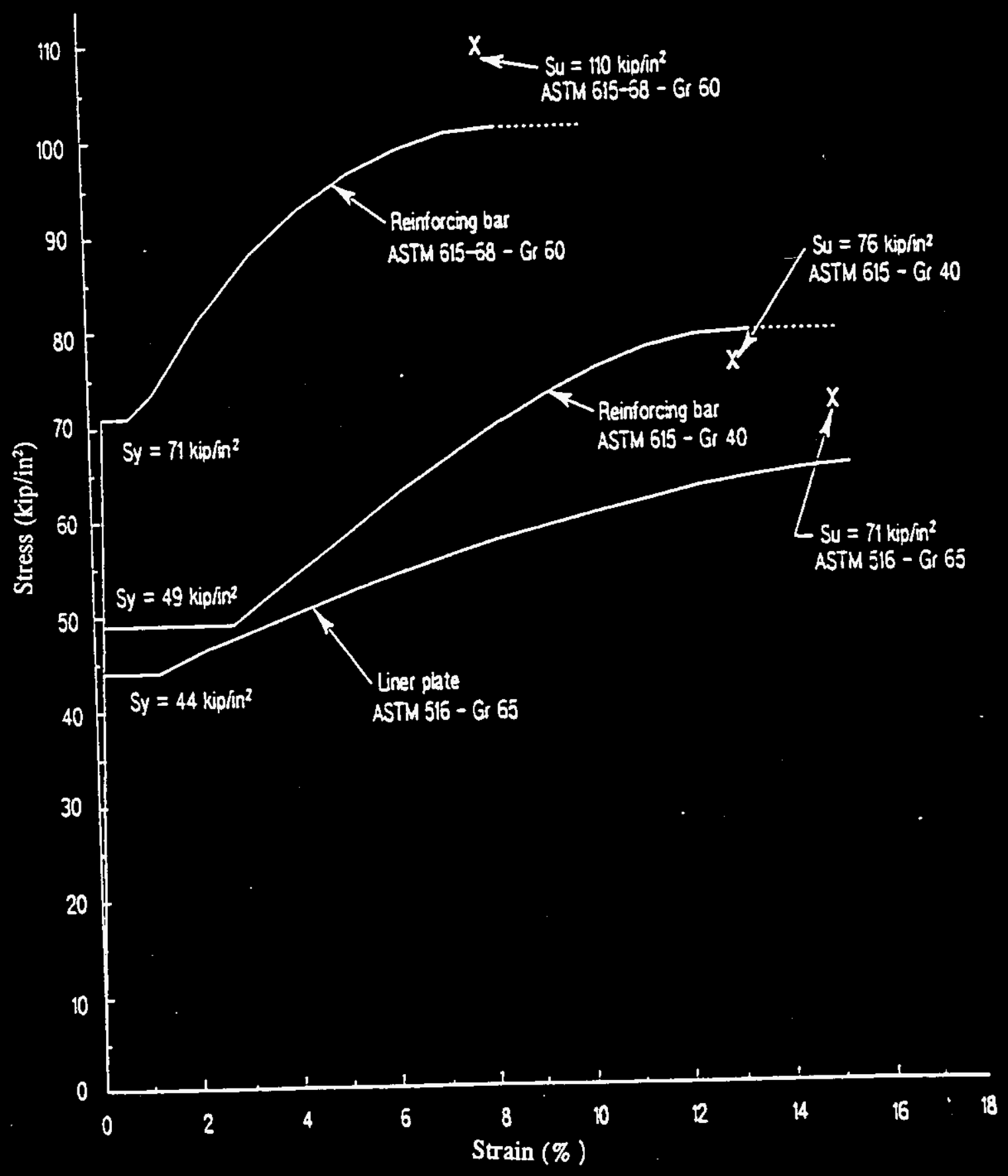


Table 6.1-1. Design Stress Intensity Values, $S_{\mathrm{m}}$.

\begin{tabular}{|c|c|c|c|c|c|}
\hline \multicolumn{6}{|c|}{ Design Stress Intensity Values, $\mathrm{S}_{\mathrm{m}}\left(10^{3} \mathrm{lbf} / \mathrm{in}^{2}\right)$} \\
\hline Material & $100^{\circ} \mathrm{F}$ & $200^{\circ} \mathrm{F}$ & $300^{\circ} \mathrm{F}$ & $400^{\circ} \mathrm{F}$ & $500^{\circ} \mathrm{F}$ \\
\hline $\begin{array}{c}\text { SA-515, 516 } \\
\text { Gr. 60 }\end{array}$ & 20.0 & 19.5 & 18.9 & 18.3 & 17.3 \\
\hline $\begin{array}{c}\text { SA-515, 516 } \\
\text { Gr. 65 }\end{array}$ & 21.7 & 21.3 & 20.7 & 20.0 & 18.9 \\
\hline $\begin{array}{c}\text { SA-537 } \\
\text { Class 1 }\end{array}$ & 21.7 & 21.7 & 21.3 & 21.3 & 21.3 \\
\hline
\end{tabular}

Notes:

1. $S_{\mathrm{m}}$ values are tabulated from Table I-1.1 of Section III of the ASME Code. For Section VIII analyses, the analyst shall verify that the tabulated values above are consistent with the ASME Code Section III values. 
Table 6.1-2. Nominal Mean Coefficients of Thermal Expansion for Steel vs. Temperature.

\begin{tabular}{|c|c|c|c|c|c|c|c|c|c|}
\hline \multicolumn{8}{|c|}{ Nominal Mean Coefficients of Thermal Expansion for Steel } \\
$\left(10^{-6}\right.$ in/in- $\left.{ }^{\circ} \mathrm{F}\right)$
\end{tabular}

Notes:

1. Thermal Expansion Mean Coefficient values are tabulated from Table I-5.0 of Section III of the ASME Code. For Section VIII analyses, the analyst shall verify that the tabulated values above are consistent with the ASME Code Section II values. 
Table 6.1-3. Moduli of Elasticity for Steel vs. Temperature.

\begin{tabular}{|c|c|c|c|c|c|}
\hline \multicolumn{5}{|c|}{ Moduli of Elasticity, E $\left(10^{6} \mathrm{lbf} / \mathrm{in}^{2}\right)$} \\
\hline \multirow{2}{*}{ Material } & 70 & 200 & 300 & 400 & 500 \\
\hline \hline $\begin{array}{c}\text { A515, 516 } \\
\text { A537 } \\
\text { (Note 2) }\end{array}$ & 29.5 & 28.8 & 28.3 & 27.7 & 27.3 \\
\hline $\begin{array}{c}\text { A515 } \\
\text { Gr. 65 } \\
\text { Thickness 0ver 1 in. } \\
(C>0.30 \%)\end{array}$ & 29.3 & 28.6 & 28.1 & 27.5 & 27.1 \\
\hline
\end{tabular}

Notes:

1. E values are tabulated from Table I-6.0 of Section III of the ASME Code. For Section VIII analyses, the analyst shall verify that the tabulated values above are consistent with the Section II values.

2. Values are valid for Grades 55, $60 \& 65$ for the A-515 steel for thicknesses 1 in and under, for Grades 55 and 60 for the A-515 steel for thicknesses 4 in. and under, for Grades 55, 60 \& 65 for the A-516 steel, and for both classes and all thicknesses of the A-537 steel. Carbon content, C, for these materials and thicknesses is less than $0.30 \%$. 
WHC-SD-WM-DGS-003

Revision 0

Table 6.2-1. Reinforcement Steel Properties.

\begin{tabular}{|c|c|c|c|c|c|c|c|}
\hline \multirow{3}{*}{ Grade } & \multicolumn{3}{|c|}{ Yield } & Ultimate & & \multirow{3}{*}{$\begin{array}{c}\text { Poisson's } \\
\text { Ratio }\end{array}$} & Mean Coefficient \\
\hline & $\begin{array}{l}\text { Minimum } \\
\text { Specified }\end{array}$ & Mean & Range & $\begin{array}{l}\text { Minimum } \\
\text { Specified }\end{array}$ & & & Thermal Expansion \\
\hline & \multicolumn{3}{|c|}{$\left(10^{3} \mathrm{lb} / / \mathrm{in}^{2}\right)$} & $\left(10^{3} \mathrm{lbf} / \mathrm{in}^{2}\right)$ & $\left(10^{6} \mathrm{lbF} / \mathrm{in}^{2}\right)$ & & $\left(10^{-6} \mathrm{in} / \mathrm{in}-{ }^{\circ} \mathrm{F}\right)$ \\
\hline 40 & 40 & 49 & $38-66$ & 70 & \multirow{2}{*}{29} & \multirow{2}{*}{0.3} & \multirow{2}{*}{6} \\
\hline 60 & 60 & 71 & $58-90$ & 90 & & & \\
\hline
\end{tabular}




\subsection{MARGIN ASSESSMENT}

Margin assessments to code-based limits and buckling load interaction of secondary concrete tank are presented in Sections 7.1 and 7.2, respectively.

\subsection{MARGIN TO CODE LIMITS}

To provide meaningful safety margins to ACI code limits, careful consideration must be given to the effect of demand interactions. Specifically, axial loads on a reinforced-concrete section affect capacities for moment, transverse shear, and in-plane shear. This interaction of demand components complicates the assignment of capacity associated with a given demand. Calculating the safety margin on the basis of a constant capacity can under-predict the actual margin, because increases or decreases in axial load can reduce the capacity of the section to moment, transverse shear, and in-plane shear.

Because of nonlinear behavior of the tank, the analyst is cautioned against linearly extrapolating the results to obtain margins. The following circumstances motivate this discretion:

- For an increase of a specific load, which is a subset of the total load set, the effect on demands at a given concrete section is not known. The response at the section due to the total load set can be a balance of positive and negative responses from the individual loads. The section demands can increase disproportional to the subset load increase. Therefore, linear extrapolation has no basis.

- For a proportional increase of all applied loads, the resulting increase in demands at a given section cannot be assumed to be proportional to the load increase because of nonlinear behavior of the structure.

The true margin for an addition of a specific load or load set should be determined by incrementally applying the load addition in a restart analysis, and identifying the load at which the section capacity is reached. Knowing the actual load, $\mathrm{L}_{\mathrm{D}}$, and the load that caused the section capacity to be reached, $\mathrm{L}_{\mathrm{C}}$, the true margin can be determined as follows:

$$
\text { True Margin }=\frac{L_{C}-L_{D}}{L_{C}}
$$

The terms in the above equation are represented in Figure 7.1-1, which shows a hypothetical relationship of applied load versus axial demand. By comparing the ratio of $P_{D} / P_{C}$ to $L_{D} / L_{C}$, it is clear that margins computed on the basis of demand are accurate only for a linear relationship with the applied load. 


\subsection{BUCKLING LOAD INTERACTION OF SECONDARY CONCRETE}

The buckling evaluation of the tank dome requires consideration of the potential interaction of uniform loads (dome deadweight, soil-overburden pressure, and uniform live load) and concentrated loads (live load over small area) applied to the dome. In the buckling evaluation of the cylindrical wall portion of the tank, interaction between uniform axial compressive stresses from the dome loads transferred to the cylinder and the lateral soil pressure must be considered. Baker (1972), for dome loading, and Seide (1981), for wall loading, recommend that a linear interaction equation be applied. When appropriate safety factors are introduced for a given shell geometry and load condition, the linear interaction equation becomes

$$
\sum \frac{S F_{b_{1}} P_{i}}{P_{b_{1}}^{\text {red }}} \leq 1
$$

where

$$
\begin{aligned}
P_{i} & =\text { ith applied stress (load) } \\
\boldsymbol{P}_{\boldsymbol{b}_{t}}^{\text {red }} & =\text { Corresponding ith corrected buckling stress (load) } \\
\boldsymbol{S F}_{\boldsymbol{b}_{\boldsymbol{l}}} & =\text { Corresponding ith buckling safety factor. }
\end{aligned}
$$

\section{Safety Factors}

The buckling safety factor, $\mathrm{SF}_{b}$, depends on the type of shell and its characteristic postbuckling behavior; $\mathrm{SF}_{\mathrm{b}}=1.75$ for shells with increasing capacities in the post-buckling regime and $\mathrm{SF}_{\mathrm{b}}=\mathbf{3 . 5}$ for shells with decreasing capacities in the post-buckling regime.

The safety factor, $S F_{b_{\text {u }}}$, applicable to buckling of the tank dome under uniform pressure loading is based on the similarity between the buckling behavior of a spherical cap under uniform external pressure and that of an axially compressed circular cylinder (Popov and Medwadowski 1981). Popov and Medwadowski identify the post-buckling behavior of an axially compressed circular cylinder as characterized by a decreasing capacity in the post-buckling regime. Therefore, a safety factor of 3.5 is applicable to buckling of the tank dome under uniform pressure.

The safety factor, $\mathbf{S} \boldsymbol{F}_{b_{f}}$, applicable to buckling of the tank dome for a load applied over a local area about the apex is based on observations made by Baker (1972) and Bushnell (1985) that the postbuckling behavior of a spherical cap loaded in such a manner is characterized by an increased loadcarrying capacity in the post-buckling regime. Therefore, a safety factor of 1.75 is applicable to buckling of the tank dome under the influence of a concentrated load at its apex.

The safety factor, $S F_{b_{a}}$, applicable to buckling of the tank cylindrical wall under the influence of axial compression is 3.5 , based on the above discussion for $S F_{b_{a}}$.

The safety factor, $S F_{b_{L}}$, applicable to buckling of the tank cylindrical wall under the influence of external lateral pressure warrants some detailed discussion. Bazant (1991) states that the postbuckling behavior of a cylinder under external lateral pressure is not expected to involve a steep softening and experience confirms this. Budiansky (1968) identifies a parameter " $b$ ", the sign of which is indicative of the characteristic post-buckling behavior of the cylinder. If " $b$ " is positive, the 
load capacity increases after buckling; if " $\mathrm{b}$ " is negative, the load capacity drops after buckling. In Figure 7.2-1 (Budiansky 1968) the variation of " $b$ " as a function of the Batdorf parameter, $\mathrm{Z}$, given by

$$
Z=\left(\frac{L^{2}}{R t}\right) \sqrt{1-v^{2}}
$$

is presented for two cases of a cylindrical shell under uniform external pressure. One case is applicable to a simple support at the ends of the cylinder and the other to a periodically radially restrained cylinder. For the first case, " $b$ " is positive for all values of $\mathrm{Z}$ below approximately 5.5 . For the second case, " $b$ " is positive for all values of $Z$ below approximately 9.0 . The $Z$ value computed for Hanford double-shell UST cylindrical wall is 16.5 .

Therefore, the specific characteristics of Hanford DST cylindrical wall construction suggests the applicability of a safety factor of 3.5 in addressing the potential for buckling under such conditions. 
Figure 7.1-1. Applied Load vs. Axial Response.

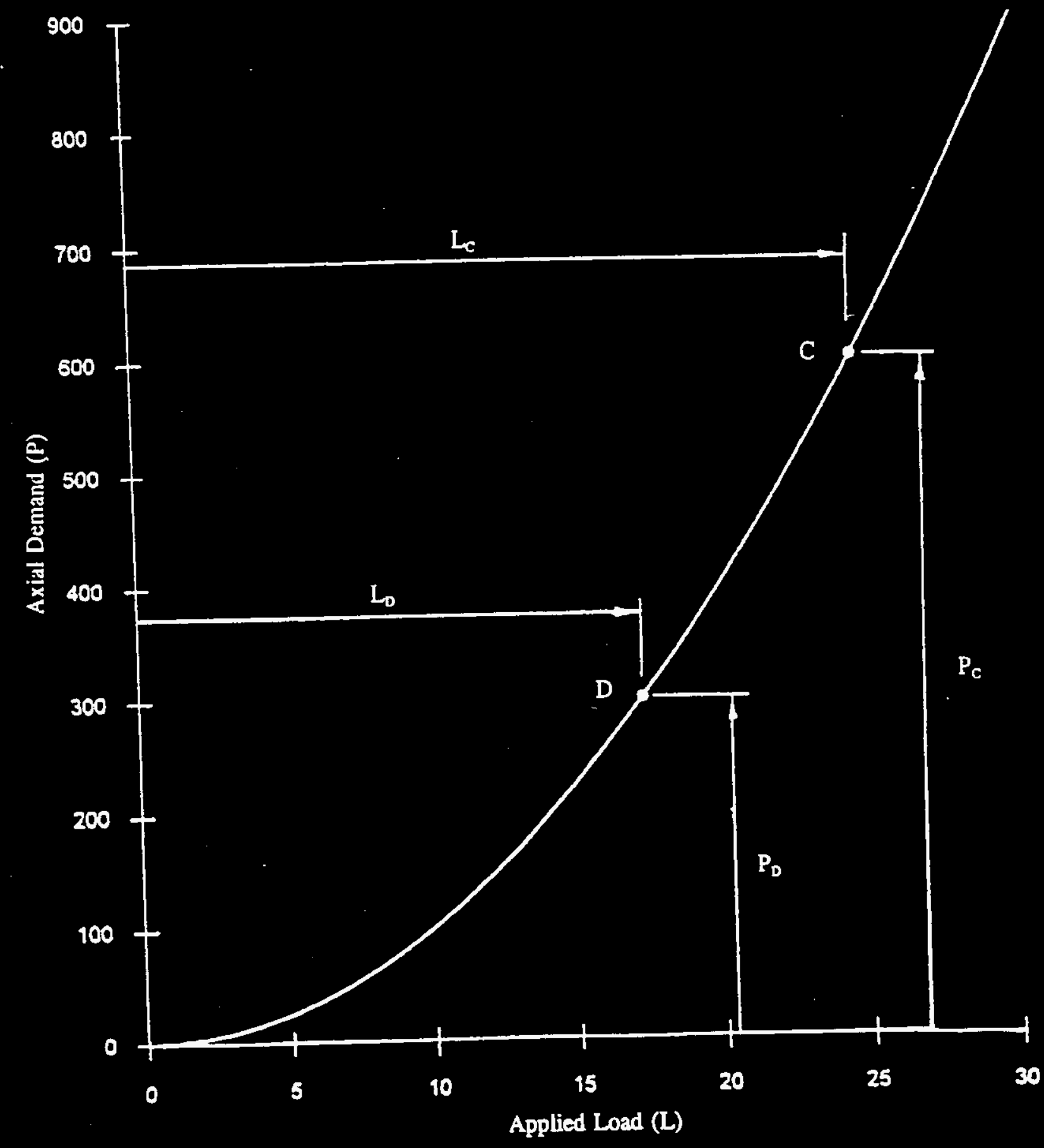


Figure 7.2-1. Variation of Parameter, b, as a Function of Batdorf Parameter, Z, for Post-Buckling Behavior of a Cylinder (Figure 3 of Budiansky 1968).

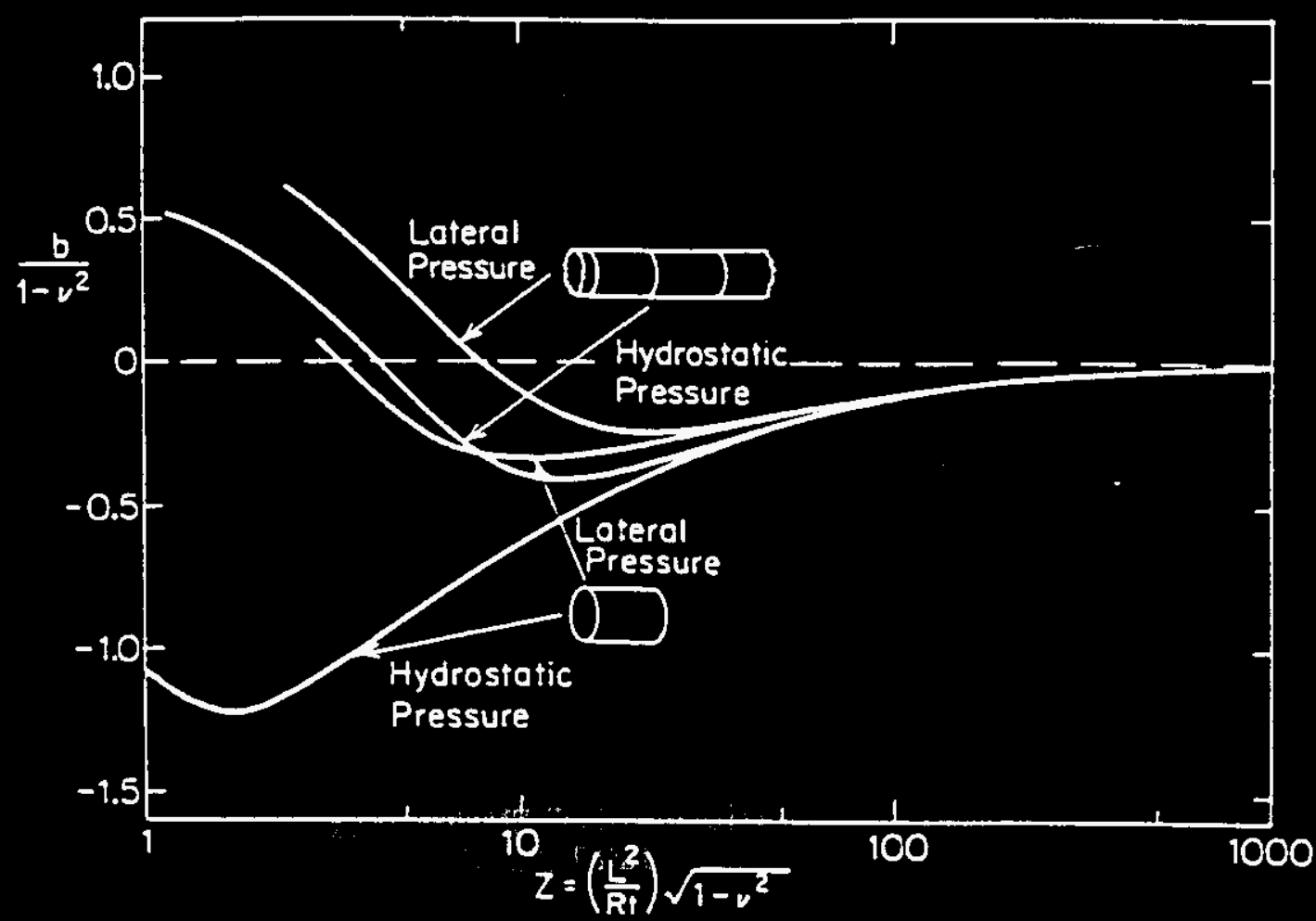




\section{THEIS PACW INYHNYONALT}

IOFT BLANK 


\subsection{REFERENCES}

ACI SP-67, 1981, Concrete Shell Buckling, E. P. Popov and S. J. Medwadowski, ed., American Concrete Institute, Detroit, Michigan.

ACI 318-89, 1992, "Building Code Requirements for Reinforced Concrete, " ACI 318-89, ACI Manual of Concrete Practice, American Concrete Institute, Detroit, Michigan.

ACI 349-90, 1992, "Code Requirements for Nuclear Safety-Related Concrete Structures, Code and Commentary," ACI Manual of Concrete Practice, American Concrete Institute, Detroit, Michigan.

ACI 349.1R, 1992, "Reinforced Concrete Design for Thermal Effects on Nuclear Power Plant Structures," ACI 349.1R-91, ACI Manual of Concrete Practice, American Concrete Institute, Detroit, Michigan.

ACI 523.1R-86, 1992, "Guide for Cast-in-Place Low-Density Concrete," ACI Manual of Concrete Practice, American Concrete Institute, Detroit, Michigan.

ACI 523.3R-75, 1992, "Guide for Cellular Concretes Above 50 pcf, and for Aggregate Concretes Above 50 pcf with Compressive Strengths Less Than 2500 psi," ACI Manual of Concrete Practice, American Concrete Institute, Detroit, Michigan.

ACI 547R-79, 1992, "Refractory Concrete: Abstract of State-of-the-Art Report," ACI Manual of Concrete Practice, American Concrete Institute, Detroit, Michigan.

API, 1978, Recommended Rules for Design and Construction of Large, Welded, Low-Pressure Storage Tanks, API Standard 620, American Petroleum Institute, Washington, D.C.

ASCE, 1980, Structural Analysis and Design of Nuclear Plant Facilities, ASCE Manual 58, American Society of Civil Engineers, New York, New York.

ASCE, 1986, Seismic Analysis of Safety Related Nuclear Structures and Commentary on Standard for Seismic Analysis of Safety Related Nuclear Structures, ASCE Standard 4-86, American Society of Civil Engineers, New York, New York.

ASME, 1980, Metal Containment Shell Buckling Design Methods, ASME Section III, Division 1, Class MC, Code Case N-284, American Society of Mechanical Engineers, New York, New York.

ASME, 1991, Criteria of Section III of the ASME Boiler and Pressure Vessel Code for Design by Analysis, American Society of Mechanical Engineers, New York, New York.

ASME, 1992, Boiler and Pressure Vessel Code, Section III, Divisions 1 and 2, American Society of Mechanical Engineers, New York, New York.

ASME, 1992a, American Society of Mechanical Engineers Boiler and Pressure Vessel Code, Section III, Division 1, Subsection NC, American Society of Mechanical Engineers, New York, New York. 
ASME, 1992b, American Society of Mechanical Engineers Boiler and Pressure Vessel Code, Section VIII, Division I, American Society of Mechanical Engineers, New York, New York.

ASME, 1992c, American Society of Mechanical Engineers Boiler and Pressure Vessel Code, Section VII, Division 2, American Society of Mechanical Engineers, New York, New York.

ASME, 1992d, American Society of Mechanical Engineers Boiler and Pressure Vessel Code, Section III, Division 2, Subsection CC, American Society of Mechanical Engineers, New York, New York.

ASME, 1992e, ASME Boiler and Pressure Vessel Code, Section II-Materials, Part D-Properties, American Society of Mechanical Engineers, New York, New York.

B-101-C1, 1973, Specification for Primary and Secondary Steel Tanks, Project B-101, 241-SY Tank Farm, prepared for the U.S. Atomic Energy Commission by Automation Industries, Inc., Vitro Engineering Division, Richland, Washington.

B-101-C2, 1974, Specification for Excavation and Tank Foundations 241-SY Tank Farm, Project B-101, prepared for the U.S. Atomic Energy Commission by Automation Industries, Inc., Vitro Engineering Division, Richland, Washington.

B-101-C3, 1974, Construction Specification for Completion of 241-SY Tank Farm, Project B-10I, prepared for the U.S. Atomic Energy Commission by Automation Industries, Inc., Vitro Engineering Division, Richland, Washington.

B-120-C3, 1976, Construction Specification for the 241-AW Tank Farm Project B-120 Foundation, prepared for the U.S. Energy Research and Development Administration by Vitro Engineering Corporation, Richland, Washington.

B-120-C4, 1976, Construction Specification for Primary and Secondary Steel Tanks, Project B-120, 241-AW Tank Farm, prepared for the U.S. Energy Research and Development Administration by Vitro Engineering Corporation, Richland, Washington.

B-120-C5, 1977, Construction Specification for the 241-AW Tank Farm, Project B-120, Concrete Shell, prepared for the U.S. Energy Research and Development Administration by Vitro Engineering Corporation, Richland, Washington.

B-120-D1, 1976, Design Specification for Primary and Secondary Steel Tanks, Project B-120, 24I-AW Tank Farm, prepared for the U.S. Energy Research and Development Administration by Vitro Engineering Corporation, Richland, Washington.

B-130-C3, 1977, Construction Specification for the 241-AN Tank Farm Project B-130 Foundation, prepared for the U.S. Energy Research and Development Administration by Vitro Engineering Corporation, Richland, Washington.

B-130-C4, 1978, Construction Specification for Primary and Secondary Steel Tanks, Project B-130, 241-AN Tank Farm, prepared for the U.S. Department of Energy by Vitro Engineering Corporation, Richland, Washington. 
B-130-C5, 1978, Construction Specification for the 241-AN Tank Farm, Project B-130, Concrete Shell, prepared for the U.S. Department of Energy by Vitro Engineering Corporation, Richland, Washington.

B-130-D1, 1978, Design Specification for Primary and Secondary Steel Tanks, Project B-130, 24I-AN Tank Farm, prepared for the U.S. Department of Energy by Vitro Engineering Corporation, Richland, Washington.

B-340-C3, 1982, Construction Specification for the 241-AP Tank Farm Tank Foundations, prepared for the U.S. Department of Energy by Kaiser Engineers Hanford Company, Richland, Washington.

B-340-C4, 1982, Construction Specification for Primary and Secondary Steel Tanks 241-AP Tank Farm, prepared for the U.S. Department of Energy by Kaiser Engineers Hanford Company, Richland, Washington.

B-340-D1, 1986, Design Specification for Primary and Secondary Steel Tanks 24I-AP Tank Farm, prepared for the U.S. Department of Energy by Kaiser Engineers Hanford Company, Richland, Washington.

Baker; E. H., L. Kovalevsky, and F. L. Rish, 1972, Structural Analysis of Shells, McGraw-Hill, New York, New York.

Barnard, P.R., 1964, "The Collapse of Reinforced Concrete Beams," International Symposium of Flexural Mechanics of Reinforced Concrete, November 10-12, 1964, Miami, Florida, ACI SP 12, American Concrete Institute, Detroit, Michigan.

Bazant, Z. P., and L. Cedolin, 1991, Stability of Structures: Elastic, Inelastic, Fracture, and Damage Theories, Oxford University Press, New York, New York.

Beavers, J. A., N. G. Thompson, and R. N. Parkins, 1987, Stress-Corrosion Cracking of LowStrength Carbon Steels in Candidate High-Level Waste Repository Environments, NUREG/CR-3861, BMI-2147, Battelle-Columbus, Columbus, Ohio.

Bednar, H. H., 1986, Pressure Vessel Design Handbook, Second Edition, Van Nostrand Reinhold Company, New York, New York.

BNL, 1993, Bandyopadhyay, K., et al., Seismic Design and Evaluation Guidelines for The Department of Energy High-Level Waste Storage Tanks and Appurtenances, BNL 52361, U.S. Department of Energy, Brookhaven National Laboratories, Associated Universities, Inc., Upton, New York.

Budiansky, B., and J. C. Amazigo, 1968, "Initial Post-Buckling Behavior of Cylindrical Shells Under External Pressure," Journal of Mathematics and Physics, Volume XLVII, pp. 223-235.

Bushnell, D., 1985, Computerized Buckling Analysis of Shells, Martinus Nijhoff Publishers, AD Dordrecht, The Netherlands. 
Davis, E.A. and F.M. Connelly, 1959, "Stress Distribution and Plastic Deformation in Rotating Cylinders of Strain-Hardening Materials, "Journal of Applied Mechanics (Transactions of the ASME), New York, New York.

Divine, J. R. and W. M. Bowen, 1984, Tank Corrosion Study, High Temperature Corrosion Tests, Four Month Evaluation, Letter Report to Rockwell International, Pacific Northwest Laboratory, Richland, Washington.

DOE, 1989, General Design Criteria, DOE Order 6430.1A , U.S. Department of Energy, Washington, D.C.

DOE, 1993, Natural Phenomena Hazards Mitigation, DOE Order 5480.28 , U.S. Department of Energy, Washington, D.C.

Donavan, J. A., 1977, Fracture Controlling Nitrate Stress-Corrosion Cracking of Mild Steel, Corrosion '77, San Francisco, California.

ECCS, 1988, Buckling of Steel Shells - European Recommendations, European Convention for Constructional Steelwork (ECCS), The Construction Press, London.

Ferguson, P. M., et al., 1988, Reinforced Concrete Fundamentals, John Wiley \& Sons, New York, New York.

Geomatrix, 1994, Seismic Design Spectra 200 West and East Areas Hanford Site, Washington, WHC-SD-W236A-TI-016, Rev. 0, prepared by Geomatrix Consultants for Westinghouse Hanford Company, Richland, Washington.

Ghanekar, V.K., and J. P. Jain, 1990, Handbook for Limit State Design of Reinforced Concrete Members, Structural Engineering Research Center, Roorkee, India.

Giller, R. A., 1992, Bibliography and Summary of Geotechnical Studies at the Hanford Site, WHC-SD-GN-ER-30009, Rev. 0, Westinghouse Hanford Company, Richland, Washington.

Hanford Specification, B-101-C1, 1973, Specification for Primary and Secondary Steel Tanks Project B-101 241-SY Tank Farm, prepared by Automation Industries, Inc., Vitro Engineering Division, Richland, Washington.

Hsu, Thomas T.C., 1993, Unified Theory of Reinforced Concrete, CRC Press, Roca Baton, Florida.

HWS-7789, 1968, Specification for Primary and Secondary Steel Tanks PUREX Tank Farm Expansion, Project IAP-614, Hanford Engineering Services, A Division of Vitro Corporation of America, Richland, Washington.

HWS-7790, 1968, Specification for Excavation and Tank Foundations PUREX Tank Farm Expansion Building 241-AY, Project IAP-614, Hanford Engineering Services, A Division of Vitro Corporation of America, Richland, Washington. 
HWS-7792, 1968, Specification for Completion of 241-AY PUREX Tank Farm Expansion Project IAP-614, Hanford Engineering Services, A Division of Vitro Corporation of America, Richland, Washington.

HWS-8981, 1970, Specification for Excavation and Tank Foundations Project HAP-647, Tank Farm Expansion 24]-AZ Tank Farm, Hanford Engineering Services, A Division of Vitro Corporation of America, Richland, Washington.

HWS-8982, 1970, Specification for Primary and Secondary Steel Tanks Project HAP-647, Tank Farm Expansion 241-AZ Tank Farm, Hanford Engineering Services, A Division of Vitro Corporation of America, Richland, Washington.

Jones, R. H. (ed.), 1992, Stress-Corrosion Cracking, ASM, International, Materials Park, Ohio.

Julyk, L. J., et al., 1994, Tank 241C106 Structural Integrity Evaluation for In Situ Conditions, WHC-SD-W320-ANAL-001, Rev. 0, Westinghouse Hanford Company, Richland, Washington.

Kassir, M. K., K. K. Bandyopadhyay, and M. Reich, 1993, Thermal Degradation of Concrete in the Temperature Range From Ambient to $315^{\circ} \mathrm{C}\left(600^{\circ} \mathrm{F}\right)$, BNL 52384, U.S. Department of Energy, Brookhaven National Laboratories, Associated Universities, Inc., Upton, New York.

Kurihara, C., et al., 1992, "Sloshing Impact Pressure in Roofed Liquid Tanks, " PVP-Vol. 232, American Society of Mechanical Engineers, New York, New York.

Lysmer, J., et al., 1991, SASSI User's Manual, Bechtel Corporation, San Francisco, California.

MacGregor, J. C., 1976, "Safety and Limit States Design for Reinforced Concrete," Canadian Journal of Civil Engineering, Vol. 3, No. 4, Canada.

Manjoine, M.J., 1975, "Ductility Indices at Elevated Temperatures," Journal of Material Technology (Transactions of the ASME), New York, New York.

McMackin, P. J., et. al., 1973, "Headed Steel Anchors Under Combined Loading," AISC Engineering Journal.

Miller, J.D., 1990, Analysis of Shell-Rupture Failure Due to Hypothetical Elevated-Temperature Pressurization of the Sequoyah Unit 1 Steel Containment Building, NUREG/CR-5405, Sandia National Laboratories, Albuquerque, New Mexico.

Mirza, S., and J. C. MacGregor, 1979, "Variability of Mechanical Properties of Reinforcing Bars," Proceedings ASCE, Structural Division, Vol. 105, No. ST5, pp.921-937.

Moore, C. J., et al., 1995a, Concrete Structural Analysis Tools and Properties for Hanford Site Waste Tank Evaluation, WHC-SD-WM-DA-207, Rev. 0, prepared by ICF Kaiser Hanford Company for Westinghouse Hanford Company, Richland, Washington.

Moore, C. J., R. D. Holtz, and G. R. Wagenblast, 1995b, Soil Structural Analysis Tools and Properties for Hanford Site Waste Tank Evaluation, WHC-SD-WM-DA-208, Rev. 0, prepared by ICF Kaiser Hanford Company for Westinghouse Hanford Company, Richland, Washington. 
Nelson, 1961, Design Data, Nelson Concrete Anchor Studs, Manual No. 21, TRW Nelson Stud Welding Division, Elyria, Ohio.

Nelson, 1977, Embedment Properties of Headed Studs, Stud Design Data 10, TRW Nelson Stud Welding Division, Elyria, Ohio.

Nilson, A. H., et al., 1982, A State-of-the-Art Report on Finite Element Analysis of Reinforced Concrete, American Society of Civil Engineers, New York, New York.

Oland, C. B., and J. P. Callahan, 1978, Bond Between Concrete and Steel Reinforcement at Temperatures to $149^{\circ} \mathrm{C}\left(300^{\circ} \mathrm{F}\right)$, ORNL/TM-6086, Oak Ridge National Laboratory, Oak Ridge, Tennessee.

Ollgaard, J. G., Slutter, R. G. and Fisher, J. W., 1971, "Shear Strength of Stud Connectors in Lightweight and Normal-Weight Concrete, "AISC Engineering Journal.

Orangun, C. O., J. O. Jirsa, and J. E. Breen, 1977, "A Re-Evaluation of Test Data on Development Length and Splices," ACI Journal, Proceedings, 74, pp. 114-122.

Peterson, W. S., 1994, Evaluation of Strength and Modulus Degradation Due to Temperature Effects on Hanford Concrete, WHC-SD-WM-DA-153, Rev. 0, Westinghouse Hanford Company, Richland, Washington.

Pianka, E. W., 1994, Soil Weight at Hanford Waste Storage Tank Locations, WHC-SD-WM-SOIL-001, Rev. 0, Westinghouse Hanford Company, Richland, Washington.

Pianka, E. W., 1995, Soil Load above Hanford Waste Storage Tanks, WHC-SD-WM-TI-665, Rev. 0A, Westinghouse Hanford Company, Richland, Washington.

Popov, E. P., and S. J. Medwadowski, 1981, "Stability of Reinforced Concrete Shells: State-of-theArt Overview," in Concrete Shell Buckling, ACI SP-67, American Concrete Institute, Detroit, Michigan.

RHO, 1981, Effects of Long-Term Exposure to Elevated Temperature on the Mechanical Properties of Hanford Concrete, RHO-C-54, Rockwell International, Rockwell Hanford Operations, Energy Systems Group, Richland, Washington.

RHO, 1986, Functional Design Criteria 241-AP Tank Farm Project B-340, SD-340-FDC-001, Rev. 2, L. W. Roberts of Rockwell International, Rockwell Hanford Operations, Energy Systems Group, Richland, Washington.

Rolfe, S. T., and J. M. Barsom, 1977, Fracture and Fatigue Control in Structures Application of Fracture Mechanics, Prentice-Hall, Inc., Englewood Cliffs, New Jersey.

Schwenk, E. B., 1992, Tank Wall Measurement Technical Study and Specification, WHC-SD-W151-ES-002, Rev. 0, Westinghouse Hanford Company, Richland, Washington.

Scordelis, A. C., 1981, "Stability of Reinforced Concrete Domes and Hyperbolic Paraboloid Shells," in Concrete Shell Buckling, ACI SP-67, American Concrete Institute, Detroit, Michigan. 
SDC-4.1, 1993, Hanford Plant Standards, HPS-SDC-4.1, Rev. 12, Standard Arch-Civil Design Criteria, Design Loads for Facilities, U.S. Department of Energy-Richland Operations Office, Richland, Washington.

Seide, P., 1981, "Stability of Cylindrical Reinforced Concrete Shells," in Concrete Shell Buckling, ACI SP-67, American Concrete Institute, Detroit, Michigan.

Shannon \& Wilson, 1995a, Geotechnical Investigation KEH W-236A, Multi-Function Waste Tank Facility, 200 East Area, Hanford Site, Richland, Washington, H-1053-05,

Shannon \& Wilson, Inc., Geotechnical and Environmental Consultants, Seattle, Washington.

Shannon \& Wilson, 1995b, Geotechnical Investigation KEH W-236A, Multi-Function Waste Tank Facility, 200 West Area, Hanford Site, Richland, Washington, H-1070-50, Shannon \& Wilson, Inc., Geotechnical and Environmental Consultants, Seattle, Washington.

Shrivastava, H. P., 1995; Primary Tank Slosh Loads for Multi-Function Waste Tank Facility, WHC-SD-W236A-CN-001, Rev. 1, Westinghouse Hanford Company, Richland, Washington.

Shurrab, M. S., M. D. Thomson, (both WHC), J. R. Friley, M. R. Garnich, M. W. Rinker, and F. A. Simonen, (all PNL), 1991, Parametric Studies to Support Inspection Criteria of the Hanford Site Double-Shell Waste Storage Tanks, WHC-EP-0508, Vol. 1, Section 3.0, "Evaluation of Strain Gage Data from Tank 241-SY-103, " Westinghouse Hanford Company, Richland, Washington.

Smith, H. D. and M. R. Elmore, 1992, Corrosion Studies of Carbon Steel under Impinging Jets of Simulated Slurries of Neutralized Current Acid Waste (NCAW) and Neutralized Cladding Removal Waste (NCRW), PNL-7816, Pacific Northwest Laboratory, Richland, Washington.

Sullivan, L. H., 1995, A Safety Assessment for Proposed Mixing Operations to Mitigate Episodic Gas Releases in Tank 241-SY-101: Hanford Site, Richland, Washington, LA-UR-92-3196, Rev. 14, prepared by Engineering and Safety Analysis Group, Technology and Safety Assessment Division, Los Alamos National Laboratory, Los Alamos, New Mexico.

TPA, 1995, Hanford Federal Facility Agreement and Consent Order (Tri-Parity Agreement), RL-TPA-93-01, Rel. 2, dated April 18, 1995, U.S. Department of Energy-Richland Operations Office, Richland, Washington.

UCRL, 1990, Design and Evaluation Guidelines for Department of Energy Facilities Subjected to Natural Phenomena Hazards, UCRL-15910, University of California Research Laboratory, Livermore, California.

Weiner, E. O., 1995, Design Basis Earthquake Time-Histories, WHC-SD-GN-DA-30018, Rev. 0-A, Westinghouse Hanford Company, Richland, Washington.

WHC, 1992, Double-Shell Tank Interim Safety Equipment List, WHC-SD-WM-SEL-026, Rev. 0, Westinghouse Hanford Company, Richland, Washington.

WHC, 1993a, Aging Waste Facility Interim Safety Equipment List, WHC-SD-WM-SEL-020, Rev. 2, Westinghouse Hanford Company, Richland, Washington. 
WHC, 1993b, Hanford Site Tank Farm Facility Interim Safety Basis, WHC-SD-WM-ISB-001, Rev. 0, Westinghouse Hanford Company, Richland, Washington.

WHC, 1994, Tank Waste Remediation System Life Management/Aging Management Program Plan, WHC-SD-WM-PLN-068, Rev. 0, Westinghouse Hanford Company, Richland, Washington.

WHC, 1994b, Tank Farm Surveillance and Waste Status Summary Report - July 1994, WHC-EP-0182-75, prepared for the U.S Department of Energy - Office of Environmental Restoration and Waste Management by Westinghouse Hanford Company, Richland, Washington.

Winkel, B. V., 1994, Concrete Material Characterization, Reinforced Concrete Tank Structure, Multi-function Waste Tank Facility, WHC-SD-W236A-ER-013, Westinghouse Hanford Company, Richland, Washington

WSRC, 1994, "WRSC Acceptance Criteria for Strains in Tanks and Vessels," Attachment B, of SMAC-3, Structural Mechanics Acceptance Criteria HLW, WSCRC-TR-94-335, Rev. 1, Westinghouse Savannah River Company, Aiken, South Carolina.

Zapp, P. E., 1990, Effect of Temperature on the Nitrite Requirement to Inhibit Washed Sludge (U), Internal Memo WSRC-TR-909-292, Westinghouse Savannah River Company, Aiken, South Carolina.

Zarghamme, M. S., and F. J. Heger, 1983, "Buckling of Thin Concrete Domes," ACI Journal, November-December 1983, pp. 487-500, American Concrete Institute, Detroit, Michigan. 